\title{
LIBERALISATION OF TRADE IN EDUCATION SERVICES \\ The implications of GATS for education in New Zealand, especially pertaining to primary and early childhood education
}

\author{
A research paper submitted in partial fulfilment for the \\ Degree of Master of Development Studies \\ Victoria University of Wellington \\ New Zealand
}

February 2004

Karen Jane Jones 


\section{Abstract}

This paper situates trade in education services in the broader debates regarding the marketisation of education in New Zealand. It conducts a critical appraisal of the ideological influences on policy decisions to explore potential implications of GATS for the New Zealand education system. This discussion considers GATS in terms of the particular ideological and political project that underpins it. Market principles were introduced into New Zealand education fifteen years ago with the policies that rapidly and radically transformed the administration of the education system. These reforms, derived from neo-liberal economic discourse and New Right ideology, directly challenged the fundamental principles of equity, access and free public provision - ideals that had embedded education in its social context and relations, and structured education policy in New Zealand for the previous 50 years. Redefining education as a detached commodity traded in an education marketplace, and driven by imperatives of efficiency, profitability and "consumer choice", created the environment necessary for expanding international education markets. Trade in education services is New Zealand's fourth largest export earner. This research involves a review and analysis of literature to explore possible influences and implications of market and trade imperatives on the provision of primary and early childhood education services. In particular it discusses issues of equity, access, and the influences which shape the values and culture of education. It argues that prioritising commercial over social principles distorts the (traditional) role of education in terms of nation-building, identity formation, and the promotion of democratic values and citizenship. This is an exploratory and even speculative paper, raising issues and questions that can only be answered by full and open discussion involving all stakeholders and informed by comparative research. Acknowledging the tensions between the proponents of different perspectives and views it urges more open debate about where are we going with the ongoing and future role of education in New Zealand society. 


\section{Acknowledgements}

I acknowledge and thank Professor Vijay Naidu for his guidance and direction in his capacity as supervisor of this research paper. I would also like to express my appreciation to NZEI and especially to Stephen Day for his assistance with material supporting this research. The opportunity to attend and participate in the QPEC Conference 2003 was also a valuable part of the data collection process, and for this opportunity I thank the QPEC conference organising committee and School of Earth Sciences, Victoria University of Wellington. The mutual support of my colleagues during the process of writing and proof-reading this paper was invaluable and in particular I would like to thank Jo and Patty. Sometimes a serendipitous juncture stimulates us to take up a particular topic for research. The seed for this topic was sown during a short taxi ride I shared with Robert Wade on our way to the airport following the 2002 Devnet conference at Massey, and so I thank Robert for his encouragement. Finally to my family I express my gratitude for gracefully allowing me the time out to commit to this course of study. 


\section{Table of Contents}

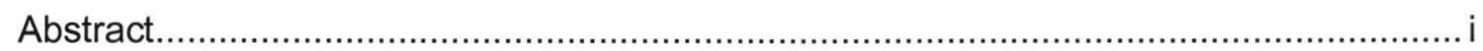

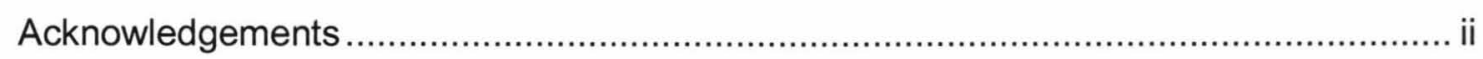

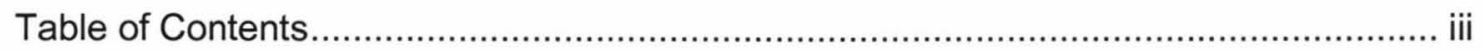

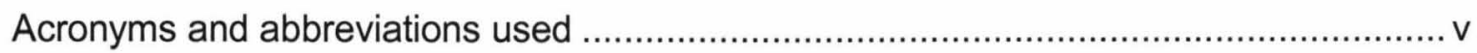

Chapter One: INTRODUCTION ................................................................... 1

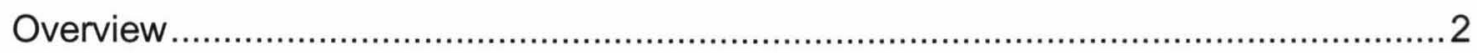

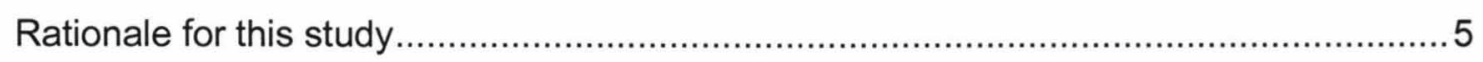

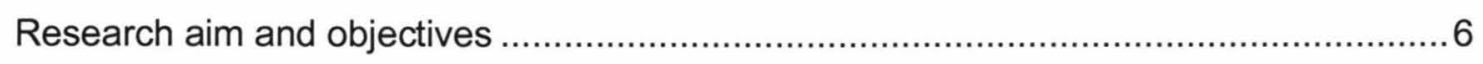

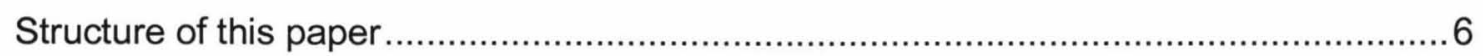

Chapter Two: RESEARCH FRAMEWORK ................................................... 8

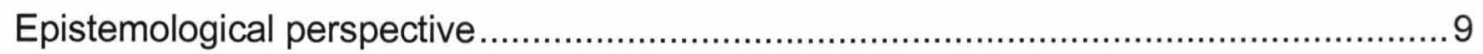

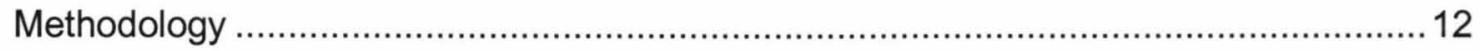

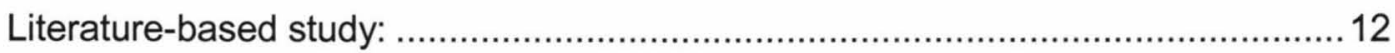

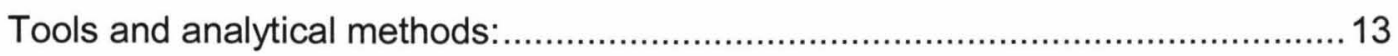

Limitations experienced with this method and analysis: ..................................... 14

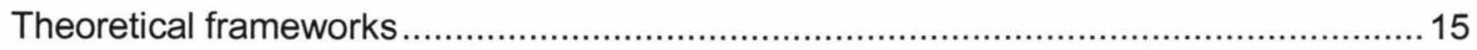

Political Context: Situating WTO and GATS in the context of modern world affairs

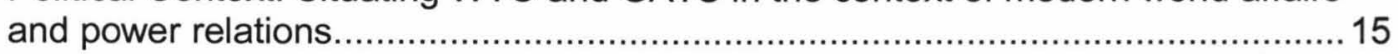

Development Context: Free trade as a tool for development? .............................. 19

Educational Context: Markets and educational policy frameworks ......................... 22

Chapter Three: TRADE, GATS AND WTO PROCESSES ............................... 28

The broad principles, aims and objectives of WTO and GATS ................................. 28

Principles and rules of GATS: ...................................................................... 29

Benefits of multi-lateral agreements for free trade - the arguments for GATS ................ 33

Issues and possible consequences - the general arguments against GATS ..................34

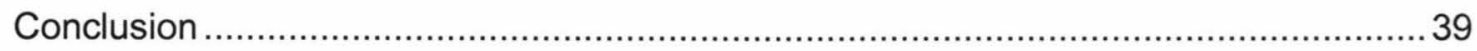




\section{Chapter Four: APPLICATION OF GATS TO EDUCATION AND NEW}

ZEALAND'S EXPORT INTEREST............................................................... 40

WTO and GATS rules and processes applied to education........................................ 41

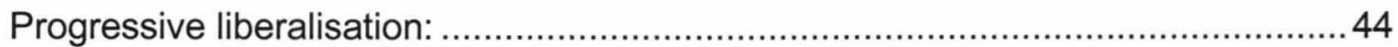

GATS negotiations on new rules relating to domestic regulations (Article VI):.........44

Eliminating barriers to trade in education: ............................................................ 45

New Zealand's policy position regarding education services in GATS ...........................46

The New Zealand export education industry ...........................................................5 50

\section{Chapter Five:CONSTRUCTING THE EDUCATIONAL MARKETPLACE ........ 61}

Transforming education from a socially embedded public service to a detached tradable

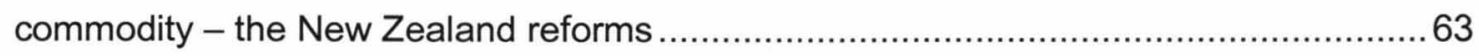

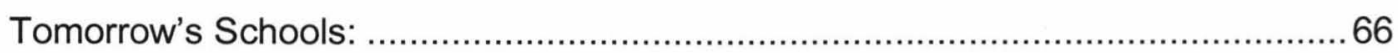

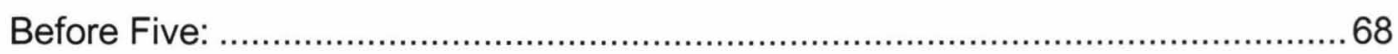

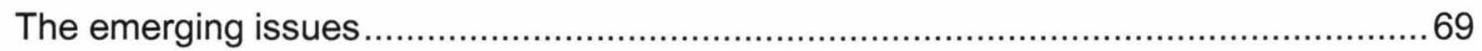

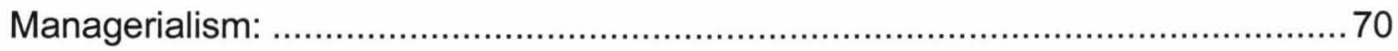

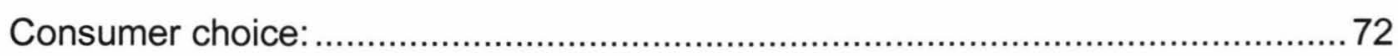

Issues of equal opportunity and social justice: .................................................. 77

Pedagogical issues and consequences for curricula development: ......................79

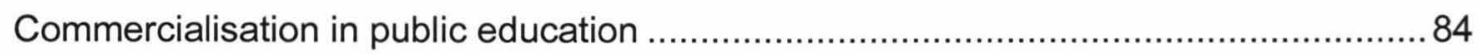

The role of education for nation building and identity formation ................................. 90

Chapter Six: DISCUSSION AND CONCLUSIONS ........................................... 98

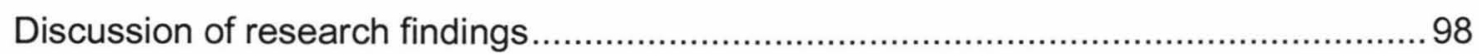

How GATS may affect the ability of future governments to shape the education system

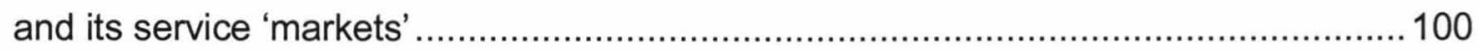

Exposing New Zealand's education system to foreign providers: what could it mean? 104

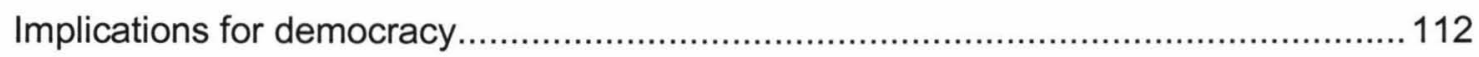

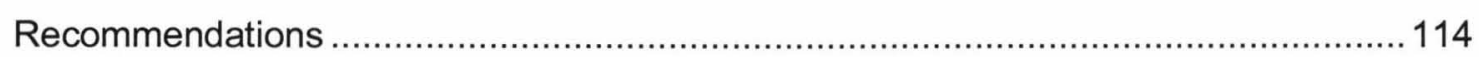

Recommendations for New Zealand policy making:........................................... 115

Directions for further research....................................................................... 120

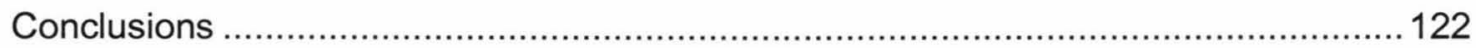

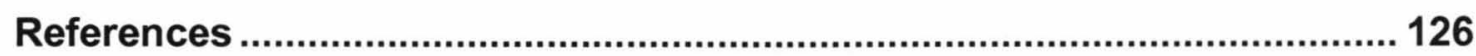




\section{Acronyms and abbreviations used}

\begin{tabular}{|c|c|}
\hline ASTE & Association of Staff in Tertiary Education \\
\hline AUS & Association of University Staff \\
\hline BOT & (school) Board of Trustees \\
\hline CEPA & New Zealand/Singapore Closer Economic Partnership Agreement \\
\hline $\mathrm{CIA}$ & Central Intelligence Agency (US) \\
\hline $\mathrm{CPC}$ & Central Product Classification number \\
\hline CTU & Combined Trade Union \\
\hline DOPs & Desirable Objectives and Practices \\
\hline ECE & Early Childhood Education \\
\hline El & Education International \\
\hline ENZT & Enterprise New Zealand Trust \\
\hline ERO & Education Review Office \\
\hline ERT & European Round Table \\
\hline ESOL & English as a Second Language \\
\hline ESP & Enterprise Studies Programme \\
\hline EU & European Union \\
\hline FFP & Foreign Fee-Paying student \\
\hline G21 & Group of 21 developing Countries \\
\hline GATS & General Agreement on Trade in Services \\
\hline GATT & General Agreement on Tariffs and Trade \\
\hline HCT & Human Capital Theory \\
\hline ICT & Information and Communications Technology \\
\hline IMF & International Monetary Fund \\
\hline MFAT & Ministry of Foreign Affairs and Trade \\
\hline MFN & Most Favoured Nation principle \\
\hline MOE & Ministry of Education \\
\hline NBER & National Business and Economic Review \\
\hline NFTA & North American Free Trade Agreement \\
\hline NGO & Non-governmental Organisation \\
\hline NPM & New Public Management \\
\hline NQF & National Qualifications Framework \\
\hline
\end{tabular}




\begin{tabular}{|c|c|}
\hline NT & National Treatment principle \\
\hline NUT & National Union of Teachers (in UK) \\
\hline NZBCSD & New Zealand Business Council for Sustainable Development \\
\hline NZEI & New Zealand Education Institute \\
\hline NZQA & New Zealand Qualifications Authority \\
\hline OECD & Organisation for Economic Cooperation and Development \\
\hline PCT & Public Choice Theory \\
\hline $\mathrm{PFI}$ & Private-sector Finance Initiative \\
\hline PPP & Public Private Partnership \\
\hline PPTA NZPPTA & New Zealand Post Primary Teachers Association \\
\hline PrEP & Primary Enterprise Programme \\
\hline QPEC & Quality Public Education Coalition \\
\hline SARS & Severe Acute Respiratory Syndrome \\
\hline SEM & Sponsored Educational Materials \\
\hline SSC & State Services Commission \\
\hline TEC & Tertiary Education Commission \\
\hline TIASA & Tertiary Institutes Allied Staff Association \\
\hline TINA & There Is No Alternative \\
\hline TRIMS & agreement on Trade -Related Investment Measures \\
\hline TRIPS & Trade-Related aspects of Intellectual Property agreement \\
\hline UK & United Kingdom \\
\hline UN & United Nations \\
\hline UNDP & United Nations Development Programme \\
\hline UNESCO & United Nations Education Social and Cultural Organisation \\
\hline US & United States (of America) \\
\hline WB & World Bank \\
\hline WDM & World Development Movement \\
\hline WEM & World Education Market \\
\hline WST & World System Theory \\
\hline WTO & World Trade Organisation \\
\hline YES & Young Enterprise Scheme \\
\hline
\end{tabular}




\section{Chapter One}

\section{INTRODUCTION}

To market, to market to buy a fat pig,

Home again, home again jiggity jig

To market, to market to buy a class pack

School again, school again, jiggity jack

The international dimension of educational services and their inclusion in multilateral trade agreements is beginning to emerge as a major issue for debate in educational arenas and trade discussions around the world. However there is a dearth of informed analysis and a lack of open debate on the issues in the political, educational and wider communities in New Zealand. This paper aims to highlight the contentious issues and stimulate further discussion and debate.

In this chapter I describe, in summary, the general question of liberalisation of trade in education and the application of the General Agreement on Trade in Services, and its significance in both the educational and political contexts that define it. This overview provides both a background to the topic and introduces the central arguments and key assumptions underlying the issues raised in the research. I then outline my rationale for undertaking this research and its contribution to this emerging field. The final section defines the research aim and objectives and explains the structure of the paper and what to expect from the document. 


\section{Overview}

GATS does not represent the beginning of trade in education services. The international dimension for education has intensified quite independently of the WTO/GATS context. However such an agreement has ramifications beyond the offer of predictable market conditions for those directly benefiting from this 'growth industry'. Situating trade in this broader context requires a review of the reforms commencing in the late 1980s and into the 1990s which moved New Zealand education toward a market-based approach, and laid the foundations for intensification of international trade in education.

The international nature of education has been variously described as internationalisation, cross-border education, international education and more recently trade in education, with "internationalisation"1 being most comprehensive (Knight 2003). Internationalisation is not new to the education sector. For a long time, international exchange of ideas, pedagogy and educational theories and curriculum and mobility of teachers, students and education and training programmes have made important contributions to the sector. However it is only very recently that this activity in the sector has been described as commercial trade and been subject to international trade rules.

The sector itself is beginning to distinguish between a 'cultural approach' to international exchanges and the 'commercial approach' of international trade in education (Larsen and Vincent-Lancrin 2002). An economist or trade analyst however would regard any activity that adds export value, even indirectly through accommodation and so on, as having commercial implications. The threat here is 'commercial reductionism' whereby pressures for trade liberalisation are reducing the conceptualisation of internationalism in education to commercial delivery of education across borders (Knight 2002c:10). In this environment it is very important for wide reaching debate and discussion to be held within education communities to examine how trade rules might affect education systems, including for example, education policies, governance and administration, curriculum and professionalism.

\footnotetext{
${ }^{1}$ Internationalisation includes the international interaction and exchange of structures, curricula and pedagogies, ideas and expertise; this is quite distinct from international education and cross-border education, which refer more specifically to trade in education. The former implies collaboration whereas the later implies dealing with education on a purely commercial basis.
} 
The World Trade Organisation (WTO) trade liberalisation agreement, the General Agreement on Trade in Services (GATS) provides new opportunities for trade in education which is very attractive to New Zealand providers of export education, however GATS is also seen to present significant risks increasing the impact of trade liberalisation for education services (Knight 2002a). Leading up to the Doha negotiating round, the education sector became increasingly aware of GATS and involved in thinking about its implications for the sector, evidenced in New Zealand in the submissions by the education professional organisations (NZEI 2003; AUS 2003b; NZPPTA 2003). Education is one of the least committed sectors in GATS however the future market for cross-border education is growing and that is why education is targeted for further liberalisation in this round of GATS negotiations.

There is a tendency for polarisation between proponents and opponents of GATS. On one side supporters see it as providing clearly laid out ground rules for participation in the growing international educational market (LaRocque 2003b) and highlight the benefits trade can bring in terms of innovation to delivery systems, greater student access and economic efficiencies (Knight 2002c). On the other side critics see GATS as commodification and privatisation, threatening public provision of education. The issues and their potential implications go beyond the prima face application of 'trade rules', to concern about the transformation of educational services embedded in the social relations of communities to "commercialised commodities traded within an international marketplace" (Kelsey 2003c:2; 2003a).

As a strategy, the expansion of the international educational marketplace can not be isolated from the neoliberal policies that have directed the processes of reform in $\mathrm{New}$ Zealand over the last two decades. A key theme running through the education reforms has been the shift in policy rhetoric towards greater economic responsiveness and competitiveness. This is manifested in both structural and content-based transformations, the changing role of government and in new public management approaches. A recurring and central theme in this paper is the contradictions between the ideology, rhetoric and objectives of reforms and the realities and complexities of education on the ground. 
Under neo-liberal discourse the meaning of social development has been reversed so that "social, cultural, human and intellectual development has been reconceptualised as economic transactions" (Dodd 2002:4). The notion of a 'knowledge economy' has arisen globally from the recognition that education is an essential part of a strong economy, and therefore education needs to be structured to support the economy. High economic value is placed on education as a commodity which has created a globally competitive education marketplace.

This paper brings together two distinct fields in education and development literature. The first is the emerging literature on international education, GATS and trade related debates. The second spans the literature addressing the impacts of the neoliberal reforms. This paper considers these reforms in terms of the structural transformation processes of 'marketisation', and 'managerialism'2 and the content-based transformation that redefined the central role of education, curriculum and teaching methods, to produce a more skilled work-force and self-reliant enterprise culture. These shifts are central to concerns about the extent to which rules of trade might take priority over educational principles and norms of public service.

For education GATS potentially represents a rescaling of governance from the national to the global level. It is essential to critically anticipate ${ }^{3}$ the possible implications this may have across the spectrum - from domestic governance and regulation of education, and the politics of education, to the potential social, economic and political consequences for societies and individuals. Some of the issues raised may need to be dealt with in the near future and if not anticipated and resolved by informed democratic processes within New Zealand they may only be resolved through complex legal argument between governments through the WTO disputes settlement mechanism.

\footnotetext{
${ }^{2}$ Briefly marketisation refers to the creation of the competitive educational marketplace and recasting learners as consumers, and managerialism to establishing new public management systems for administration and service delivery based on commercial models and practices. These terms are discussed more fully in the main body of this paper.

${ }^{3}$ By necessity this will be speculative, but based on what are quite obvious tendencies.
} 


\section{Rationale for this study}

This study seeks to understand WTO, GATS and its implications for education generally and for primary and early childhood education ${ }^{4}$ in particular. The education sectors in New Zealand "most likely to be affected by GATS are the early childhood and tertiary sectors where large numbers of private providers already exist and receive government subsidies due to the policies of the last government" (NZEI 2002a:4). Efforts by the present government to "remove elements of competition from these sectors and introduce new regulations to guarantee quality and consistency... [are already] restricted by GATS rules" (ibid: 4). Emerging international literature is primarily focusing on the potential impacts of this agreement for tertiary education and as yet there is very little consideration of potential consequences for education experienced during the formative years of childhood.

There are many different facets and multi-disciplinary perspectives that could contribute to this field of research. For this reason, this research paper represents a comprehensive analysis of the existing literature describing the different positions and dimensions in which the issues need to be considered, including the phenomenon of power. It seeks to pull these together to provide an overview which demonstrates the interconnectedness of international trade agreements, educational policy settlements and structural changes, and business involvement in education, and the multitude of issues they have generated, and which teases out central themes around the key questions: 'where are we going?' 'is it desirable?' and 'what should be done?' in order to anticipate implications and possible consequences. The contemporaneous nature of GATS, with significant consequences for the future but a lack of empirical evidence in the present, means attempting to anticipate and predict possibilities, by drawing on the trends emerging out of the market environment created by the neo-liberal reforms.

There is a small but growing body of literature in the international arena ${ }^{5}$ on GATS and its implications for education. In the political, educational and wider communities in New Zealand there is a dearth of informed analysis and open debate on the issues that surround the notion of

\footnotetext{
${ }^{4}$ Early childhood and primary education are classified together as a single sub-sector within the GATS classification system.

${ }^{5}$ A significant contribution to this literature comes from New Zealand academics, including ex-patriot educationalists, who have been critics of the New Zealand educational reforms.
} 
education as a tradable service in an international marketplace. There is little that can be concluded about the impacts of trade in services from available trade data. This research paper aims to contribute towards a greater understanding of GATS and its possible consequences for education here in New Zealand, drawing on both local and international literature.

\section{Research aim and objectives}

My overall aim in undertaking this research is to contextualise and problematise the subject of GATS relating to education services, to provide a basis for discussion, debate and further research and analysis. To focus and manage this task the following objectives were set:

\section{Objective One:- Contextualise the General Agreement on Trade in Services}

Objective Two:- Describe the application of GATS to education services; provide an overview of New Zealand's export education industry and the policies guiding the processes in New Zealand to open up trade in education service delivery

Objective Three:- Broadly discuss and debate the possible consequences and implications of the application of GATS on the provision of education services, particularly in primary school and early childhood sectors, by situating trade in educational services in the debates regarding the 'marketisation' of education in New Zealand and identifying critical issues

\section{Structure of this paper}

This paper consists of six chapters of which this introduction is the first. Chapter Two outlines the epistemological perspectives and assumptions that underpin this research and provides an overview of the theoretical frameworks that inform the political, development and educational perspectives surrounding the topic. Chapters Three through Five provide the narrative starting with the 'big picture' context in which the trade in services agreements are situated, then applying this to education services in general and the growth of New 
Zealand's export education in particular and finally focusing more specifically on the construction of the education marketplace for the primary and early childhood education sector in New Zealand. Each chapter conveys key information, ideas and relevant criticism from the literature the intention in each chapter is to be both expository and argumentative.

Chapter Three looks at the question 'what are WTO and GATS?' and then raises the general concerns and arguments surrounding GATS. Chapter Four focuses more specifically on the application of GATS to education and the development of the New Zealand export education industry, and whose interests it serves. Chapter Five examines the context of marketisation, continuous commercialisation and privatisation in which GATS negotiations are taking place. This provides the framework to critically discuss the question 'what are the consequences for New Zealand primary and early childhood education systems of redefining education from a socially embedded public service to a detached tradable commodity regulated by the rules of global trade?'

In Chapter Six I revisit the main ideas and critical issues discussed in earlier chapters, linking together the various key points and themes to discuss possible consequences of the application of GATS on the provision of educational services, particularly in the primary and early childhood sector. I summarise major themes and arguments that are emerging for further debate and research. 


\title{
Chapter Two
}

\section{RESEARCH FRAMEWORK}

\author{
'The question is', said Alice, \\ 'whether you can make words mean so many different things'. \\ 'The question is', said Humpty Dumpty, \\ 'which is to be the master - that is all'
}

Lewis Carroll, Alice in Wonderland

This chapter has two parts. The purpose of the first part is to outline my approach and assumptions in doing this piece of research. I briefly outline my research perspective, conceptual frameworks, instruments, and values that I bring to inform my research process: analysis, judgement and responses to the issues specific to this paper. I then describe the methodology employed and the limitations experienced.

The second part of the chapter appraises the theoretical frameworks underpinning the topic from each of the political, development and educational dimensions. I outline the ideological world views and assumptions underlying the political and economic processes driving contemporary processes of globalisation and the power-relations out of which the marketisation and free-trade discourses emerge, and dominant perspectives in contemporary discussions about these. Both the proponents and opponents of the central themes and issues discussed in this study are positioned from particular, and sometimes clearly articulated, world-views. These become central to the debates on those themes and the issues and therefore where appropriate are raised more specifically in the body of the paper. In each context I briefly explore some of the theoretical frameworks underlying the perspectives of other relevant scholarship. In the interests of brevity and at the risk of oversimplification, I refer only to the most pertinent. 


\title{
Epistemological perspective
}

\author{
If my heart could do my thinking
}

And my head begin to feel

I would look upon the world anew

And know what's truly real

\section{(Van Morrison)}

I have not attempted to situate this research within a single theoretical paradigm.

However, my overall approach is influenced primarily by two streams of scholarship: interpretive and critical. The interpretive paradigm realises that research is a reflective process of 'interpreting meaning' and seeks to understand culturally derived and historically situated points of view (Jones and Borbasi 2003).The dimension of interpretation in this paper involves taking up and making sense of the concerns of the commentaries, analysis and interpretations in the literature. I accept that social realities are constructed through language ${ }^{6}$ and therefore language is considered a central feature of socio-cultural situations (ibid).

Within the broad scope of critical research, I endeavour to combine a critical theory approach with a policy scholarship perspective. The former recognises the centrality of power relations, structural and ideological oppressions and policy contradictions while the latter employs a theoretical framework to interpret and analyse fundamental principles of policy change within their political and ideological context (Grace 1998). From a review of the literature, I seek to problematise the issues around the research topic, and analyse positions of various proponents and opponents, examining the underlying belief systems, assumptions and power relations behind the policies, structures and practices. Finally I propose to draw out and anticipate key normative ${ }^{7}$ questions and arguments.

\footnotetext{
6 'Language as discourse' forms the basis of Heidegger's approach to the study of understanding, especially the understanding of texts (hermeneutics) (Jones and Borbasi 2003).

${ }^{7}$ All theories and positions contain normative assumptions either explicitly or implicitly (Smith 1997). In this paper, I take the reflective, interpretive approach that explicitly acknowledges the questions and arguments are value judgements.
} 
The analysis is based on the premise that politico-strategic and politico-economic systems and practices are founded in ideological phenomena defining and maintaining power relations. There is nothing inevitable or unchangeable about these. However I am interested in the way these political and social relations are articulated through every medium of socialisation. Foucault's understanding of discourse draws attention to how this happens, in the way that things are named, talked about and given meaning through social practice (Dahlberg, Moss, and Pence 1999). Foucault was particularly interested in the relationship between discourse and power, in the way discourses construct the world and are strongly implicated in the production of 'truth' (Foucault 1980).

Acknowledging that the systems, structures and policies of society are constructed and reconstructed through social processes, I also recognise that there is nothing objective in our study of these. My focus is on interpretation and my approach founded on a belief in the finite, contextually and temporally bounded character of 'knowledge'. In asking the purpose of these systems and processes of world affairs, who they serve, and how others are affected, our discussion is, of necessity, incomplete and contingent, within this particular context and at this specific time, and therefore our conclusions are not definitive (Pettman 2000). We cannot assume to portray the world as it 'really is'. The nature of the material depends on the researcher's beliefs, motivations and intentions. The interpretative approach ${ }^{8}$ allows me the scope as a researcher to acknowledge my own experiences, interpretations and ideas, as a participant socially, culturally and politically situated in the 'realities' of the research topic.

In undertaking this research my intention is action-oriented, ${ }^{9}$ that is, to contribute to our understandings of issues with the view that this should also contribute to change for the better. In my view we need to understand what is happening in order to decide whether it is what we will support for the future or if we should try to change it. Because 'knowledge' is relative and embedded in social context, its production and reproduction are processes that can contribute to challenging dominant ideologies and power structures in society.

\footnotetext{
${ }^{8}$ Within the historical-hermeneutic approach essentially facts do not exist independently of experience; and interpretation is the objective (Murray and Overton 2003).

${ }^{9}$ Within the paradigm of critical theory combined with action theory, social structures are viewed as dynamic systems originating in human action; "people both shape and are shaped by sociopolitical and cultural arrangements... and people are capable of transforming their sociopolitical environment and themselves ...through individual and collective action" (Clare 2003:126).
} 
I have also taken a critical approach because it allows the explicit incorporation of moral or ethical questions. The issues raised and the debates surrounding them are intrinsically bound up in societal beliefs, principles and values. Academic criticism engenders a sense of discrimination, both positive and negative, with an implication of informed judgement (Williams 1983 revised edition). However I start from the premise that consideration of critical issues and to gain understanding of human affairs in the world requires the use of a more comprehensive range of faculties than rational analysis alone. I believe we need to be multidimensional in approach; "to augment rationalism with other ways of knowing" (Pettman 2000:215). So what are these faculties or tools of considering and knowing? Saul speculates some qualities (a useful but not definitive list $)^{10}$ each of which he considers to be of equal importance and working in dynamic relation to each other, so that balanced employment of all these qualities provides the best possibilities for considering the real questions of human conditions (Saul 2001). As Freire points out, a critical consciousness allows “...[people] to develop their power to perceive critically the way they exist in the world within which they find themselves; they come to see the world not as a static reality but as a reality in process, in transformation" (Freire 1970:70).

In thinking about this research topic I am not a solitary entity, but am engaged in a social act, participating in an ongoing process, made possible by the language, culture and society which I am part of (Pettman 2000). In a sense I am entering into a critical and imaginative conversation with others who are also interested in this topic. By undertaking a review and analysis of the literature, I am primarily listening to what others have to say on the various aspects of the subject and identifying the critical idioms they are using, entering into the conversation myself through my interpretative discussions and my endeavours to link together the central themes and conclusions.

Academic rigour strives for consistency, exactitude and precision in judgement, based generally on systematic analysis and principles of reasoning. I argue however that contradiction, inconsistency and paradox are intrinsic to the nature of human world views and behaviours and thus also to our endeavours to explain and understand them. Therefore while endeavouring thoroughness and conscientiousness, I acknowledge that

\footnotetext{
${ }^{10}$ Saul lists "Common Sense, Ethics, Imagination, Intuition, Memory and Reason" (in alphabetical order) (Saul 2001:13). 'Commonsense' could be perceived as particularly problematic as an analytical tool, however my interpretation turns to the Aristotlean conception of 'phronesis', i.e. "prudence, practical commonsense or wisdom" (Flyvbjerg 2001). So commonsense works as a counterbalance to instrumental rationality, and allows for a more practical reasoning-in-context.
} 
my discussion and argument is informed not only by 'reasoning' and therefore apparent rational and logical inconsistencies nevertheless contribute to the understandings and issues raised. This paper is an attempt at a coherent but contestable story of an aspect of world affairs that are presently unfolding.

Personal background and positioning: This research paper forms partial fulfillment of a Master of Development Studies, towards which I have also completed papers for Master of International Relations. My original Bachelor of Arts with Honours was undertaken in Geography, with a supporting major in Anthropology, at Otago University back in the late 1970s, during an era of social protest, particularly about the nature of Maori-Pakeha relationships. My return to academic research follows from a background spanning 25 years transiting the fields of teaching, participation and leadership in local community-based initiatives, community development and social policy work through a local authority and management of an NGO. I acknowledge that these experiences and contexts, which included participatory action research projects, along with my own philosophical leanings have informed my perspectives on the research process and influence the shape this inquiry takes.

My commitment to research stems from a passion for inquiry that generates ideas and actions in the social, cultural and political spheres. As a parent, educator and researcher I have multiple roles to fulfill. At the same time I am also a citizen with some understanding of, and emotional involvement with the needs of our country.

\section{Methodology}

\section{Literature-based study:}

My intention is to scope the literature to provide a broad and comprehensive understanding and critical appreciation of the topic and emerging issues.

The research primarily draws on existing primary and secondary data available in the public domain, and comprising academic research, journals, published texts and books, conference proceedings, reports, official publications and policy documents, education 
and trade related publications, electronic databases and internet sources, media articles, submissions, newsletters and correspondence from relevance professional bodies and agencies. To a limited extent this is supplemented with personal data from professional contacts and communications between people who have expertise related to the topic.

A comprehensive data search, scoping the New Zealand and international databases, internet sources and New Zealand media publications pertaining to 'GATS and education services' was undertaken. This search primarily focused on the periods post inauguration of GATS in 1994, and post 1988 education reforms, however relevant material prior to these two critical milestones has also been included where it contributes to the analysis.

As a text-based study, the literature review is integrated into all stages of the paper. The findings and discussions are presented as a narrative emerging from the literature and therefore also woven throughout the body of the paper. Thus, throughout the paper there is an ongoing connection between the discovery or identification of ideas from the research material and the researchers own thoughts and further development of those ideas.

\section{Tools and analytical methods:}

The 'data' is primarily in the form of words, and the qualitative analysis is interpretive and intersubjective. Drawing on the combination of faculties and tools for knowing and understanding outlined in the epistemological perspective above, the key analytical instruments I employ in this research are description and interpretation, leading to some concluding arguments and recommendations. Specifically these tools allow me to:

Description and analysis:-scan documents to identify distinctive parts of the subject, common concepts, key points and main issues, and major sources of difference between the opposing arguments; explain the relationships between the parts; and provide evidence for the interpretations and arguments

Interpretation and argument:- engage in critical discussion, incorporating reflection, insight, imagination and intuitive connection of seemingly disparate notions and ideas, drawing together and integrating central ideas and perspectives, postulating, 
considering and imagining how the issues and relationships (above) might affect the situation and future outcomes, and present judgements and arguments on behalf of a position.

\section{Limitations experienced with this method and analysis:}

There were two significant limitations in sourcing data for this study. Firstly there is dearth of existing research and literature on this subject, particularly in the context of early childhood and primary education, and secondly the nature of the subject, in terms of possible implications of trade liberalisation and GATS is somewhat futurological. Therefore I make use of analogy, anticipating possibilities by inference, from both the emerging body of GATS related literature particularly in the tertiary education arena and from the perceived relevance of issues and trends identified in the literature that appraises the impacts of the education reforms post 1988.

Both the nature of the subject and the type of material available posed restrictions on the type of data available. Specifically there was a significant lack of empirical information and qualitative evidence supporting the issues under discussion. Some sources of secondary data, particularly books and some journals, have typically been 'processed' and therefore are subject to more qualifications than other types. These limitations have been reasonably accommodated, as the objectives of this paper are not empirically focused and given the short time-frame for the research.

There are other difficulties inherent in textual analysis, particularly in terms of evaluating and synthesising the views of others. It is difficult to know much about the hidden assumptions, intentions, connections and distortions that go into the production of a particular set of secondary datum. Social data generally contains bias and therefore every effort is made to ascertain the basis on which information has been compiled. There is also a risk of misinterpreting the intention of the author.

The breadth of material to be researched and analysed, due to the comprehensive nature of the topic, proved to be ambitious within the timeframe available. However this scope was justified as a necessary preliminary step in an emerging area of research, to be useful both as a springboard for further research and as an informative tool for people 
working or interested in progressing the discussion and debates surrounding educational markets.

\section{Theoretical frameworks}

\section{Political Context: Situating WTO and GATS in the context of modern world affairs and power relations}

This paper draws on explicit awareness of Critical Theory ${ }^{11}$ that the hierarchical power relationships of institutional regimes support dominant ideologies and generate certain beliefs and self-understandings, which are frequently accepted as natural and therefore unchallengeable. "Culture, ${ }^{12}$ relations of power, ideology and hegemony ${ }^{13}$ are central constructs in critical theory" (Clare 2003:129). In this research it is therefore important to explore the ideological positions that underpin the free trade debate.

The WTO is a system created through the globalisation of the modernist politico-cultural project, in all its manifestations. The central dynamic or driving force of that project is described by World System Theory (WST $)^{14}$ as global capitalism. The principles and aims of WTO and its agreements have been framed within one of the dominant ideologies defining this project, the politico-strategic dimension of liberal internationalism, to expedite the market driven goals of the politico-economic dimension of liberalism. However, diverging from WST, I do not hold with the view that life within this system is self-contained, or that the world system itself is overarching (complete).

\footnotetext{
${ }^{11}$ I refer here to the Frankfurt School of Critical Theory (Bronner and Kellner 1989).

${ }^{12}$ The Frankfurt School of Critical Theory views culture as integral to structuring and mediating social processes and structures, and to the transforming action of language, in resisting and reconstituting those processes and structures. Culture provides the means of control, authority and consensus for the exercise of power.

${ }^{13}$ The way in which dominant groups are able to define and maintain social situations and power relations can be understood through Gramsci's concept of hegemony, referring to the means to legitimate social and political control through influencing the consciousness of people to accept the particular world view and values of the dominant group, in order for society to function to the benefit of this group. This is achieved through all the structures, activities and media of society and agencies of socialisation. Thus hegemony is a form of dominance that involves and balance both force and consent (Hoare and Smith 1971).

${ }^{14}$ Wallerstein, the 'father' of World System Theory argued that all elements, in a system are interlinked and exist in dynamic relationship with each other. From this holistic perspective, attempts to distinguish economic, political and socio-cultural phenomena are misleading (Hobden and Jones 1997).
} 
Rather I find a post-structural approach, recognising the open and contingent nature of any system, and the dynamic with what is 'outside', the 'other' helpful (Howarth and Stravrakakis 2000). In the words of Robert Cox "globalisation as it is discussed in much of the literature, is a thesis foreshadowing one civilisation" (Dale and Robertson 2003:14).

Habermas' makes a useful distinction between the 'system' and 'lifeworld':

On the one hand, action in the modern world is co-ordinated by systems which function according to means-end rationality; the market is a paradigmatic example of such a system... On the other hand, actions are coordinated primarily be communicatively mediated norms and values, and by the socially defined ends and meanings which constitute the fabric of the lifeworld

(Meehan 1995:6-7)

Free Trade and the removal of barriers to business is central to modern interdependency theory (Burchill 1996) and implies a misleading degree of equality and shared vulnerability in the international economy. It is based on the assumption of a universal 'Truth', of the ideal of the global capitalist system and that an integrated world market will 'deliver', as long as we can contain some of its excesses and imbalances. Within such a frame of reference liberal internationalists see the policy challenge as focused on making the world safe for free trade in goods and services. ${ }^{15}$ This view maintains a "common sense ${ }^{16}$ notion of the neutrality and rationality of markets and capital that belies the constraints and inequities produced by the inherent power relationships.

WTO attempts to place a 'governance system' into the international arena. However as with all supranational agents, in a state-centric world, to act effectively they require the support or acquiescence of the principal (strongest) states and therefore the 'power' remains in the hands of those principal states. Under the guise of international ideals those strongest players can expediently use its multilateralism to expand and strengthen

\footnotetext{
${ }^{15}$ Mike Moore maintains a belief in the role of international governance, specifically WTO, to establish a system of freedom and equality of opportunity acting in direct opposition to the power and privilege accrued through state protectionism (Moore 2003:7).

${ }^{16}$ Gramsci argues that the dominant group projects it's own ideology, values and life choices through processes of socialisation and information management so that it becomes accepted as 'common sense' (Hoare and Smith 1971).
} 
their economies, and ensure that the conditions of transnational capital ${ }^{17}$ continue. Underlying the behaviours of dominant players, most notably the US, are political frameworks premised on a mercantilist ${ }^{18}$ approach, which has framed the 'rules' under which interdependency operates. This has created a fundamental dichotomy between the purported goals of WTO and how the rules are actually formed, interpreted, implemented, enforced and disputed. Thus while WTO is promoted as a multilateral forum for equity and justice, guided by "the tenets that international trade should be without discrimination, freer, predictable, more competitive and beneficial to developing countries" (MFAT 2003a:2), in practise it is a vehicle for the promotion and protection of the self-interests of the strongest states.

The principles of WTO agreements can not in themselves manage 'fairly' the behaviours of a capitalist market place dictated as much by the politics of realism as liberalism. The words of John Randolph "you may cover whole skins of parchment with limitations, but power alone can limit power" (cited in (Morgenthau 1966)) adeptly describe the world views of many dominant players. Ostensibly, in the view of some promoters, WTO and its agreements have been created as a system to maintain stability in the market-place, through the 'balance of power'. Even within this framework the rules of these agreements will only provide a restraining balance of power, if members are restrained by equal or stronger pressure by others. So the EU for example does provide some counter-balance to the US, and it is interesting to note that they are the members most actively using WTO disputes mechanism.

At the macro level, the forces at work are firstly a form of imperialism. Referring to Hardt and Negri's work called 'Empire', Cox describes this as the concept of a political order that is centralised and extends itself into all parts of the world. It is not a formal institutionalised structure, but a real structure... [centred on] Washington now" (Dale and Robertson 2003:21). Secondly the state system based on the Westphalian concept, and

\footnotetext{
${ }^{17}$ The director of the WTO service's division has pointed out that "without the enormous pressure generated by the American financial services sector, particularly companies like American Express and Citicorp, there would not have been services agreement" (Monbiot 2001).

${ }^{18}$ Mercantilism refers to economic protectionism that derives from a realist view that human nature is fundamentally selfish, and therefore states are forced to compete to maintain or expand their existence (Gilpin 1987). World trade negotiations are fundamentally mercantilist in nature, i.e. 'horse-trading' practices designed to ensure "my gain is your loss" (Moore 2003:135).
} 
supra-state organisations of power (e.g. EU) and thirdly, the emerging bottom up force of civil society, ${ }^{19}$ driven largely by non-governmental organisations.

The notion of 'civil society' embodies the amalgam of social and cultural institutions and activities in society, that form the central sites of socialisation, transmitting and giving legitimacy to the dominant world views, beliefs and values on the one hand, and on the other hand it is in this realm that the spaces for counter-hegemonies emerge, creating within civil society the contested 'spheres of struggle' (Johnston et al. 2000:85).

The legitimacy of GATS is secured in the assumption that it is an abstract, neutral instrument of objective rationality, based on 'timeless' and 'disinterested' general principles and rules. The principles of GATS are based on the premise that each member state is 'equal' and thus in theory, it should provide security through the multiplicity of interests. This perception is challenged on two fundamental levels. Firstly in reality the market place is hegemonic, and therefore the 'desired security' is in fact locked-in by the rules of GATS for the benefit of the dominant key players only. In negotiations governments are acting on behalf of business interests and are making decisions that will be effectively irreversible, thus fundamentally altering the balance of rights and responsibilities between the State and corporations. In particular the rules are oriented to benefit transnational corporations, and the decisions about these rules are taken through the exercise of power by the strong over the weak. While operating across several countries, transnational corporations tend to be aligned with a major state power and do not promote the interests or well-being of states or more importantly people and their communities.

The second challenge focuses on the language of GATS as an ideological discourse. In her analysis of the technical text of GATS Kelsey identifies "the barriers and

\footnotetext{
${ }^{19}$ Civil Society is not a homogeneous category or definitive 'organisational form'. In the context of free trade debates, Anheier, Glasius and Kaldov, ccited in (Moore 2003), differentiate four core categories within a 'typology' of civil society groups regarding their positions on globalisation:

Supporters - transnational business and their allies; favouring global capitalism.

Rejectionists - a diverse mix of anti-capitalist social movements, authoritarian states, nationalists and fundamentalist movements; from both right and left political stances, want to preserve national sovereignty, some opposing only the global nature of capitalism, others more extreme.

Reformists - most IGOs, some in international institutions, many social movements and networks; aiming to 'civilise' and humanise globalisation.

Alternatives - grass roots groups and social movements, wanting to 'opt out' of globalisation.
} 
opportunities that the Agreement itself presents to critical engagement" (Kelsey 2003b:267). Understanding the Agreement itself as an 'ideological phenomenon' is "pivotal to understanding how the interests of international capital are effectively privileged and how competing understandings that insist that GATS embodies and perpetuates the inequalities of social relations are excluded" (Kelsey 2003b:267).

\section{Development Context: Free trade as a tool for development?}

Many things are done in the name of development, ${ }^{20}$ or in the name of progress. The international institutions, such as the World Bank and WTO, promote and practice within an ideology of 'mainstream or intentional development'. ${ }^{21}$ The principles of trade reform as institutional and policy reform, the fiscal dimension and trade policies for poverty alleviation provide the context for a World Bank 600 page handbook to assist developing countries in the development reforms through trade and WTO (Hoekman, Matto, and English 2002).

Trade is viewed as a key to economic development, the premise being that when trade flows freely it generates economic growth. Economic development has a positive 'carryon' effect on poverty alleviation. Competition 'spurs' an efficient services infrastructure, which in turn is a precondition for economic growth. Kofi Annan, United Nations Secretary General is recorded as saying to the Financial Times (5-3-01) "that no single change could make a greater contribution to eliminating poverty than fully opening prosperous countries' markets to goods produced by poor ones" (MFAT 2003c:3). Some advocates promote WTO and its agreements as 'agents' of the concept of a 'global village' built from a 'global economy', seeing global interdependence transcending nation states as a positive future and one that could assist world peace building. Indeed liberals claim that economic interdependency has a pacifying effect on international relations (Burchill 1996).

20 "'Development' has been called the central organising concept of our time" (Cowen and Shenton 1995:27). However it is a highly contentious and debated concept. The assumption of 'progress' underlies much conventional or mainstream usage.

${ }^{21}$ Conventional or mainstream development theory and practice encompasses both classical and neoliberal economics, and includes practices that promote the progressive expansion of capitalism (Johnston et al. 2000:169). 
The contrary view holds that the inequalities and injustices exacerbated by WTO will contribute to international insecurity; in the words of the CIA "the rising tide of the global economy.....will foster political, ethnic, ideological and religious extremism, along with the violence that accompanies it" (Coates 2003:1). A growing economic chasm separates those who benefit from the world trading system from everyone else, entrenching and expanding the divide between rich and poor within and between countries. For example, tiered systems of education and social security within countries are becoming the norm all over the world. Trade rules do not adequately recognise or redress the imbalances between rich and poor countries.

Implicit to all WTO public material is the claim that trade liberalisation is about improving opportunities and benefits for those who sell the goods and services, but it must be remembered that the gains of those who dominate the international trading arena are won at the expense of the less powerful. To date there is no evidence that developing countries will benefit from GATS. To the contrary it is likely that WTO rules hamper their economic development (World Development Movement 2003).

Opponents argue that WTO rules are fundamentally anti-development, whereby developing countries lose the right to employ trade policy and a variety of critical trade measures as a development tool (Zmag 2003). It is difficult for developing countries to compete against foreign suppliers, with foreign investment frequently pushing out local businesses, which can not be protected or 'nurtured' in the same way that first world countries did during their own development. Foreign competition puts pressure on local employment opportunities resulting in job losses. These developing countries lack the capacity to readjust with training in new skills, development of alternative sectors or new technologies.

The continuing quest for economic growth is the organising principle of current public policy regimes, and yet there is widespread concern that this principle is breaking down the ecological and social fabric - very factors that support a sustainable efficient economy. The problem is not business, markets or trade per se, but the powerful and perverse domination of this system driven by the imperative to "replicate' money. Some critics believe that there can be policy alternatives other than this extreme form of liberalisation, questioning the underlying assumptions of global capitalism - its 
commitment to growth, big business and deficit funding, and citing these practices as a “leading cause of, and not a solution to" rapidly accelerating poverty (Korten 1995).

Decision making and negotiating processes are controlled by the most powerful economies - US, EU, Japan and Canada, assisted by countries such as New Zealand and Australia, Singapore and Chile who have a significant stake in creating open markets and a global service industry (Robertson 2003). Consequently, many developing countries regard WTO and its processes as fundamentally unfair and inequitable. Current trade negotiations are perceived as reinforcing patterns of historically-embedded asymmetries. Thus it is no surprise that educationalists in developing countries are concerned about the asymmetries between countries that are education exporters, and particularly US. For example Schugurensky "questions about the potential implications for education in terms of accessibility, equality of opportunity and social polarisation in the [Latin American] region" (Schugurensky and DavidsonHarden 2003). The collapse of the WTO talks at Cancun, with the rise of G21 block of developing countries, marks a potential shift in WTO power relations.

There is growing acknowledgement, even amongst politicians, corporate leaders and economists, that IMF and World Bank orthodoxy, requiring developing countries to embrace trade liberalisation, is increasing global poverty. For example Byers now believes "this approach is wrong and misguided... [and] a different approach is needed: one which recognises the importance of managing trade with the objective of achieving development goals" (Byers 2003:1).

The most fundamental issues of development are at their core, issues of power. Korten differentiates between 'increasing economic growth' and 'improving the lives of people' and examines the role of global institutions in depriving people and local communities of the power to meet their own needs in responsible sustainable ways. Who holds the power to decide is the pivotal issue. A globalised economy denies this 'right' by transferring the power to make relevant choices to transnational corporations. Korten seeks a paradigm shift; he believes the principles of WTO should include local economic self-reliance and global equity and the role of economic governance should be publicly transparent and fully accountable to another body such as the United Nations. Because political leaders are entrapped in the myths and rewards of the dominant political and 
economic ideologies and institutions, Korten claims that to even begin a process of value re-creation and institutional change, leadership most likely will come from within civil society, as the foundation of democratic governance. (Korten 1995).

In the $21^{\text {st }}$ Century knowledge has emerged as the essential development strategy of all societies. Promoting a development agenda for education as opposed to a trade agenda, Education International launched a global campaign in 1998 to defend and enhance public education on the premise that "education is a right, which should be guaranteed by the State within the framework of a public service and not be subjected to the laws of the market", claiming that

only public education provides all children with a sound foundation for lifelong learning granting both sexes equal access to early childhood services and schools, irrespective of the economic, social and cultural background of their parents, and thus contributes to equal opportunity for all ... [and that] public education is still a key instrument of social liberation, peace, progress and justice ... [and] contributes to the reduction of inequality, supports social cohesion and national progress

(Education International 2001:1-2)

\section{Educational Context: Markets and educational policy frameworks}

For this research paper I have sourced literature within educational contexts with two core themes in mind: firstly, material that focuses on the policy changes in the New Zealand education system over the last two decades, and secondly, material dealing directly with trade in education, GATS and its potential consequences. Central to the critiques of both are the impacts of the market ideology and debates about the role of education in society.

Starting from the position, that globalisation is the outcome of transformative processes that involve real actors with real interests (economic and political), there is a need for education theorists to develop frameworks to make sense of the profound changes characterising education today. These processes and the transformations they are driving raise core ethical issues about the place that public services, particularly education, occupy in defining democracy and citizenship and embedding at the level of social formation the national identity and culture of our society. 
These systemic transitions represent a fundamental shift in power, driven by the imperatives of capital (Robertson, Bonal, and Dale 2002). One of the defining characteristics of the current era of globalisation is the accelerated expansion of capital, especially financial capital, its compression in 'time-space' and its drive to overcome geographical barriers. ${ }^{22}$ This dynamic of capital needs to be embedded in social institutions that are supportive of its continuing expansion. Education "contributes to the array of means addressing capital's need for infrastructural support to enable its continuing accumulation, brings about the necessary degree of social order for that accumulation to proceed, and provides the system as a whole with legitimisation" (Robertson, Bonal, and Dale 2002:2).

The New Zealand education reforms from the late 1980s and 1990s, that resulted from the New Right inculcation of policy making that linked education with economic responsiveness and productivity, represented a fundamental and substantive shift from the perspectives that had shaped educational policy in the period of the welfare state. Public policy reform in New Zealand became captured by a 'scientised' economic discourse, in which an abstract neoliberal model of rational economic behaviour provided the explanation for all human behaviour (Fitzsimons, Peters, and Roberts 1999:35). This discourse provides a systematic account of how people act in objectifying and individuated ways and is then used to model decision making in society and in markets. The economic theories underpinning the neoliberal approach (also known as economic rationalism) to educational policy include ${ }^{23}$

- Monetarism, Friedman's approach to 'sound money' as the fundamental concern of state policy

- Human Capital Theory (HCT) which treats education as an investment in a person and to treat its consequences as a form of capital; thus investment in education accounted for the fact of economic growth (Schultz)

- Public Choice Theory (PCT), lead by Buchanan, applies the assumption of the selfinterest basis of human nature and the theory of rational economic behaviour to political and governmental realms; attaching as 'myth' the idea that government or public service is able to serve the public good. The overall effect of this rule is to

\footnotetext{
22 The power of the discourse of 'globalisation' lies in its portrayal "as an abstract challenge to be met, rather than the agent-driven processes of capital development" (Mulderrig 2003:4).

${ }^{23}$ Olssen provides a good explanation of these concepts applied to education (Olssen 2002:chpt 2).
} 
limit the role of government and to redesign public institutions to reflect the preferences of individuals

- Quasi market strategies, arising from PCT; in particular contracting out services, increasing competition between units in the public sector, separating commercial and non-commercial functions, separating advisory, regulatory and delivery functions, managerialist techniques for accountability, monitoring and reporting

- Agency Theory, representing work relations hierarchically as a series of contracts between one party, the principal and another party, the agent

- Transaction Cost Economics, accounting for the efficiency costs of transacting business and proposing forms of organisation, administrative and governance structures, that render transaction costs efficient

- Property Rights Theory, grounds the self-interested behaviour assumed in the neoliberal theories, whereby the theory of 'ownership' provides "one's effective rights to do things and effective claims to reward as a result of one's actions" (Olssen 2002:19).

These theories applied to 'public services' are collectively represented as New Public Management (NPM). The failure of much policy analysis, according to critics, lies in these neopositivist methods and their technocratic orientation (Fischer 1998).

Central to the theoretical basis of this paper is an understanding of the effect of neoliberalism on power relationships in education, and particularly to the impact it has had on the role of educationalists and their relationships with government. Olssen puts this very well, representing neo-liberalism

as a positive form of power that represents all social relations as relations of exchange... In relation to education, it has been able to effect its changes through new indirect forms of control via the use of markets and various other new techniques of government... refuses to extend power or authority to groups of people who claim professionalism by virtue of shared competence, but represents such groups solely as aggregates of self-interested individuals, it replaces networks of delegated power which characterise the professional mode of organisation with hierarchical chains-of-line management which disempowers and 'de-authorises' the labour of the intellectual."

(Olssen 2002:53) 
From a Foucaultian ${ }^{24}$ point of view neoliberalism can be seen as a form of governmental rationality, constructing the notion of the minimalist state and constructing an enterprise culture (Gordon 1991). An illusion of neutrality has masked the ontological and ethical assumptions underpinning neoliberal reform. The process of restructuring was presented as both natural and inevitable; that 'there is no alternative' (TINA). "The appeal to 'apolitical' (or 'nonpolitical') [neutrality in] policy principles is itself an important part of the politics of reinforcing a nonneutral ideological position" (Fitzsimons, Peters, and Roberts 1999:41). When subjected to scrutiny, the state far from reducing, is as large as ever, and the freedoms, far from increasing choice, are illusory. "Legislators are lessening the extent to which they direct policy, but radically changing its direction: and the power of the state is not shrinking, but is rather being directed towards substantive change in the social order" (Jonathon, 1997, p.27 cited in (Olssen 1999:55)).

The New Right approach in educational policy-making has not derived solely from the singular theoretical paradigm of neo-liberalism, but rather a combination of neo-liberal and neo-realist (neo-conservative) approaches (Apple 2001). Both are rationalist theories, which while they are often portrayed as alternative and incompatible, they both share a specific positivist and rationalist approach to how to create knowledge, focusing on the same issues but from different sides and from different views of human nature. ${ }^{25}$

There is an established tradition of critical approaches to educational policy studies. The most valuable of these play a role to stimulate (rather than 'settle') policy debates, providing arguments rather than conclusions. Apple has made significant contributions to this field of critical analysis of education policies, raising and answering key questions about the large-scale effects of policy (Apple 2003). Apple places our common understandings of the 'consumer' and the 'market' into a social critical framework, which interrogates their functioning in the 'real world' of education. "Looking at education as part of a mechanism of market exchange makes crucial aspects literally invisible,

\footnotetext{
${ }^{24}$ Foucault is interested in the question of how power is exercised and provides a critiques of the contemporary tendencies to over emphasise the problems of the state and reduce it to a certain functionality (Gordon 1991).

${ }^{25}$ Pettman, in describing the underlying assumptions about human nature that influence different ideological positions, refers to the realist belief in human nature as essentially 'bad' while the liberalist belief assumes human nature is essentially rational (Pettman 2000). What results in the debate between neo-realists and neo-liberalists is that the former emphasises comparative (win-lose) outcomes, while the latter prefers to focus on absolute outcomes (gains) (Smith 1997).
} 
thereby preventing critique before it starts" (Apple 2001:20). Rational choice theory takes rationalism and individualism to extremes, it is too abstract and unrealistic and simplistic, and therefore failing to improve policy (Pettman 2000). There is no recognition of the dynamic interdependence of citizens seeking and fighting for the 'public interest' as well as their individual interests.

Critical policy scholarship ${ }^{26}$ is a relatively new field contributing to critiques of neopositivist ${ }^{27}$ policy approaches. It is historically informed, and draws on qualitative and illuminative techniques to expose the possible relationships between the politico-socioeducational contexts. "It is a post-positivist ${ }^{28}$ conception of policy science, designed to address the multi-dimensional complexity of social reality" (Fischer 1998:129). Situated in a broader interpretative framework, the approach offers a better description of what social scholars actually do in practice. Rather than totally rejecting empirical methods of social sciences, Fischer argues "that the issue is how to situate them within the context of normative concerns that give them meaning" (ibid).

Contributing to the development of this emerging field is the work of Grace in his critical analyses of the educational reforms undertaken in New Zealand using a 'policy histography ${ }^{29}$ approach. Grace engages in and represents his analysis in the notion of 'temporary policy settlements'. ${ }^{30}$ The concern in this field is foremost with 'being critical ${ }^{31}$ and is particularly interested in the critique of oppressive social structures and practices (Harvey 1990). Critical sociology endeavours to imagine a relationship between the specific and the general of social life to generate new insights and new actions. What

\footnotetext{
${ }^{26}$ Variously named critical policy scholarship, critical policy analysis or policy sociology (Gale 1999).

27 'Neopositivist' is used here as an umbrella term for the various combinations of neo-liberalism, neoconservatism, new public management or managerialism, and public choice theory; economic theories based on positivism: an epistemology that holds that reality exists and is driven by laws of cause and effect and is value free, as the laws or generalisations exist independently of social and historical context.

${ }^{28}$ Post-positivism is grounded in the idea that although reality exists it can never be fully understood or explained given the problem of social meaning. i.e. it emphasizes the social construction of theory and concepts, multiplicity and contextual nature of causes and effects, and the requirement for critical interpretation (Fischer 1998).

${ }^{29}$ Policy histography is an approach that seeks to understand the historical conjuncture leading to structural change, identifying "the substantive issues with policy at particular hegemonic moments" (Gale 1999:1).

${ }^{30}$ Grace talks of education policy "in terms of a succession of crises and settlements. Education settlements are resolutions of crises situations in which a particular balance of ideologies, power relations and interest groups has been achieved in a policy outcome" (Grace 1998:91).

31 'Critical' has become a difficult word; its predominant sense is 'fault-finding' but it also has an underlying sense of judgement and in this academic context, refers to 'informed judgement' (Williams 1983 revised edition).
} 
critical policy histography adds is the question 'what do these reveal about who is advantaged and who is disadvantaged by these arrangements?'

In setting the context for the development of early childhood education over the last century Helen May looks at how the contradictory positions are accommodated in each new era of policy settlement ('gaze ${ }^{, 32}$ ) where the dreams for social and political change promoted by the advocates in the sector interface with the worldviews and 'responsibilities' for social and political order sought by the politicians. ${ }^{33}$

This chapter has provided a theoretical overview in which the discourses of proponents and opponents of liberalisation of trade in education and marketisation can be understood. With these frameworks in mind I will now look at the rationale of WTO and GATS and its objectives.

\footnotetext{
${ }^{32}$ May refers to the 'political gaze' of the time, revealing how "the rhetoric of the advocate and the politician might at times accommodate a similar language and rationale but they are based on different assumptions" (May 2002:13).

${ }^{33}$ For other critical analyses of policy particularly in the early childhood sector the reader is referred to Ross and Loveridge: Coming from a relational theorist perspective, Heidi Ross also focuses on the importance for policy to be embedded in the social life and relationships of people and practice; that "policy is, in the end, relational" (Ross 2002:415). In the field of education, this relational approach is not only applied to the development of policy, but also to the pedagogical framework and moral dimensions of teaching. Citing both Bowers and Freire, Ross uses relational theory to reveal how systems of education package myths of modernity (Ross 2002). Loveridge draws on discourse theory to historically examine "the ways in which early childhood has been discursively constituted" (Loveridge 2002:177).
} 


\section{Chapter Three}

\section{TRADE, GATS AND WTO PROCESSES}

The purpose of this chapter is to contextualise the liberalisation of trade in educational services in the governance and decision-making processes of the international treaty (GATS), and in the debates surrounding free trade versus managed trade in the context of development and the expansion of global economy.

\section{The broad principles, aims and objectives of WTO and GATS}

The World Trade Organisation (WTO) is the international body dealing with a multilateral system of rules of trade between nations. It has three main purposes. The first and overriding purpose is to help trade "flow as freely and predictably as possible so long as there are no undesirable side-effects" (WTO 2003c:1). This is achieved through WTO agreements - legal rules for international commerce that bind governments to keep their trade policies within agreed limits. The second purpose is to serve as a forum for trade negotiations to progressively remove trade barriers and the third purpose is dispute settlement.

WTO is an organisation of member states, officially operating by consensus with each member government having power of veto. It was formed in 1995 following the Uruguay Round $^{34}$ of trade negotiations between governments. Its base rules were provided by the General Agreement on Tariffs and Trade (GATT) that has existed since 1948. WTO now

\footnotetext{
${ }^{34}$ The WTO was formed after eight years of negotiations at a meeting of trade ministers that took place in Uruguay in 1994, which has since been termed the First 'Ministerial Round'.
} 
administers more than twenty trade agreements including the General Agreement on Trade in Services (GATS), the agreement on Trade-Related Investment Measures (TRIMS) and the Trade-Related Aspects of Intellectual Property agreement (TRIPS).

Unlike the original GATT, which was effectively a business contract between countries, WTO became an independent legal governing body with international status, legislative, judicial and executive powers. As such it is potentially the most powerful global institution at this time. Within the trade context, its legislative and enforcement powers can challenge the laws, practices and policies of individual countries (Barlow 2001b).

The agreements are negotiated by ambassadors or ministers who represent their governments and are responsible for advancing their government's agenda. To achieve the required 'consensus', members must persuade other members to a point of agreement, by which all 137 members then agree to be 'bound'. Although all WTO members are 'sovereigns' over their 'customs territory', by joining WTO they undertake to make laws that comply with WTO Agreements and to change laws that do not (WTO 2001c).

\section{Principles and rules of GATS:}

GATS was negotiated as part of the 1994 Uruguay Round, along with the formation of WTO. It came into force in 1995 and is the first set of multilateral legally binding rules (called 'commitments') that opens service sectors to foreign competition and that require foreign suppliers to be treated the same as domestic suppliers (without discrimination). It was developed as a result of the huge growth in the services economy over the past 30 years, and the potential for trade in services resulting from the communications and technology revolution.

GATS has four elements, the fundamental principles and obligations, rules for specific sectors, the specific commitments of individual countries and exemptions from the Most Favoured Nation principle (MFN). 
Excluding MFN principle, GATS is modelled on the GATT and applies the same fundamental principles. ${ }^{35}$ These principles are summarised below from GATS Articles (WTO 2003a), however it must be noted that there is a great amount of ambiguity, uncertainty and difference about the interpretation and understanding of some Articles, even by WTO Secretariat and amongst WTO members (Krajewski 2001).

Scope of services covered: GATS is wide reaching; it includes all services in any sector except public "services supplied in the exercise of governmental authority", being "supplied neither in a commercial basis nor in competition" - Article1:3. The meaning of this exemption is ambiguous, however most sources concur that it applies only to services funded completely by government and provided free (Barlow 2001b; Grieshaber-Otto and Sanger 2002; Kelsey 2003c). Government services that are publicly supplied on a commercial basis are subject to GATS rules, although may be outside a country's current schedule of commitments. Services are categorised by type ${ }^{36}$ and method of supply. ${ }^{37}$

Horizontal Commitments: The general obligations in GATS apply to all services, as listed by WTO, even those excluded from that country's schedule of commitments.

These are:

Most Favoured Nation:- A 'horizontal' rule, (MFN) Article II, is the central principle of WTO and means that all member countries must be treated equally. Once foreign businesses from one country are operating in a particular country's market, then businesses from all member countries must also be allowed, under the same conditions. Governments were allowed to list exemptions from the MFN on

\footnotetext{
${ }^{35}$ The artificial construct of 'trade in services' was given legitimacy in the formulation of GATS, by adapting the accepted notion of 'trade in goods'. The GATT provided the terminology, the core principle of rulesbased trade and parameters for the function and content of the GATS. This implied an equivalence between 'goods' and 'services', that denied the purpose, nature and social relations particularly of services such as education (Kelsey 2003b).

${ }^{36}$ In WTO every service is identified by a UN Central Product Classification number.

${ }^{37}$ The WTO identifies four 'modes' for supplying services (MFAT 2003a:1).

Mode 1: Cross border supply; the service is supplied by a provider located in one country to a consumer in another, for example via internet, phone, fax or mail.

Mode 2: Consumption abroad; the service is supplied to a consumer from one country who has travelled to the territory of the supplier, for example tourism, education for foreign students.

Mode 3: Commercial presence; the service is supplied by foreign business entity who has established a presence in another country, through direct investment, incorporation, branch establishment or joint venture. Mode 4: Presence of natural persons; the service is supplied by a foreign person who temporarily travels to deliver in another country.
} 
entering the agreement, but these exemptions are in principle temporary, lasting only ten years.

Transparency:- The other key horizontal principle, under Article III, requires all member countries to publish promptly all measures that affect services and the operation of the agreement, inform the WTO Council of Trade in Services of changes to laws, regulations or administrative mechanisms affecting services covered by the agreement.

Domestic Regulations: A clear goal of GATS is to remove barriers to trade in services, and the rules for domestic regulation, Article VI, are intended to ensure that policies, regulations, licensing requirements, standards and qualifications "do not constitute unnecessary barriers to trade in services"(Kelsey 2003c:18). Due to the ambiguity of wording, there is debate about whether these restrictions apply to domestic regulations horizontally across all sectors or only to the sectors where governments have made specific commitments. Governments retain the right to regulate in order to meet national policy objectives, Annex 1.b.

Vertical or Sector Specific Commitments: Governments retain the right to specify the sectors on which they will make commitments and each WTO member country provides a schedule of specific commitments. These are legally binding irreversible commitments to open specific services to foreign competition and to treat foreign suppliers as domestic suppliers, providing predictable and stable guarantees to foreign providers. The rules specifically limit how a commitment can be modified or withdrawn (Article $\mathrm{XXI}) .^{38}$ These are very restricted and in any case may only be considered after it has been in force for three years.

\footnotetext{
${ }^{38}$ In exceptional circumstances Article XIV General Exceptions may be invoked to protect major public interests, including safety, human, plant or animal life or health, national security or public morals. Governments may seek temporary waiver from an obligation, or may suspend commitments if in serious balance-of-payments difficulties.

If a commitment is modified or withdrawn, compensation, in the form of replacement with another commitment of equal value must be negotiated with Members whose trade is affected.

Governments are permitted to attach specific conditions to the sector commitments as long as they are listed at the time of making the commitment. They may also make additional commitments regarding qualifications, standards or licensing.
} 
The two principle rules governing the sector-based commitments are:

Market Access: Under Article XVI governments are required to guarantee access in the specified sectors and can only restrict access within the policies defined in this Article. Foreign suppliers are subject to the same domestic regulations as national suppliers. Market Access commitments do not prohibit the right to regulate services or to limit the number of service suppliers, however all regulations should be 'least trade restrictive' and market mechanisms are to be included wherever possible.

National Treatment: Covered by Article XVII, this fundamental tenet of free trade forbids governments from favouring their domestic sectors over foreignbased suppliers. Within the National Treatment rule a government may legitimately impose conditions on suppliers such as the use of local expertise, sub-contractors, transferring technical expertise to local industries etc, as long as foreign suppliers will be treated in the same way as nationals. However these conditions must be specified when making a commitment regarding that service, they can't be added later.

Progressive liberalisation towards free trade: Under GATS Articles $X I X, X X, X X I$, members are committed to undertake successive rounds of negotiations to progressively liberalise conditions for international trade in services. The current round (Doha Round) commenced in 2001 and is scheduled for completion by January 2005.

\section{Special and differential treatment for developing countries: GATS Annex 1.b,} Articles III, IV, V, XV, XIX contain special provisions which give developing countries special rights, including for example, longer time periods of implementation, commitments or measures to increase trading opportunities for developing countries. These are intended to encourage development and economic reform to the benefit of developing countries. In the Doha declaration (2001) some issues for developing countries, regarding the implementation of WTO agreements, are identified.

The dispute settlement system: WTO rules and the country schedules of commitments are legally binding and therefore WTO operates a system to ensure the rights and obligations are preserved. The outcome of the dispute settlement process should be complete restoration of full compliance with WTO rules (WTO 2001c). 


\section{Benefits of multi-lateral agreements for free trade - the arguments for GATS}

"Promoting openness, fairness and predictability in international trade for the benefit of humanity..." Mike Moore (WTO 2001c: pg, emphasis in original). WTO promotes six core benefits of services liberalisation - economic performance, development, consumer savings, faster innovation, greater transparency and predictability (for traders) and technology transfer (WTO 2003a), however their case is based solely on economic growth statistics and the principle of 'comparative advantage'. ${ }^{39}$ GATS is promoted as assisting developing countries to attract foreign investment through foreign establishment of services in their countries - foreign investors want a stable environment, and developing countries can use the agreement to stipulate criteria that tie foreign establishments to for example, local employment quotas, universal provision, training requirements, transfer of new technologies.

According to the New Zealand Ministry of Foreign Affairs and Trade (MFAT) the purpose of the World Trade Organisation is to remove the barriers, particularly tariffs supporting agriculture in high-income countries. They estimate that if tariffs halved, poorer countries would gain US\$150 billion annually, three times what they receive in development aid (Source: Speech by Patricia Hewitt, British Secretary of State for Trade, to Chatham House London, Oct 25 2001, cited in (MFAT 2003c:2)). MFAT holds the view that smaller countries like New Zealand are advantaged by WTO, "with the weight of 143 other countries behind us New Zealand is able to make more ambitious demands of larger countries" (MFAT 2003b:3). It is challengeable whether these demands are being realised.

From the perspective of the export education industry for example, GATS is considered a positive development because it establishes a formal international framework with clear 'democratically' defined rules for trading activities that are already underway. It also gives greater surety of access to existing and new markets. Proponents of GATS refute

39 'Comparative advantage' describes "the principle whereby individuals or territories produce the goods or services for which they have the greatest cost or efficiency advantage over others" (Johnston et al. $2000: 102)$.The outcome tends to be specialisation. A condition for the realisation of comparative advantage is free trade. 
arguments that raise issues regarding the potential of WTO agreements to undermine the independent sovereignty of member governments. 'Sovereignty' is not compromised by the concept of interdependence and cooperation that multilateral rule-making requires. They claim the 'consensus' decision-making process allows small countries to participate in WTO on an equal footing with large trading countries. Each member government is responsible for how it dialogues with its citizens and for determining how they best represent the interests of their country. In promoting the freedoms and flexibilities apparently available to countries, proponents are failing to admit that their exemptions and limits will be targeted for elimination in successive rounds of GATS negotiations.

WTO insists that member countries' rights to regulate are explicitly guaranteed in GATS; however it acknowledges that a member government will have to justify a specific regulation if disputed by another member. WTO claims it does not make rules about domestic policy objectives of governments but it does make rules about the way in which these policies are achieved, to ensure they are "reasonable, objective and impartial" (WTO 2003c:2) and do not "constitute unnecessary barriers to trade in services" (WTO 2003a:3) - in particular national policies must accord with Market Access and National Treatment rules. This begs the question of 'on whose terms and in whose interests' are these to be judged and interpreted?

\section{Issues and possible consequences - the general arguments against GATS}

The mandate of GATS is to liberate trade in services, gradually phasing out government 'barriers' to international competition in the service sector, through a multilateral framework agreement. In the last three years GATS has come under increasing scrutiny, with international campaigns mounting opposition. ${ }^{40}$ Views about liberalisation of trade in services and consequences are polarised. Civil society actions, particularly demonstrations by anti-globalisation protesters, illustrate the growing movements in opposition to WTO for its anti-democratic decision-making processes and "its lack of

\footnotetext{
${ }^{40}$ Significantly the Seattle blockade at the launch of the millennium round of GATS negotiations 1999.
} 
interest in the non-marketable value of the spheres of activity it seeks to liberalise" (Ziguras 2003:90).

Unifying some of the diverse views held by the critics, Coates argues that under GATS governments will make decisions that will be effectively irreversible (Coates 2003). They are negotiating international agreements to lock in rules that will apply to all future governments and future generations. Thus the 'economic constitutionalism" ${ }^{\prime 1}$ of neoliberalism is established thereby "minimising the scope of political intervention in the economy" (Robertson and Dale Draft 2003:2). These rules will fundamentally alter the balance of rights and responsibilities between the State and corporations. In particular the rules are oriented to benefit multinational corporations, and the decisions about these rules are taken through the exercise of power by the strong over the weak.

Governments are not equal entities in the international arena. The use of a standard set of WTO rules is questionable when they are applied to such a vast range of services, across many different countries, with different social and cultural histories and at different stages of development. The rules themselves institutionalise the current system of global inequality. ${ }^{42}$ The generic nature of GATS rules ignores the substantive differences in the nature of services. The Agreement covers the full range of service sectors, some of which are culturally important, environmentally sensitive or subject to monopoly provision and some provide basic essential services. Yet WTO agreements contain no minimum standards to protect labour, human rights, social or environmental standards, values or culture.

Implicit in the concept of services is the notion 'to serve', involving interpersonal relationships intrinsically social and cultural. This meaning is erased under GATS, whereby all services are merely tradable economic commodities, identified by a UN Central Product Classification number. Kelsey argues that this categorisation of services is a "symbolic ideological device [by which services are both] abstracted into categories... [and] fragmented into sub-category product numbers" (Kelsey

\footnotetext{
${ }^{41}$ Kanishka Jayasuriya cited in Robertson defines economic constitutionalism as "placing emphasis on issues of market transparency and the judicial limitations on the influence of rent-seeking coalitions or discretionary political intervention in the functioning of the economy" (Robertson and Dale Draft 2003:2). 42 The principle of special and differential treatment for developing countries has very weak status in WTO.(Bello 2003).
} 
2003a:transcript notes). This categorisation process distorts reality by reducing complex and diverse features of socially embedded services in simple codified forms.

Although negotiators talk about trade as if the aims are to promote development of the poorest countries or to protect public health and the environment, in reality the negotiations aim to give as much advantage as possible to each nation's business interests. The US followed by the EU play a dominant role. For these players "GATS is first and foremost an agreement for the benefit of business" (Barlow 2001a:9). The multinationals that stand to benefit were deeply involved in the negotiations to establish GATS. Developing countries have virtually no chance of competing in global market where trade in services is dominated by transnational corporations from US, EU and Japan (CID 2003).

Opposition to GATS also focuses on imbalances of power within WTO itself and how these unequal power relationships between countries impinge on the processes and thence the outcomes. WTO is viewed by many as a powerful, secretive and antidemocratic body. With unequal distribution of economic power in the world; limited capacity in developing countries to negotiate the agreements; and limited capacity of smaller countries and/or developing countries to take and argue their trade issues in WTO disputes settlement system, the rules, polices and practices of world trade relations favour wealthy countries (Twyford 2003). While the Doha Round (2001) introduced possibilities to address some of the problems, WTO texts continue to exclude the developing countries key demands that their issues be addressed.

The 'locked in' nature of the GATS process is a principal concern. Not only are governments unable to reverse commitments, but they are also restricted in their ability to make new policy decisions in the future. To retain any future policy flexibility would require governments to have considerable foresight prior to making commitments. GATS effectively locks in deregulation of services, privatisation and other structural reforms as undertaken by countries such as New Zealand over the last 15-20 years, or by many developing countries through International Monetary Fund (IMF) and World Bank requirements. 
It is claimed that WTO legislative and judicial powers undermine the rights and freedoms of individual countries/ democratic societies. GATS sets international legal precedents in assigning new rights to foreign companies, which ensure they have access to the market with no 'unnecessary' barriers or conditions imposed by governments, potentially restricting governments' powers to use internal laws and regulations to protect and promote the public interest. Historically, there has been a growing tension between the rights of societies and governments to determine the rules that govern all companies established within their borders, and the rights of companies.

This problem is central to many criticisms of GATS. The wording around the domestic regulation rules in GATS is ambiguous and gives rise to uncertainty about how the degree of necessity will be determined (CID 2003). "Domestic policies to protect the cultural diversity of communities, minorities and countries could be considered obstacles to trade"' (Barlow 2001b). Barlow claims that "every single time (but one) the WTO has been used to challenge a domestic health, food safety, fair trade or environmental law, the WTO has won" (ibid: 3). Kelsey describes GATS as a "legal quagmire... [leaving us] to work out how far previous New Zealand governments have signed away the right of future governments to regulate the public interest" (Kelsey 2003c:89).

Civil society groups express major concern over the requirement to progressively open up services in ongoing negotiations. Firstly there are the issues around the 'pace' of liberalisation and external pressures placed on governments. The intent of the current round of negotiations is to increase the number and extent of services committed by countries. $^{43}$

Secondly there is the threat to the status of public services and the pressure for governments to open these up. Here the issues of international trade become entwined with issues of privatisation. A candid example is the current pressure from the US on the

\footnotetext{
${ }^{43}$ GATS negotiators [for EU] recently have been given instructions to broaden and deepen the agreement by:

- Increasing the number and extent of services covered by countries

- Eliminating country exemptions that protect GATS-inconsistent rules and regulations from challenge

- Targeting critical sectors such as health, education, water and postal services which many countries did not fully cover in the last round of talks, and

- developing new GATS rules restricting 'domestic regulations' which would curtail governments' ability to enforce environmental, consumer, health, social security or other public interest rules and standards that WTO deems 'more burdensome than necessary' (Barlow 2001a:9).
} 
Australian government to fully privatise Telstra to reduce its market dominance and effective monopoly over the network (The Dominion Post 2003). The question of who owns and runs public services is a core ethical issue, "a defining factor in a democratic society" in the view of organisations such as One World Action (Bennett 2003) For those who believe in a strong democracy, accountability for public services is vital. The nature and quality of services such as healthcare, education, water supply and transport and access to these is an expression of democracy, the relationship between citizens and the state. They are concerned about the mounting pressure under GATS progressive liberalisation rules to give the commercial sector more access to public services. There is debate on the potential impacts on local government service delivery, again with problems of interpretation of terminology in GATS articles.

Contextualised, GATS rules intrinsically advantage transnational companies over domestic private enterprise in terms of economies of scale, capacity and access to capital, technology, research, marketing and the support of political power relations. While trade liberalisation promoters claim competitive pricing will push down the cost of services there is no evidence of this beyond isolated or short-term cost cutting. Trade in services is much more complicated that the transfer of goods across borders. Services are the key infrastructural components of a healthy society and a well-performing economy. The impact on longer term costs of services, maintenance and development of sustainable infrastructures and community-wide access remains an issue.

There are also significant further issues around foreign and transnational companies 'managing' social, educational, cultural, infrastructural, and environmental services. For example communications, audio-visual and entertainment services that nurture creativity, art and talent foster perceptions of identity, character and cultural life and diversity are threatened by the potential dominance of international media and brands. With the object of GATS being to eliminate any protections a government could use to support local cultural sectors, we face a future of increased mass-produced cultural homogenisation (Kelsey 2003c). Countries that withheld cultural services from their schedules or listed exemptions for cultural policies are now under pressure from the US in various bilateral negotiations as well as in GATS requests. 


\section{Conclusion}

In a narrow sense trade policy could be viewed simply as a trade market tool. However GATS is very different from other trade agreements. It is in fact an international agreement that establishes global rights for businesses, and reaches further into domestic policy-making than any other agreement, with legal, political, economic, social and cultural ramifications. It "has widespread and direct consequences on the lives and livelihoods of individuals and communities" (Kelsey 2003c:32).

There is implicit recognition, even amongst some proponents of trade liberalisation agreements, that not everyone benefits and that competing priorities can be jeopardised. Yet there has been very little assessment of the implications of GATS undertaken by governments and there is a great deal of uncertainty about what GATS will mean for member countries in the long term. The ambiguity, uncertainty and fact that future consequences have yet to be realised, makes some of the debate speculative and hard to demonstrate. However rules that remove or restrict the tools of governments to manage and regulate their economic, social and ecological environments may progress the concept of single global market and benefit a few key players in that market to the detriment of the sustainable well-being of societies and countries at large.

Politically and economically the international arena is an un-equal playing field; the question remains how to ensure fair benefit to everyone? Trade is central to the economic well-being of countries like New Zealand. It also contributes to our participation in the 'global community' building business and personal links with people around the world. However the debate here is not about trade itself, but the implications of the rules, principles and objectives of WTO and its binding agreements. Some critics believe that there are policy alternatives and that appropriate foreign investment is possible without GATS. Some call for reform of WTO to address fundamental inequalities and transparency to create system which puts people's needs before capital freedom (World Development Movement 2003).

This chapter provided a description of WTO and GATS, raising the general concerns and arguments about trade in services. The next chapter looks more specifically its application to education services and the educational trade market. 


\section{Chapter Four}

\section{APPLICATION OF GATS TO EDUCATION}

\section{AND NEW ZEALAND'S EXPORT INTEREST}

As demonstrated in the last chapter, services, accounting for almost two-thirds of global economic activity, were an obvious target to be opened to the world market through GATS. Education is viewed as an area that could yield substantial profits in the global economy. ${ }^{44} \mathrm{~A}$ crucial stage in the reconceptualisation of education from a public service socially and culturally embedded in local context to a detached commodity that can be traded in the commercial market occurred with the changes in governance of education through the New Zealand reforms, which are addressed in Chapter Five.

The business of borderless education is rapidly emerging. Innovations in information and communications technologies are providing alternate and virtual ways to deliver in particular higher education. A much wider range of providers are delivering education services across national borders (Knight 2002b). The commercial side of borderless education is growing and is a focus of GATS.

WTO is only one of several supranational organisations that affect national education policies. Others include UNESCO, the Organisation for Economic Cooperation and Development (OECD), the World Bank and regional institutions and agreements such as APEC and Asia 2000. However WTO and in particular GATS operates in quite a different manner from those organisations in that it works through binding rules and commitments that extend into areas of domestic legislation, rather than by persuasion or

\footnotetext{
${ }^{44}$ In 2001 "investment bankers Merrill Lynch predicted that through GATS and commercial pressures all education worldwide will be privatised within 10 years and that there are massive profits to be made for transnational corporations" (Cooke 2003:1).
} 
leverage (Robertson, Bonal, and Dale 2002). At UNESCO for example the participants find points of common references to set up series of co-operative agreements and ventures which can be reversible and participants remain in control of their level of commitment to the global community. In contrast WTO requires acceptance of rules that merge 'points of reference' into a generic international agreement that becomes irreversible as countries commit to it (Barblan 2002).

GATS can also potentially affect education practices and systems, their orientation and control, across a far greater range of their activities than any of the other supranational organisations. GATS is a contributing component of the re-articulation of the nature and form of education and its governance to make education services more amenable to the global economic and financial accumulation strategy.

This chapter overviews trade in education in three parts: The first part explains WTO and GATS rules and processes applied to education services. The second part identifies New Zealand's policy base for trade in education services - the government's aims and objectives for GATS with regard to education, what evidence informs that policy and in whose interests noting the emphasis on opening up trade in education services. The final part overviews the New Zealand export education industry, central concerns and potential threats and risks identified by the industry itself, discussing both the perceived benefits of GATS for the industry and the ways in which GATS may affect or restrict the flexibility, choices and integrity of the development of international education in the context of domestic education.

\section{WTO and GATS rules and processes applied to education}

Education is one of the twelve service sectors covered by GATS. WTO member countries can specify to which of the four modes of supply their commitments in education services apply (Sauve and OECD 2002). Table 1 gives examples of trade in education services across the modes of supply: 
Table 1: Modes of Supply of Education Services ${ }^{45}$

\begin{tabular}{|l|l|l|}
\hline $\begin{array}{l}\text { Mode of Supply } \\
\text { (GATS) }\end{array}$ & GATS Definition & Examples in Education \\
\hline Cross-border supply & $\begin{array}{l}\text { The supply of a service "from } \\
\text { the territory of one member into } \\
\text { the territory of any other } \\
\text { member". The service travels } \\
\text { but both the provider and the } \\
\text { consumer stay at home. } \\
\text { Comparable to the export of a } \\
\text { good }\end{array}$ & $\begin{array}{l}\text { Distance education } \\
\text { Virtual education institutions } \\
\text { Education software } \\
\text { Corporate training through } \\
\text { ICT }\end{array}$ \\
\hline Consumption abroad & $\begin{array}{l}\text { The supply of a service "in the } \\
\text { territory of one member to the } \\
\text { service consumer of any other } \\
\text { member". Comparable to } \\
\text { tourism or business travel by } \\
\text { the consumer }\end{array}$ & $\begin{array}{l}\text { International students } \\
\text { enrolled in NZ institutions }\end{array}$ \\
\hline Commercial presence & $\begin{array}{l}\text { The supply of a service "by the } \\
\text { service supplier of one } \\
\text { member, through commercial } \\
\text { presence in the territory of any } \\
\text { other member". GATS speak } \\
\text { for foreign direct investment }\end{array}$ & $\begin{array}{l}\text { Local education institutions, } \\
\text { partnerships or satellite } \\
\text { campuses } \\
\text { Language training } \\
\text { companies } \\
\text { Private training companies } \\
\text { Business training e.g. } \\
\text { Microsoft }\end{array}$ \\
\hline $\begin{array}{l}\text { Movement of natural } \\
\text { persons }\end{array}$ & $\begin{array}{l}\text { The supply of a service "by a } \\
\text { service supplier of one } \\
\text { member, through presence of } \\
\text { natural persons of a member in } \\
\text { the territory of any other } \\
\text { member". Comparable to } \\
\text { temporary emigration on } \\
\text { business travel by the service } \\
\text { supplier }\end{array}$ & $\begin{array}{l}\text { Professors, teachers, } \\
\text { researchers, working abroad } \\
\text { on a temporary basis }\end{array}$ \\
\hline
\end{tabular}

Education services are defined in GATS classification system under five sub-sectors: (a) Primary including Early Childhood, (b) Secondary, (c) Higher, (d) Adult, and (e) Other ${ }^{46}$ (Larsen, Martin, and Morris 2002). Because GATS allows countries to tailor commitments to specific sub-sectors, WTO rules such as market access and national treatment apply only to the sub-sectors committed. However as previously discussed in Chapter Three, general obligations for example most favoured nation (MFN) and transparency rules, apply horizontally to all services within the scope of GATS

\footnotetext{
${ }^{45}$ Adapted from Sauve 2002:53.

46 'Other' is defined as education services at the first and second levels in specific subject matters not elsewhere classified, and all other education services that are not definable by level.
} 
regardless of whether the service is included in the schedule of commitments. Therefore a member country is obliged to extend MFN treatment to all members and for all sectors, unless they listed an exemption, ${ }^{47}$ for specific measures governing particular services, which was possible only as a one-off opportunity in the Uruguay Round.

MFN applies irrespective of the degree of open market operating, which is of particular relevance to education services. GATS Article 1.3 excludes services provided under government authority and without commercial purpose. This is generally interpreted to mean that in order to be excluded from the scope of GATS, the education system must be completely funded and administered by the state and have no commercial purposes (Robertson, Bonal, and Dale 2002). In most if not all countries the private sector plays a role in the education system. Therefore even though education, particularly the compulsory sector, is widely viewed as a public sector activity the education system falls within the scope of the application of GATS.

GATS general framework of obligations (horizontal rules) therefore applies to education services in all member countries of WTO. So for example if a foreign provider establishes a branch campus in country $\mathrm{A}$, or provides a remote access programme to candidates on Country A, then Country A must permit all WTO members the same opportunity or treatment. This applies even if the country has made no specific commitment under GATS to provide foreign access to their markets (Knight 2002b). GATS transparency rules require members "to publish all measures, at all levels of government that pertain to or affect the operation of the treaty.... [introducing] new administrative demands on governments that may be particularly onerous for school boards" (Grieshaber-Otto and Sanger 2002:39).

On the other hand the extent to which the sector specific rules apply, i.e. national treatment and market access, has been a matter of choice for each member and is referred to as the 'voluntary bottom-up strategy' by WTO. Grieshaber-Otto notes that "The GATS domestic regulation rules require members to ensure that measures relating to qualification requirements... [and] technical standards and licensing requirements do not constitute unnecessary barriers to trade in services...Negotiations are now underway to carry out this mandate" (Grieshaber-Otto and Sanger 2002:43). These negotiations

\footnotetext{
${ }^{47}$ MFN exemptions have a sunset clause whereby in principle they should expire after ten years.
} 
are likely to be contentious even for proponents as governments come to understand just how far-reaching the proposals are.

\section{Progressive liberalisation:}

Internationally the majority of member countries of WTO have not offered their own education markets up to foreign competition and the education sector remains one of the least committed sectors under GATS. This may be attributed, at least in part, to concerns about the preservation of national identities and cultural development and in part to the need for countries to strike a balance between pursuing domestic education priorities and exploring opportunities to expand export education. "Concerns that foreign providers will not adequately address equity and access issues" are also expressed (Australian Government and AEI-International Education Network 2002:21). Only 44 of the 144 WTO members have made commitments to education, and mostly these were restricted in terms of scope (education sub-sectors) and modes of supply. New Zealand's commitments to education, discussed below, are amongst the most liberalised. Yet

for education providers and students there has been little impact, but there has already been impact for governments, both in the binding nature of these commitments and in the requirements (more normative than enforced) for transparent regulation and judicial review of decisions

(Australian Government and AEI-International Education Network 2002:21)

Deregulation is in the interests of education exporting countries such as New Zealand, along with United States, Australia and Britain. Accordingly the US has argued that member countries' policies on transnational education should be "reviewed and liberalised to the greatest extent possible" (WTO 1998:2).

\section{GATS negotiations on new rules relating to domestic regulations (Article VI):}

Although the existing text is vague about the distinction been legitimate and illegitimate regulatory and administrative actions, the current GATS negotiating agenda includes formulating new rules and disciplines regarding domestic regulation. Currently it is being debated at WTO whether these proposals will apply as horizontal rules, across all services, even those for which members have not made specific commitments (Grieshaber-Otto and Sanger 2002; Kelsey 2003c). 
The proposed rules include a test of 'necessity' which may "force education to continually demonstrate that they have opted for the least trade-restrictive requirements and practices", to achieve a legitimate objective, and likewise "new rules on government procurement [may] require all contracts of significant size to be tendered internationally" (Grieshaber-Otto and Sanger 2002:141). These negotiations include proposals to extend "measures relating to qualification requirements and procedures, technical standards and licensing requirements [to ensure these] do not constitute unnecessary barriers to trade in services" (GATS article VI: 4).

\section{Eliminating barriers to trade in education}

It is important to note that international trading of educational services was already expanding prior to the conception of GATS. However the educational agenda of GATS is clearly part of a larger process in which transnational executives ${ }^{48}$ along with other players in export education and policy makers are seeking to create conditions for market expansion. Identification and elimination of perceived barriers to trade is the raison d'etre of GATS.

Examples of perceived 'barriers' to trade in education might include visa restrictions, taxation that disadvantages foreign institutions, licensing and accreditation arrangements and subsidies that privilege domestic institutions and qualifications, national requirements about setting up an institution including national advantages such as establishment grants, limits on the number of providers and controlled needs test (Robertson, Bonal, and Dale 2002).

In considering the US negotiating position, Mundy and Iga argue that the US "adopts a position of hegemon and free-rider" (Mundy and Iga 2003). While presenting an aggressive liberalisation position, the US is cautious about permitting foreign competition into its own domestic education markets. The US and Australian submissions to WTO focus on GATS as a mechanism to reduce barriers to progressive liberalisation of education (Sauve and OECD 2002). The 'barriers' they identify may inhibit foreign suppliers, however efforts to eliminate barriers through a binding irreversible trade

\footnotetext{
48 "Glenn Jones, CEO of Virtual University Jones International Inc. is head of the Global Alliance for Transnational Education, one of the principal lobbying groups offering consultation to the WTO in its efforts to eliminate barriers to trade" (Kalafatides 2001:1).
} 
framework, is not perceived to be an appropriate approach even by leading educational trade organisations, such as the Canadian, American and European Associations for higher education (Association of Universities and Colleges of Canada et al 2001).

Even Sauve, a supporter of GATS, argues that many of the impediments to "greater cross-border exchanges of education may be more appropriately pursued outside a trade policy setting" (Sauve and OECD 2002:47) for example, through agreements on educational qualifications or academic and cultural exchanges. He cites the rapid pace of change in education services provision outside of WTO framework and suggests the bounded nature of GATS could be detrimental to both suppliers and consumers.

\section{New Zealand's policy position regarding education services in GATS}

Due to the small size and openness of its economy, New Zealand has very little direct negotiating power in trade agreements, and has therefore focused trade negotiations on promoting WTO international trade rules that are binding on all members and which benefit New Zealand by establishing a freer trade environment for New Zealand exports. New Zealand's position, seeking to promote the services sector in trade agreements, is founded on the underlying belief that a multilateral framework of rules and principles that aim to progressively liberalise trade in services will assist growth of such trade by providing certainty and stability of access and contribute significantly to economic development and prosperity. A key policy goal identifies that "New Zealand's ability to compete as a knowledge based economy and reduce its reliance on agricultural goods trade is strongly linked to growth in our services exports" (MFAT 2003e:). The growth and position of New Zealand's export education industry are discussed in the latter part of this chapter.

In the original 1994 GATS schedules New Zealand made full commitments, under a National government, on Modes 1, 2 and 3 across the first three sub-sectors (primary, including early childhood, secondary and tertiary) however this applies only to 'education in private institutions'. No commitments have been made in adult education and other 
education services, and only limited commitments in mode 4, the natural movement of people. This means that educators, teachers and managers employed by foreign education institutions are permitted to enter and work in New Zealand for limited periods subject to the visa conditions. However the 'market access' undertakings across the other 3 modes of supply mean that the New Zealand government can not limit the foreign ownership of providers, the number of providers, the number of students they may enrol or the legal form of new entrant providers (Australian Government and AEIInternational Education Network 2002).

The 'national treatment' undertakings mean that the government cannot discriminate between domestic and foreign suppliers in the allocation of subsidies $^{49}$ (with a commercial presence in New Zealand) or when New Zealand students study by distance education or travel overseas to study. New Zealand "has made no commitments in research and development services, but has done so in the $\mathrm{CEP}^{50}$ (sic) with Singapore for 'social sciences and humanities'” (Kelsey 2003c:43).

New Zealand's 1994 commitments to free trade in education in private institutions across all sectors were made "without any substantial examination of its domestic policy implications" (Kelsey 2000b:3). The government position appears to be that it denies the possibility of potential issues for domestic education policy arising from GATS commitments, or indeed from the impacts of the growth in export education industry (Kelsey 2003c). The communications between CTU and MFAT in December 2001 reveal significant concerns regarding the government's interpretation of the status and implications of current GATS commitments particularly five key points.

\footnotetext{
49 "Government funding to institutions or to students constitutes a subsidy in trade terminology, and subsidies are considered 'measures' under the GATS. So, if a country commits to National Treatment in a particular service sector, then any funding available to domestic suppliers must also be made available to foreign suppliers" (Ziguras, McBurnie, and Reinke 2003:3).

50 "CEPA is a GATS-plus agreement, as it includes services commitments which extend beyond Singapore and New Zealand's respective schedules of GATS commitments. Article 22 of the Agreement also provides for the facilitation of the development of mutual arrangements on qualifications and professional registration between New Zealand's professional bodies and regulatory agencies and their Singaporean counterparts" (MFAT 2003c:4).
} 
These were:

- limitations of conceptualising education as simply a tradable commodity

- delineation between public and private education

- position of subsidies

- commitment to progressive liberalisation

- 'Not More Burdensome than Necessary' test and the 'Least Restrictive Necessary' test

(CTU 2001:1)

Given the legal ambiguities surrounding the interpretation of GATS texts, CTU believes that "where two valid interpretations exist...it is appropriate to adopt a precautionary approach. Such a stance both provides protection against such worse case scenarios and ensures that when disputes arise in the future, New Zealand's sovereignty is not dependent solely upon the relative strength of either our arguments or trading power" (CTU 2001:3).

New Zealand has made no further commitments in the education sector at this point in the current Doha round (MFAT 2003f). The focus is on negotiating to open up access to other overseas education markets while holding back from making any further education commitments itself. However AUS has expressed "concern that the New Zealand government has failed to withdraw education entirely from the GATS" (Rosenburg 2003:1).

New Zealand's policy of openness to trade in education seeks to continue the growth in investment and increased foreign exchange earnings from export education. The further liberalisation of education trade under GATS is seen as helping "to maximise the potential of New Zealand's rapidly growing export industry...GATS will provide the certainty that our export education organisations need to protect their investments and will help formalise arrangements for access to good education opportunities" (LaRocque 2003a:1).

MFAT officials' assessment of New Zealand's interests is understandably economic and focused on both the expansion of export education and securing the best situation possible for New Zealand's trade in all services. In this context the framing of education as a tradable commodity appears appropriate. However it creates an intrinsic tension with regard to the conception of education as a socially embedded public good. It also establishes a basis for prioritising trade imperatives over educational needs, and a future 
in which educational policy will increasingly be determined by trade ministers in the context of trade policy instead of by education ministers in consultation with educational professionals and communities.

Further indication of the current New Zealand Government position can be found in its negotiating proposal for education services under GATS tabled at WTO (WTO 2001b), which acknowledges the central role governments will continue to play both as suppliers and regulators of education, and in ensuring the quality of education through accreditation and quality assurance systems. In its request that other members make commitments in education sub-sectors, the scope is focused on sectors "less affected by the sensitivities relating to the divide between public policy and commercial activity" (Sauve and OECD 2002:65).

The rationale driving the New Zealand proposal for further liberalisation claims economic and social benefits, emphasizing "that in addition to additional revenue generation there are benefits at the individual, institutional and societal level through academic exchange, technological transfer and cross-cultural linkages" (Knight 2002b:12). The New Zealand proposal also seeks to improve the education services classification system to identify more accurately the current delivery of educational services, which reflects the market approach to delivery outside of traditional institutions (WTO 2001b).

In preparing its initial offer (2003) for the current WTO services negotiations the government asserted that "New Zealand will make its own sovereign decision on what to include in an initial offer. This will be based on an assessment of what will advance New Zealand's overall interest and well-being" ${ }^{51}$ (MFAT 2003d:1). No further commitments in education were made in this offer, however one of the guiding principles is to "accord priority to achieving advances in sectors where our exports interests are strongest and where we can enhance the services sector's contribution to growth and innovation" (MFAT 2003d:2). In its 2001 proposal the government expressed this dilemma between its drive to open up markets for export education while making no further commitments in the home education sectors as "[striking] a balance between pursuing domestic education priorities and exploring ways in which trade in education services can be further liberalised" (Sauve and OECD 2002:67).

\footnotetext{
${ }^{51}$ The initial offer included a ten guiding principles for preparation of that offer (MFAT 2003d).
} 
Nevertheless the Government asserts that the reduction of barriers to trade and investment does not equate to an erosion of core public education systems and standards (WTO 2001b). However these assertions are presented as rhetorical optimism without any informed argument or substantiating evidence. More research is needed to understand the perceived rationale and benefits. While the consumer rationale could mean providing a wider range of choices to consumers, it also raises issues around assurance of appropriate levels of access and quality and the perception that the economic rationale is sabotaging social development goals of education and scholarship.

The New Zealand education unions (NZEI, PPTA, ASTE, TIASA and AUS) and the combined Trade Union (CTU) have continued to voice concerns about the implications of GATS for education in New Zealand. The position the education unions have expressed to ministers of both trade and education, is that education is a core public service and as such "has no place in an international trade agreement that facilitates the further liberalisation and commercialisation of provision and funding of education and related research, and intensifies the risks of creeping privatisation and foreign control" (Goulter 2002:1).

\section{The New Zealand export education industry}

Trade in education services is New Zealand's fourth largest export earner, ${ }^{52}$ a $\$ 1.7$ billion industry (Fancy 2003a; Ministry of Education 2002c). This figure is expected to rise to $\$ 4-5$ billion within the next ten years (Asia 2000 Foundation 2003). By far the most significant mode of supply is consumption abroad - in 2002 over 80,000 students from other countries came to New Zealand for educational purposes, mainly from China, South Korea and Japan (Asia 2000 Foundation 2003; Ministry of Education 2002c). New Zealand was the third fastest growing destination for foreign tertiary students between 1990 and 1999 (McKinlay 2002).

\footnotetext{
52 in 1999 the education sector was New Zealand's $4^{\text {th }}$ largest export earner and $15^{\text {th }}$ largest foreign exchange earner overall (MFAT 2000).
} 
However other modes of supply are starting to take off. The Ministry of Education conducted a stocktake in 2002 which revealed that half the public tertiary providers are involved in providing offshore tertiary education programmes (Ministry of Education $2002 d) .{ }^{53}$ Offshore education is provided through distance education, made increasingly easier through communications technologies, or by establishing a campus and teaching presence offshore.

The concentration of offshore programmes in South-East Asia, China/Hong Kong and the Pacific parallels existing international education relationships (Ministry of Education 2002d). For example, a Wellington company, EdPAC, has set up a high school in China that will feed approximately 250 international students a year into Wellington schools and tertiary institutions. The school in Dongying employs New Zealand and Chinese teachers. Other examples include Marlborough Boys College campus in Changzhou and a feeder school in China run by Taranaki's Western Institute of Technology (Quirke 2003c:A5). In October 2003 New Zealand publishing company, Wendy Pye Group, entered a business partnership with the aim to operate 30 schools within a year in southern China, running a computer disk and book based learning to speak English programme. The schools offer officially recognised New Zealand qualifications (Weir 2003).

On-line degrees are an emerging area of educational service provision. Auckland University is part owner of Universitas 21 who recently launched a joint venture with a US company, Thomson Learning, targeting markets in India and China. Auckland University sources say "New Zealand students are not a target for the on-line university, but it was not impossible [for them] to enroll" (AUS 2003a:3).

Recognition of the opportunities of rapid expansion of offshore education provided the focus of a workshop in 2002 primarily for the public tertiary sector, which discussed the benefits and risks and initiated a strategy for this sub-sector of the industry (Ministry of Education 2003b). The reported risks related to strategic, financial, operational, academic, accreditation, reputation and marketing risks but notably did not include social, societal, cultural, or curricula considerations.

\footnotetext{
${ }^{53}$ An increase from 6 providers in 1997 to 17 providers in 2001; delivering 63 programmes ( 6 programmes in 1997 ) to 2200 students (380 in 1997) (Ministry of Education 2002d).
} 
Almost $80 \%$ of FFP students are in the tertiary sector, including English language schools, almost $17 \%$ in secondary schools and the remaining $4 \%$ in primary schools (Ministry of Education 2002c). However over the last two years the growth of international students in the primary sector was phenomenal, around $240 \%$, raising public concerns for student welfare. The government has since imposed requirements for parents of young students to be resident in New Zealand during the period of their child's education. The Ministry of Education may be underestimating the numbers of foreign students in primary schools. For example many schools take in 'eco-tourism' students who are not counted in the official statistics. ${ }^{54}$

The distribution of FFP school students throughout New Zealand is not even, with $50 \%$ of all students in the Auckland region in 2000. While two-thirds of all secondary schools had at least one FFP student, significantly half of all FFP students were shared among just $10 \%$ of secondary schools, and only $11 \%$ of primary schools are participating in export education. (Ministry of Education 2002b:2). Schools in the highest socioeconomic status communities (high decile) are attracting significantly more FFP students than low decile schools (ibid). However the presence of FFP students in some primary schools is quite significant. In $200215 \%$ of students at Owairoa Primary School (Howick) were foreign fee-paying, bringing approximately $\$ 1$ million additional income to the school (Shackleford 2003).

The Ministry of Education is now endeavouring to take a strategic approach to promoting the export education industry. Their focus is on identifying potential benefits at the individual, institutional and societal levels, including greater diversity of programmes, exposure to different cultures and perspectives, enhanced facilities and staffing, wider international networks and knowledge base and increased foreign earnings and economic benefits to other sectors of the economy (Ministry of Education 2001b).

Other proponents of export education argue the advantages of internationalising the education system by claiming a "causal link between liberalising trade in education

\footnotetext{
${ }^{54}$ Ministry figures are taken from March and July roll returns, recording a snapshot of a school's roll on a particular day. Many schools take groups of students from, for example, Korea and Taiwan for periods of 3-4 weeks, outside of those dates (Ross 2003).
} 
services, and promoting the broader social, cultural and academic benefits of international education"55 (Ziguras, McBurnie, and Reinke 2003:5). They cite the potential for the presence of international students to create increased cross-cultural understanding, bring an international perspective to the content of learning and to encourage teachers to consider new teaching approaches which could also benefit other students (McKinlay 2002). Matthews, among others, questions this assumption that internationalisation invariably strengthens international and intercultural relationships (Matthews 2002). A recent review of the literature on the impacts of international students on domestic students and institutions revealed that the actual amount of interaction between international and domestic students is low and that there are few documented changes to educational delivery in classrooms (Ward 2001).

Ward's review, commissioned by the Ministry of Education, shows that research into the educational, social and cultural impacts of international students on domestic students, educational institutions and host communities is patchy and mostly conducted from the perspective of the overseas students. Little is known about viewpoints of domestic students or local communities or the wider social, educational and cultural implications of internationalisation ${ }^{56}$ (Ward 2001).

A subsequent study undertaken in North Shore City, a high recipient area of international students, focused on overseas student perceptions, but recommended further research into community attitudes and perceptions and research into the experiences, perceptions

\footnotetext{
${ }^{55}$ The Australian government argues that "the liberalisation of trade in education services [is] the most effective way of encouraging the internationalisation of education and enhancing flows of students between countries. The long term benefits accruing from internationalising education include:

- Fostering a knowledge and appreciation of other languages, cultures and societies. The skills and knowledge that are acquired will benefit students both professionally and culturally;

- Facilitating an exchange of people, ideas and experiences. These exchanges add a richness of diversity at the national and international levels, as well as contributing to the international crossfertilisation of academic knowledge;

- Networking relationships among individuals, groups and institutions which can facilitate future economic, political and socio-cultural alliances" (WTO 2001a).

56 The generation of international education (export education) has significant implications for the initiation of policies that promote structural, curricular, and pedagogical internationalisation (Matthews 2002). Despite the contestable assumption that internationalisation strengthens international and intercultural relationships, initiatives pursued under its auspices are dominated by trade-based economic approaches to education (ibid). In particular there is an emphasis on removing barriers to trade in education and on professional development to help institutions and individuals equip themselves for participation in the international education arena. GATS is perceived as a mechanism to assist efforts to internationalise curriculum, harmonise qualifications, and recognise accreditations, along with policy guidelines and corporate approaches to institutional culture and structure.
} 
and concerns of education providers themselves. The author noted that the placement of FFP students in primary schools is particularly contentious (Butcher 2002:47).

In response to the rapid growth of FFP students in primary schools since 2000, one of the Ministry of Education's proposed export priorities is increased internationalisation of the educational institution, such that it "incorporates international dimensions and perspectives in its structures and procedures, its teaching and in the curriculum" (Ministry of Education 2002a:21). Without debating the possible pros and cons of such internationalisation for domestic students it clearly shows that export education is and will increasingly impact on educational policy priorities, school environments, teaching practices and curriculum. The corollary concern is the extent to which focus on local cultural needs, approaches and dimensions is affected at the expense of international needs and structures.

In March 2003 the government ordered an inquiry into a private company run inside the Owairoa Primary School by three of the senior employees (the principal, school marketing manager, and board chairman) which was profiting from the recruitment of FFP students. The company provided a 10 week intensive English language programme for a fee of $\$ 3100$ per student before they were formally enrolled in school classes (NZPA 2003b:A7).

The educational unions have been voicing concern about the capacity of schools arising from increased numbers of FFP students. At their 1995 conference the PPTA identified "scope for a wide range of problems to emerge unless a coherent policy on the management of FFPs is adopted" (NZPPTA Auckland Region 1995:44). PPTA reports going back to the mid-1990s, quoting actual cases, identify issues of teacher supply and workload, teacher employment conditions, training and development, curriculum delivery, student expectations, impacts of English language limitations (and lack of ESOL backup support), subject imbalances (due to FFP student choices) school/home relationships, ethical considerations and racial and cultural issues (NZPPTA 1997; NZPPTA Auckland Region 1995).

Subsequent conferences continued to reiterate and expand on these concerns and in 1997 the NZPPTA recommended that limited numbers of FFP students could be 
supported only if:

- the educational goals and needs of New Zealand students are not compromised, and

- the presence of privately funded students in a public institution does not interfere in any way with the provision of services to the state funded students in that institution, and

- the number of fee-paying students in the school does not exceed $5 \%$ of the total student roll for that school

(NZPPTA 1997:57)

In commenting on the Ministry's discussion document for developing the export education fund levy, the PPTA noted

a significant omission from this list [of research possibilities] is any reference to research into the impact of the trade in education on the education of New Zealanders. There is anecdotal evidence of teacher and student stress as a result of having large numbers of students from different language and cultural backgrounds in their classes

(NZPPTA 2002:7).

That document raises a further important issue regarding the role of FFP students in the public secondary school system. Defending the a priori role of domestic students over international students the PPTA argued that any detrimental effects on the education of domestic students as a result of the enrollment and teaching of international students should raise serious questions ( $i b i d)$. In its submission on the same discussion document the NZEI strongly opposed the underlying philosophy of export education, stating:

Education is not an industry; it is a critical service that helps forms (sic) New Zealand's identity and social fabric as well as contributing to the knowledge economy. NZEI believes that New Zealand's resource of trained and qualified teachers should be used to teach New Zealand children

(NZEI 2002c:1)

Education Minister Trevor Mallard denies any negative impact on domestic students, citing an ERO report that not only "showed international students were getting 'quality' education and care, [but also] that the presence of more than 15,000 foreign fee-paying students in primary and secondary schools was not disadvantaging their Kiwi classmates academically" (Quirke 2003a:A5). The same article however went on to show that this contrasts with earlier research commissioned by the Ministry of Education which highlighted serious concerns about the care of young international students.

NZEI has recommended "a moratorium be placed on export education in the compulsory education sector until such time as research has been undertaken exploring its 
educational value to New Zealand children and the effect on teacher supply" (NZEI 2002c:2).

The rapid growth in export education has resulted in a shift in focus from international educational exchange and a commitment to the notion of the 'knowledge commons' to commercial enterprise. This is reflected in the industry surrounding the hosting of foreign students. International student exchange schemes, such as Youth for Understanding, have been forced to close their New Zealand programmes because they are unable to secure host families; who are now "chasing fee paying students instead" (Quirke 2003d:A12). "The temptation to cut corners and exploit students in a largely deregulated market is becoming apparent" (Kelsey 2003c:44).

There are growing concerns about the level of support (or lack of) provided to international students on arrival and for their integration into New Zealand communities. Newspaper stories report on students being cheated by business people, being victims of extortion and kidnapping, getting involved in gambling and prostitution, targeted by drug dealers, facing pregnancies and abortions (Bolland 2003a; Allen 2004a, 2003).

Late 2002 Chinese officials began to lobby the New Zealand government over 'thousands' of complaints about the quality of homestay accommodation and poor education standards. ${ }^{57}$ Chinese authorities want better guarantees and extra measures to protect students in New Zealand (Allen and Quirke 2003). Some New Zealand schools and are now also concerned that students who have serious medical conditions, emotionally troubled or have gang-related pasts are being granted student visa permits and allowed to study here (Grunwell 2003).

A report into the care of young foreign fee-paying students found many children as young as five years sent to New Zealand on their own were not being looked after properly. Some schools were taking on students without knowing whether the adult enrolling them was a parent, relative or stranger. As a result the government has imposed measures to prohibit students under 10 years old from studying in New Zealand without their parent or legal guardian living with them (Haines and Allen 2003).

\footnotetext{
${ }^{57}$ The Chinese Embassy concede some complaints are misunderstandings and differences in expectation, however other more serious complaints relate to, for example, false or misleading information, lack of support, unqualified teachers (of English as a second language) (The New Zealand Herald 2002).
} 
The Ministry of Education, the export education industry and other commentators are beginning to look at the challenges facing the industry, with a number of papers and reports appearing over the last two years. Significantly these primarily focus on emerging challenges and potential risks to New Zealand's reputation as an education provider and seek means to overcome these and remove barriers to the further expansion of the industry. Key points that emerge from these Ministry and industry based commentaries include:

- The heavy dependence on one source region leaves the sector vulnerable to shocks, like the Asian crisis in the late 1990's and the SARS crisis this year (McKinlay 2002)

- Issues of quality of service and value for money for international students; and relation to the care of vulnerable young people (Ministry of Education 2001b)

- Issues relating to investment, business planning and programme management skills (ibid)

- Issues of credit transfer, accreditation and harmonisation of qualifications (ibid)

- Concerns that FFP students be seen as the means to finance the needs for continued growth in educational resources (Lattimore 2002b)

- Concerns about the absorption capacity of New Zealand educational establishments to cater for the existing number of foreign students and a fear of further expansion potentially 'crowding out' domestic students (McKinlay 2002; Lattimore 2002b)

- Issues resulting form the different levels of participation between schools on regional, socio-economic status or ethnic mix; while fees from international students may increase the total funding available to the school sector, they also exaggerate equity issues between schools (Ministry of Education 2001b; McKinlay 2002)

- Potential adverse impact on domestic students (Ministry of Education 2001b), however these risks are not well identified and the scope for consideration of potential risk to domestic students and the domestic role of education in this strategy is very narrow

The Ministry of Education's Export Education Strategy (Ministry of Education 2001b) also identifies a number of initiatives to address the opportunities and risks identified 
with the objective of building the skills, knowledge and relationships to develop the industry both onshore and offshore. As a result the Ministry is progressing initiatives to establish quality standards in both the care of students and professional development regarding international education. The mandatory Code of Practice for the Pastoral Care of International Students came into force in 2002 and was reviewed again in 2003 (Ministry of Education 2003a).

Other initiatives now being implemented include institutional and professional development resources (Ministry of Education 2003e; Holloway 2003). Also the export education industry development fund levy has been established to resource quality improvement monitoring, data collection and research, development of the industry representative body, strategic management and sector liaison, development of new product niches and markets, promotion and communication (Ministry of Education 2002a).

On the marketing side, the Government is advocating a strong New Zealand Education Brand, to which the early childhood education strategy and tertiary reforms are integral (Fancy 2003a). This includes the development of the brand New World Class educated in New Zealand and the MYNZED.com website. The Minister has identified that a central goal for export education is a quality education system, which is inextricably interdependent with domestic education. While this focus may lead to positive benefits for domestic education, it risks being skewed towards value-adding opportunities for the international sector.

New Zealand's comparative trade advantage in the provision of early childhood, school and undergraduate education presents a critical tension for educational policy development. In a paper presented to the NBER East Asia Seminar in 2000, Richard Snape warned that "[t]rade policies do a very good job of advancing trade objectives and a very poor job of advancing domestic education policy objectives" quoted in (Lattimore 2002b:3).

Export education has become an important part of regional economic development strategies, with the formation of regional education marketing bodies, under the Export Network Programme supported by Trade New Zealand. These regional initiatives, such 
as Education Nelson Marlborough, market a cluster of schools and language institutes, and provide opportunities for 'sub-businesses' to manage pastoral care and home-stay accommodation across the cluster (Neal 2002). Marketing provincial areas such as Gore, is seen as a means of diversifying the spread of international students away from the existing concentrations in main cities to the regions where there is capacity in the schools and institutions (NZER 2002). However some regions are experiencing pressure in the accommodation market, as reported by Education Taranaki, where private providers and developers are building accommodation for foreign students (Carter 2003).

Property investors are continuing to target developments to cater for the needs of international students in the main centres. In Auckland the education sector account for $11 \%$ of the city's commercial property market, while in Wellington a major initiative of the EdPAC consortium will provide 880 beds in a complex that includes food outlets, fitness, health, entertainment, internet cages, employment centres and consumer goods (The Dominion Post 2002). International students contributed more than $\$ 182$ million to the Wellington economy in 2003 , an increase of $\$ 43$ million over 2002 , despite the impact of SARS, the rising New Zealand dollar and bad publicity in China about New Zealand as a study destination (Allen 2004b).

This focus on economic growth overlooks the question of wider issues resulting from the presence of foreign students in the community such as impact on local infrastructure and public services. No studies have been undertaken that explicitly examine this question, however there is research providing "some insight into the relationship between international students and members of the host culture. These include studies of perceived discrimination and research on home stays... [and] some descriptive writings about community outreach programmes" (Ward 2001:3).

The PPTA call in November 2002 for schools not to view overseas students as 'cash cows' and to cap FFP students at $5 \%$ of school rolls drew a mixed reaction from other stakeholders. Trade New Zealand Education manager responded with the need to ensure quality levels are raised and to focus on diversification into other educational export products, such as off-shore campuses, e-learning, curriculum packages (Sutton 2002). However some schools that have become financially dependent on FFP student 
income, such as both Waitaki Boys and Waitaki Girls High Schools reacted with concern that a cap would create budget shortfalls (McCathy 2002).

This raises a further significant concern, that export education is subject to market volatility, which in turn is impacted by many variables - from external factors such as SARS, economic and political factors in donor countries, world and regional recessions, competition from other exporting countries to direct factors such as industry performance, New Zealand's image as an education destination and policy factors. For example, in a recent survey providers perceived both the direction of immigration policy ${ }^{58}$ and the imposition of the export education level as factors hindering growth (Evans 2003).

This volatility was evidenced in 2003 with the downturn in student numbers particularly affecting English language schools and leading to several closures (Allen 2004c; Allen and Torbit 2003). In January 2004 a 60\% decline in Asian student enrolment was reported (Blundell 2004:A7). Some schools are diversifying to manage their exposure to volatile markets. For example Language Overseas English School in Highland Park attracts students from South America and Europe as well as Asia (Shackleford 2003:1). This becomes an increasingly important issue as institutions become effectively dependent on export education incomes for the maintenance of acceptable level of educational provision, which is already the case for a number of tertiary institutions.

This chapter firstly provided an explanation of GATS rules applied to education services and then explored the New Zealand trade policy position with regard to education commitments under GATS and progressive liberalisation, and related this to the context of New Zealand's rapid growth in export education. It was shown that this focus on education in terms of economic factors overlooks questions and issues impacting on domestic education. The next chapter looks more specifically at the ideological debates over the commodification of education, through the creation of the 'education marketplace'.

\footnotetext{
${ }^{58}$ Tighter English language levels for new residents and potential restrictions on Chinese students' entry were cited (Evans 2003:2).
} 


\section{Chapter Five}

\section{CONSTRUCTING THE EDUCATIONAL MARKETPLACE}

\section{IMPLICATIONS FOR THE NATURE OF PRIMARY AND EARLY CHILDHOOD EDUCATION}

The last chapter discussed GATS rules in relation to education services and the development of New Zealand's export education industry. The object of this chapter is to situate trade in educational services in the debates regarding the 'marketisation' of primary school and early childhood education in New Zealand that resulted from the reforms of the last two decades and then consider how the critical issues that emerged can inform our understandings of the possible consequences and implications of GATS particularly for this education sub-sector.

In the first part of the chapter I describe and discuss the reconceptualisation of public services that GATS is symptomatic of - the construction of the education marketplace - in the context of Tomorrows Schools reforms, describing how the shift in perception from education as a public service to a commodified private good impacts on the nature of primary and early childhood education.

My discussion is founded on the premise that educational policy in any particular period reflects the provisional outcome of ongoing socio-political struggles and ideological conflicts, in which dominant interests successfully construct the current social policy hegemony (Grace 1998). The transformations in capitalism ${ }^{59}$ have major ramifications throughout social life. My concern is with how the transformations in the last quarter of

\footnotetext{
${ }^{59}$ In the modernist era, capitalism has maintained its fundamental continuity through an historical series of radical restructurings (Grace 1998).
} 
the $20^{\text {th }}$ century, transnational movement of capital and neoliberal economics, have impacted on education:

Inherently part of a set of political institutions, the education system will constantly be in the middle of crucial struggles over the meaning of democracy, over definitions of legitimate authority and culture, and over who should benefit the most from government policies and practices

(Apple 2003:1).

In the second part of the chapter I discuss the significant issues emerging from the educational reforms and the apposition of neoliberal ideologies on the role of education, showing how the market approach may shape or influence our understandings of education services. A reoccurring theme weaves through all the issues: that is the tense dichotomy between the market approach and perceptions and understanding of education as a systemic 'social good', and its role more broadly in the social fabric and culture of New Zealand. The issues are grouped as follows:

- The impacts of managerialism and nature of education management systems

- The nature of choice in education markets

- Issues of equal opportunity and social justice

- Potential impact on pedagogical issues and curricula development

- Business and commercial involvement in public education

- The role of education in terms of nation-building, citizenship, sense of belongingness, concepts of socialisation, identity formation and the influences which shape culture and values of New Zealand education

The first four, managerialism, choice, equity and curriculum, concern the impacts that resulted from explicit policy decisions. The last two are further themes emerging from the wider consequences of marketisation. These trends are then carried over into Chapter Six to form the basis of the discussion about the extent to which trade imperatives and rules of trade might take priority over educational principles and traditional roles of socially embedded educational services. 


\section{Transforming education from a socially embedded public service to a detached tradable commodity - the New Zealand reforms}

Market principles were introduced into New Zealand education fifteen years ago with policies that rapidly and radically transformed the administration of the education system. These reforms, undertaken in the late 1980 s by the Fourth Labour Government, directly challenged the fundamental principles of the established 'settlement'. Therefore an appreciation of the prior established educational settlement is necessary for a critical evaluation of the 1980 s reforms.

The historical basis for the egalitarian principles of early educational policy makers in New Zealand lay in the introduction of a "universal, compulsory and secular primary education system" with the 1877 Education Act (Olssen and Morris Matthews 1997:7). It was recognised that public education served the community by addressing social and economic needs and that "the public benefits of education were not, however, simply the sum of individual benefits" (ibid: 8 ), particularly concerning for example social and political norms of tolerance, literacy, active citizenship and democratic values. This established the idea that education is a 'public good', to be funded by the state out of taxation (Clark 1998). The principle of universal state funded education was extended to secondary schooling in 1914, however the clearest articulation of the role of the state in the provision of universal education was the 1939 statement of Peter Fraser, written by Dr Clarence Beeby for the then Minister of Education, which became the benchmark for educational policy:

The government's objective, broadly expressed, is that every person, whatever his level of academic ability, whether he be rich or poor, whether he live in town or country, has a right, as a citizen, to a free education of the kind for which he is best fitted, and to the fullest extent of his powers. So far is this from being a mere pious platitude that the full acceptance of the principle will involve the reorientation of the education system.

(Fraser 1939:2-3)

Grace (1997:91) identifies five principles contained within this statement which structured educational policy for the next 50 years. Four of these principles related to provision - the principles of equal educational opportunity, of education as a right of citizens, of free education, and of generous and extensive provision. The fifth, a 
'principle of enactment', was the principle of state agency; i.e. that state provision was the necessary means to achieve those ends, and cemented the liberal view of education as a public good.

This liberal educational paradigm came under radical attack from New Zealand Treasury in 1987, in their Brief to the Incoming Government (The Treasury 1987). Targeting the above philosophical and political foundation concepts of the existing settlement, Treasury constructed an alternative thesis, derived from neo-liberal economic discourse and New Right ${ }^{60}$ ideology, which proposed that:

- Education is not in fact a 'public good', but it could be analysed in a similar way to any other service, sharing the main characteristics of other commodities traded in the marketplace (ibid: 32-33)

- The education system was not adjusting to the rapidly changing environment and that nature of education should be responsive to and focused on business interests and the needs of the economy (ibid: 4, 27)

- The system has performed badly despite increased expenditure and increased expenditure in education does not necessarily improve educational standards or performance or equality of opportunity (ibid: 6, 8, 16, 18, 39, 130, 132, 140-42); and the reason for poor performance is provider capture, ${ }^{61}$ i.e. teachers and educational establishments pursuing their own self-interests rather than responding to the consumer (students/ parents) interests (ibid: $37-38$ ) - the important relationship between the education service and its participants is that of 'producer' and 'customer/ consumer'.

\footnotetext{
${ }^{60}$ The New Right is a mix of social conservatism with laissez-faire neo-liberalism, manifested in various forms shaped by specific contexts (Knight, Lingard, and Porter 1993).

${ }^{61}$ Treasury claimed three forms of capture as central to criticisms of the welfare state. Bertram (cited in Peters, 1988) summarises these as:
}

- Consumer capture: when a group of users of state services secures preferential treatment against the interest of other users

- Provider capture: where those who supply state services pursue their own interests at the expense of the interests of consumers

- Administrative capture: where government departments not directly involved in the production of stateprovided services act to advance their own interests at the expense of the quality of those services.

Bertram argues that the concept of 'capture', based on neo-liberal individualist assumptions about society is inherently biased and flawed in that it fails "to distinguish the different particular problems while conveying the unsubstantiated impression that there is some overarching meta-problem with the welfare state" (Peters and Marshall 1988:115). 
- Specifically the system has lacked a rigorous system of accountability, lacking a national monitoring mechanism to compare school effectiveness and account for public expenditure (ibid: 108)

- Government control has created an inflexible system that results in inequality and inefficiency and on these grounds the state is therefore not the best mechanism for the provision of education (ibid: $37-39,132,137$ ); educational services would be better provided through the operation of a free market contract whereby efficient and flexible producers respond to consumer demand (ibid: 41).

By redefining education as a commodity, with a narrow utilitarian purpose, and traded in an educational marketplace, Treasury sought to establish "a new principle to guide and govern the provision of education, one that relieved the burden from the state and placed it on the citizen" (Clark 1998:193). The New Zealand public were being informed that the existing education system needed radical reform and both the mass media and elements of the business community, particularly the Business Roundtable, contributed to the construction of this educational crisis, particularly the argument that "education in this country is producer-led and dominated" (i.e. radical teaching profession) and that "people must seize back control of the education system from the vested interests in education" (Grace 1997:95 referring to the Metro article 1987 The Lost Generation: Victims of the Great Educational Experiment). Widespread dissatisfaction with the nature of the New Zealand education system over the 1970 s and 1980 s contributed to the social and political context for reform (Boyd 1998). By targeting a very real weakness in the system, the failure to have realised the principles of equal educational opportunity especially for Maori, working-class students and women, ${ }^{62}$ and by calling for greater community empowerment and involvement in education policy and practice, the new right ideological conception of education as a commodity in the marketplace with enhanced individual choice, along with its key regulatory principles of accountability, contestability and efficient management was introduced.

\footnotetext{
${ }^{62}$ A number of academic studies documented this failure, demonstrating that success in the system was significantly related to possession of types of cultural capital valued by the system (Grace 1998; Benton 1987; Olssen and Morris Matthews 1997).
} 
The educational reforms also need to be understood in context of the wider social and economic reforms that New Zealand underwent in the 1980s, in response to deepening fiscal crisis:

By the early 1980's, the fragility of New Zealand's economic situation had become apparent. It was a country heavily indebted, with high inflation, growing unemployment, and with a growing awareness of both social inequalities and the need for all new Zealanders to come to terms with the bicultural nature of the country

(Boyd 1998:148)

Driven by the imperatives of efficiency and profitability, and situated in a global context of educational reform, the New Zealand reform agenda went much further than any other nation (Fiske and Ladd 2000). From 1988, a number of reports and policies were produced by government which charted radical reforms in the operation of education at all levels, from early childhood to tertiary.

These reforms, however, went far beyond restructuring the administration of education, changing also "the very nature and context of educational policy formation" (Codd 1990:17). The reforms that emerged were based not so much on a single ideological position, but a complex and contradictory compromise between the competing interests and visions, but nevertheless one in which "the very notion of education as a private commodity subject to market conditions became a reality"(Olssen and Morris Matthews 1997:18). Kelsey describes the reconceptualisation of education from a public service, socially and culturally embedded in local context, to a detached commodity that can be traded in the commercial market in terms of Gramsci's notion of common sense (Kelsey 2003a).

\section{Tomorrow's Schools:}

This process of radical reorganisation of education in New Zealand commenced with the 1988 'Picot report' (Department of Education 1988a), a review of public education administration that concluded that major reform to administration structures was urgently required. Along side the educationalists, the review taskforce included Treasury, State Services Commission and several prominent business people, who provided the economic and social philosophy based on neo-liberal assumptions that prioritised market behaviour of individuals, promoted the adjustment of social expenditure away from the state towards the consumer and encouraged consumers to shop around for "best value 
for money'. The rationale that public education monopolies would become competitive, market responsive and therefore efficient, was founded on the treasury tenet that education is a private good and not a public good; "education shares the main characteristics of other commodities traded in the market place" (The Treasury 1987:33).

This lead to the government's policy response Tomorrow's Schools ${ }^{63}$ which re-shaped the administration of primary and secondary schools. The education marketplace was thus established with self-governing schools, parental choice and market competition as the key ideas proposed for organising and managing the public education system: "consumers need to be able to directly influence their learning institution by having a say in the running of it or by being able to turn to acceptable alternatives" (Department of Education 1988a:4).

Couched in the language and mechanisms of corporate managerialism, the reforms were designed to create a system based on rational principles of responsibility and accountability, linked transparently to policy decisions and action. Senior treasury officials were strongly influenced by principal-agent theory. ${ }^{64}$ While enjoying local operational autonomy, local schools were nevertheless required to act on behalf of the state to achieve national purposes that justify the system of compulsory education, i.e. "the creation of educated workers and citizens" (Fiske and Ladd 2000:6). The concept of the self-governing local school, a publicly owned 'business enterprise' laid the

${ }^{63}$ Tomorrow's Schools sought to provide the following principal features (Department of Education 1988c:12):

- Institutions to be autonomous self-managing units with control over their educational resources, within overall guidelines set by the state

- Governance devolved to local Boards of Trustees (BOT) elected from their community

- Each institution to set its own objectives set out in a 'charter', which will act as a contract between the community, institution and state

- Accountability for funding and objectives through the national review and audit agency (Education Review Office, ERO)

- Institutions to be free to purchase services from a range of suppliers

- Community education forums will be set up to debate concerns - students, parents teachers, managers, administrators

- The Ministry of Education to be established to provide policy advise, administer property and handle financial flows and operational activities

- An independent Parent Advocacy Council to be established to promote interests of parents and provide support to dissatisfied parents who wish to set up their own school

- Groups of parents representing at least 21 children can set up their own school, within the national guidelines for education.

64 "According to this theory, economic relationships are affected by the self-interest of the participating parties. 'Agents' are likely to take self-serving actions, contrary to the interests of their 'principals', unless bound by explicit performance contracts (Perris 1998). 
fundamental foundation for the neo-liberal competitive market environment based on the assumption that overall public good will be served by motivating schools to pursue their own interests in a competitive environment.

\section{Before Five:}

The Meade Report, Education to be More (Department of Education 1988b), followed by the government policy document Before Five (Department of Education 1989) prescribed the equivalent radical transformation of the early childhood sector as Tomorrow's Schools did in the compulsory schooling sector. However unlike the schools sector, there was no requirement in early childhood to establish boards of trustees, leaving services to continue to run with existing management structures. ${ }^{65}$ As a result there is a clear division between "community-based services, which require parental and community involvement in the management as part of their constitutions, and private services which may operate without such involvement" (Early Childhood Education Project 1996:49). These educational reforms became the vehicle for the introduction of free-market economics characterised by moves away from government provision of services and increasing private market-based provision.

Early childhood education services have never been fully incorporated into the state education sector. Before Five promised the early childhood sector equal status with other educational sectors, but throughout the 1990s barriers particularly in relation to funding and the economic policies of the then National government that went even further to the right, prevented the full implementation of Before Five. Instead the "marginalised and often divided early childhood sector provided the government with a site to test market-led ideas such as bulk funding and increased support to private providers of education services" (May 1999:19).

Access, participation and quality were central goals of the reforms. However there is almost total reliance for provision on the market place, and so whilst crude participation rates have increased, issues of access, equity and quality remain. Nevertheless Before Five marked the end of the policy split between 'care' and 'education' and led to the development of the national curriculum for ECE Te Whariki (Ministry of Education 1996).

\footnotetext{
${ }^{65}$ Given that most early childhood services were already governed and managed at the local level.
} 


\section{The emerging issues}

These administrative reforms were not expected to have any impact on teaching itself, yet "decisions to resource and manage schools in significant new ways and to audit those same schools in a competitive rather than co-operative environment were decisions that were destined to have a major impact upon the quality of classroom life and the life of teachers"(McKenzie 1999:9). A collection of articles by educationalists a decade later portray, as suggested by Codd, "a very damning appraisal" of the reforms and the policies that followed (Thrupp 1999:5). These policies created a "culture of distrust... [with systems and practices] predicated on the assumption that people are primarily motivated by self-interest and therefore cannot be trusted to serve the common good" (Codd 1999:48). Furthermore subsequent curriculum reform followed the same trend, specifying learning objectives formulated as prescribed tasks and demonstrable skills that can be "easily measured, packaged and commodified as knowledge" (Peters and Marshall 1996:34).

Numerous articles in education journals cover aspects of Tomorrow's Schools reforms. ${ }^{66}$ The Ministry of Education has conducted its own monitoring activities and in 1997 commissioned an administrative history of the reforms (Butterworth 1998b). Ten years on an empirical study based on NZCER national surveys of the impact of the educational reforms was produced (Wylie 1999b), however the most comprehensive independent analysis of the impact of these reforms was undertaken by Fiske and Ladd, who identified the following broad consequences (Fiske and Ladd 2000:9-11):

- Polarisation, whereby a once relatively egalitarian education, became increasingly stratified by ethnic and socio-economic status

- Winners and losers, inherent to the marketplace presumption, creating successful and failing schools and individuals, with high decile schools likely to be more successful than low decile schools

- Failure to balance the competing interests of various stakeholders; and lack of mechanisms to balance the needs of broader communities, of school districts and the system as a whole.

\footnotetext{
${ }^{66}$ Pertinent references include two edited books (Olssen and Morris Matthews 1997; Sullivan 1998b) and a special issue of New Zealand Journal of Educational Studies devoted to this topic (Thrupp 1999).
} 
The neo-liberal hegemony ${ }^{67}$ established a new 'common sense' for the education system, redefining what counts as 'legitimate needs' to be met by the system and 'legitimate means' to achieve them (Apple 2003), which undermines the core values and principles of public education.

In 1998 a conference organised by the Educational Administration Society provided a forum for education sector leaders to appraise the reforms. This forum identified the tensions between the proponents of state agency and market forces, the difficulties of relationships of teachers and principals to the Ministry, the need to focus on people rather than structures in on-going reforms, and affirmed the acceptance of education as a public good that should be made available to all citizens and communities (New Zealand Educational Administration Society 1998:4).

Researchers and commentators ${ }^{68}$ in early childhood have also been highly critical of the market approach applied to education. Fundamentally the complexity of education can not be reduced to mechanical process ('product') that is passively 'received'. Rather it is a process of 'co-production' with the students themselves being "actors who have agency within education settings" (Dahlberg, Moss, and Pence 1999:50).

\section{Managerialism:}

The reforms introduced a wide range of new public management (NPM) $)^{69}$ systems to the compulsory schooling and early childhood sectors.

\footnotetext{
${ }^{67}$ Gramsci's notion of hegemonic power is a process constantly contested and renegotiated, which is reflected in the shifting role "the state plays in producing and policing what counts as legitimate knowledge both within schools and in the larger society" (Apple 2003:7).

${ }^{68}$ See also (Mitchell and Noonan 1995; Mitchell 2001; Meade 1993; Dahlberg, Moss, and Pence 1999).

${ }^{69}$ NPM is based on an underlying assumption, and arguably irrational fear, that all human behaviour is selfinterested. NPM is a mechanism to guard against this self-interest and the vested interests of (particularly) provider groups (Wylie 1995). Three core neoliberal New Right economic theories underpin NPM - 'public choice', 'agency theory' and transaction-cost economics. Underlying NPM is the belief that the private sector methods, approaches, processes and 'impartiality' are superior to the public sector, and that government intervention has interrupted the 'natural' free-market contract between producer and consumer, causing bureaucratic inflexibility and educational inequality (Hamer 2002). NPM emphasizes managing risks and assumes that applying these methods of management to any organisation will "improve its efficiency and effectiveness in achieving predefined outcomes" (Codd 1999:47).
} 
A Ministry-commissioned review of the reforms undertaken by the Butterworth's describe a "high level of satisfaction" across the stakeholder groups (Ministers of Education, MOE, the chairpersons of the three main taskforces, SSC, principal's association) but noted that representatives of the teachers' unions voiced exceptions to this view (Butterworth 1998a:14). In particular the authors reported that the reforms were perceived as a positive process of change of attitude towards rational management of enterprises, from a previous medley of administrative arrangements in early childhood and a cumbersome bureaucracy in the school sector. The Ministry of Education's view of their own cultural change described the implementation of a project management approach with "open communication, accountability and critical thinking" (ibid).

On the other hand the reflections and critical analysis of the reforms found in educational journals and conferences reveal a more mixed response, identifying both areas of positive change but also significant concerns about the transformation of the nature and culture of education. For example O'Neill's report of primary school principals' experiences welcomes the local flexibility and control over decisions and resource use that the administrative reforms brought, but questions the increased procedural administration, the adequacy of funding to achieve this and the "redefining of educational leadership" required (O'Neill 1998:404).

In the early childhood sector the free-market approach was particularly significant, resulting in the contracting out of early childhood services and a reliance on consumer choice, accompanied by an increased application of accountability and fiscal mechanisms along with changes in the role of state agencies. The public sector of early childhood education (kindergartens) has been reshaped to reflect the private market models. Government's regulatory and administrative requirements and standards for early childhood education services are outlined in the Desirable Objectives and Practices (DOPs) (Ministry of Education 2002e). The NPM framework, in accordance with agency theory, introduced contractual agreements between government and early childhood service providers in the form of a charter. ${ }^{70}$

\footnotetext{
70 The government requirements specified in the DOPs form the basis of each service's charter, with compliance monitored by the Education Review Office (ERO).
} 
In a market based approach, NPM mechanisms are deemed necessary to ensure quality assurance and accountability and therefore the only means available to the government to 'oversee' delivery by private providers, both domestic and foreign. However these externally controlled and measured quality assurance and accountability mechanisms end up defining and therefore limiting what 'quality' is, as well as having a negative impact on diversity of services.

Educators in early childhood have found the external accountability requirements, that focus on measurable outputs, have directed "attention away from the less tangible aspects of quality and have undermined the role of professionals in early childhood by taking the emphasis away from teaching and learning and the professional judgement of teachers" (Hamer 2002:38). These 'less tangible' elements emphasize the subjective, contextually based nature of quality that cannot be so easily regulated, such as nurturing, relationships, sensitive and supportive educators, values, community involvement and daily dynamics of interactive learning.

The increased emphasis on managerial systems and compliance paperwork in both the compulsory schools and early childhood sectors has not only increased work loads and taken educators time and focus away from the learning environment, but also created a culture in which trust is no longer the foundation of professional ethics (Codd 1999:45). Managerialism and de-professionalisation, are contributing to the problem of teacher shortage. "The spirit of cooperative endeavour in school communities is under threat. There is a yearning for a culture of sustainability and professional ethics" (Macpherson 1998a:1).

\section{Consumer choice:}

Contestability, through either actual or potential market competition, was considered a core mechanism as a counter to the 'maximising behaviour of public service providers' supported by public choice theory (PCT). ${ }^{71}$ However a review of studies in the literature relating to parental choice reinforces the view "that parents make their choices and express their preferences on the basis of a range of techniques, many of which could not

\footnotetext{
${ }^{71}$ PCT assumes that for a professional service to be efficient and responsive to consumer demand there must be the threat of competition from other providers and opportunities for consumers to exercise choice (Codd 1999).
} 
be described as consistent with the principles of rational choice theory" which underlies the market-based system promoted for schools (Martin 1998:310).

Likened to a 'quasi voucher' system ${ }^{72}$ to foster the market approach, bulk funding was introduced into early childhood services as a component of the Before Five policy, on the "assumption that it would provide a solution to uneven access and variable quality" (Mitchell 2001:3). Supporters claim the flexibility and freedom to self-manage allows innovation and responsiveness to local needs. Opponents argue that it widens inequality, reduces government responsibility and that there is no evidence to support the claims of innovation or responsiveness.

Funding is tagged to the child not the service and therefore available to any licensed centre that is chartered. Chartered 'for-profit' centres therefore receive the same funding as community 'non-profit' centres. ${ }^{73}$ The reforms resulted in the government having relatively little direct control over the supply of early childhood services, relying almost totally on the marketplace, community and private endeavour (May 1999). The profit making opportunities offered by this market approach are illustrated in an Auckland newspaper advertisement for 'Business opportunities' column "Childcare. An industry which will return you $20 \%$ plus on your investment. From $\$ 300,000$ to $\$ 1.4$ million" cited in (NZEI 1998:2).

Over the decade that followed there was a significant increase in the number of early childhood services, particularly a large growth in 'for-profit' centres, and in total participation rates, ${ }^{74}$ however there has also been uneven access both in relation to location and ethnicity, with comparatively low participation rates for Maori and Pacific

\footnotetext{
${ }^{72}$ The central premise of the theory of vouchers/ bulk funding views education as a market commodity, whereby markets are thought to be the best way to meet the needs of consumers and competition will ensure efficiency, responsiveness and cost-effectiveness. For a critical analysis see (Wylie 1998).

${ }^{73}$ To address access and quality issues the current government introduced 'equity funding' in 2001 for eligible community-based ECE centres. This funding distinguishes between community-owned and privately owned early childhood centres and is not available to the latter (Ministry of Education 2001a). This policy decision recognised the quality-based differences between community and privately owned early childhood centres revealed in Mitchell's 2002 NZCER report (Mitchell 2002). By providing additional subsidies for lowdecile community centres but excluding for-profit centres in a similar category could be challenged as a breach of GATS (Day and Norman 2003).

${ }^{74} 1029$ new ECE services between 1990 and 1997 ; increase from $40 \%$ to over $50 \%$ of all children under 5 years attending some form of ECE (Meade 2000). Specifically the number of for-profit centres increased from 300 in 1989 to 979 in 2002, now making up more than half the total 1673 childcare centres (Ministry of Education 2003d).
} 
Island children (Meade 2000). With no requirement to spend funds on quality ${ }^{75}$ associated aspects of provision, Mitchell demonstrates consistent differences between community-based and private services in the expenditure of government funding, with latter focusing on purchase and development of property and owner capital gain, while employing a lower proportion of qualified staff and paying lower wages (Mitchell 2002:2$3)$. She concludes that the bulk funding system works against policy objectives of enhancing quality and improving participation for all preschool children.

In the compulsory schooling system competition between schools for students and the opportunity for consumer choice came two years after Tomorrow's Schools when the then National government abolished neighbourhood enrolment zones, ${ }^{76}$ creating the "quasi-market" ${ }^{77}$. Schools are funded almost entirely on the basis of student numbers. Market image has become the driving force of school choice. Public relations and marketing skills are integral, with school energies being focused on developing market strategies and improving the image of their 'educational product'. This competing environment has dramatically changed the culture of schooling, forcing administration to devote increasing attention to marketing activities and putting strains on traditional professional collegiality and trust (Fiske and Ladd 2000:63).

Advocates of choice claim there is mounting evidence of the benefits of competition in the school sector, citing US studies that "show competition leads to increased educational achievement per dollar spent, increased educational attainment, graduation rates, test scores and graduate wages, increased teacher quality, enhanced student test scores" (Education Forum 2003:2). The same source cites UK studies showing a positive impact of school choice on ethnic and income integration in schools ${ }^{78}$ and quotes both the Smithfield project and the study by Fiske and Ladd as supporting their

\footnotetext{
${ }^{75}$ Structural quality includes aspects such as staffing - adult: child ratios, qualifications, experience, wages and conditions, staff stability, group sizes, resources, professional advisory services, in-service training and staff development. Process quality refers to the environment, interactions and relationships in the ECE setting and that shape the child's experiences (Mitchell 2002:4-5).

761991 Education Act Amendment.

77 The term 'quasi-market' refers to a halfway house between interventionist and non-interventionist state forms, separating funding from provision, establishing a form of competition between providers, but with the state remaining the funder of services (Gordon 1997).

${ }^{78}$ A study by Gorard and Fitz, Cardiff University found that the degree of socio-economic stratification declined after the introduction of the Education Reform Act introduced choice by removing zoning, from 36\% in 1989 to $30 \%$ in 1996 (Education Forum 2003:6).
} 
stance. Frankly this is a gross misrepresentation of both these studies ${ }^{79}$ which along with other New Zealand studies demonstrate significant issues both in performance and polarisation for schools and in terms of equity for families.

Parental choice is accepted and wanted by well-educated upwardly mobile and middleclass parents, informed by a belief that the world is more competitive and education to 'get ahead' more crucial than ever (Walsh 2003). Despite the reintroduction of school zoning in 2001 , where they can parents will bypass their local schools or move into a zone to ensure their children go to the school of choice. Fiske and Ladd described this climate in which parents felt compelled to exercise choice: "to be a good parent one had to make a conscious decision about which was the best school for one's child. Some parents became excessively anxious and even obsessed about whether they were making the right decision" (Fiske and Ladd 2000:183). It should also be noted that the obsession to push their children ahead in a competitive world is also driving some parents to demand formal literacy and numeracy education for their preschoolers as young as two years old at early childhood centres (NZPA 2003c).

However low income families are not in the same position to exercise choice, either because no alternative options exist in their neighbourhood, or they cannot afford transportation, fees and other related costs, or they do not perceive that they have a the power to exercise choice. Lauder et al found that "parents have widespread knowledge of which schools are perceived to be most desirable... [but] lack the positional knowledge ${ }^{80}$ and really useful knowledge ${ }^{81}$ to access such schools" (Lauder et al. 1995:9). Furthermore over subscribed schools have the right to develop an enrolment scheme in which they can designate which students they will accept, and in effect the 'choice' is shifted to schools (Fiske and Ladd 2000:222).

Advocates for parental choice justify it as a means of promoting diversity, as a parental 'right' or as a means of increasing efficiency on the assumption that the way a school is

\footnotetext{
${ }^{79}$ See discussion of the outcomes of these studies in this chapter; for further reading go to the sources: Smithfield report (Hughes et al. 1996; Lauder et al. 1995) and Fiske and Ladd (Fiske and Ladd 2000).

${ }^{80}$ Based on Hirsch's notion of positional goods, that are scarce in a socially imposed sense.

${ }^{81}$ Practical knowledge of community networks and resources that they can access to organise and manage family and working life routines.
} 
managed is the principal factor in performance (Fiske and Ladd 2000; Lauder, Hughes, and Watson 1999).

Indeed, some of the community support for the reforms was founded in expectations that they would provide opportunities for local communities and different groups, particularly in the early childhood sector, to establish centres that reflect the pluralist nature of communities and allowed different educational philosophies to be nurtured.

However the argument for market choice as a mechanism for delivering diversity by providing niche markets for schools with specific cultural, religious or pedagogical values is flawed. In reality the best opportunities for delivering such diversity have not been provided by the market, but rather by community-based opportunities incorporated within the education system (including integrated schools) - for example, the current Kura Kaupapa schools and Te Kohanga Reo, Catholic, Rudolf Steiner and Montessori schools and kindergartens.

The crucial point in the debate between pro-market advocates and their critics concerns the dynamics of student mix. Many studies show that school performance (student exam results) is largely determined by student background and prior achievement, rendering the 'management efficiency premise' false (Lauder, Hughes, and Watson 1999). The Smithfield project (Lauder et al. 1995) revealed that parents rankings of schools are closely aligned with socioeconomic and racial mix. Fiske and Ladd found that segregation by ethnicity is now higher with minorities more concentrated in lower decile schools than previously and attribute this to the exercise of school choice (Fiske and Ladd 2000:192). The decile rankings introduced to direct additional funding to areas of educational need, have become a short-hand proxy measure of school quality. ${ }^{82}$

The exercise of choice creates a spiraling of factors outside of the schools' control and subsequently impacting on school performance. A study of Christchurch schools shows a definite middle class drift ('flight') and concludes that "to equate this trend with failure and blame the school board for mismanagement, or the staff for inadequate teaching, is

\footnotetext{
${ }^{82}$ Overall performance may be related to deciles, but there is little evidence that lower decile schools are inferior in quality. Rather deciles are more related to resources at home. A lower decile school may be more successful at enhancing achievement than a top decile school" John HOD Auckland University Education Department, Hattie, cited in (Walsh 2003:3).
} 
a spurious claim which serves only to undermine the professionalism and dedication of workers in education" (Ainsworth et al. 1996:32). ${ }^{83}$ The impacts of polarisation are discussed below.

\section{Issues of equal opportunity and social justice:}

As demonstrated above, a key issue of the debate over the marketisation of education concerns the question of polarisation of school intakes in terms of socio-economic status and ethnicity. Advocates argue that parental choice can help overcome already significant stratification in the education system by opening up access to middle class public and private schools to minority students and bypassing residential segregation (Education Forum 2003).

Critics argue that parental choice "enhances privilege of those already empowered with material and cultural capital" (Hughes et al. 1996:1). This trend is a matter of concern with regard to the importance of a well balanced and diverse range students to promote democratic values such as tolerance and mutual understanding of different ways of life.

Equality of access to free education, "directed to the full development of the human personality and to the strengthening of respect for human rights and fundamental freedoms" is acknowledged as a Human Right, article 26 of the Universal Declaration. (United Nations 1948). The International Covenant on Economic, Social and Cultural Rights requires New Zealand (and all signatories) to take measures to "prevent third parties from interfering with the enjoyment of the right to education" (United Nations 1966). Ironically this obligation is potentially rendered impotent, as GATS provides no

${ }^{83}$ The findings of the research shows (Ainsworth et al. 1996:1):

- 18 of the 29 schools with populations in the lowest socio-economic group have experienced declining rolls of more than $10 \%$ over the preceding five years. Only 3 of the 29 have experienced growth of more than $10 \%$

- Of the 32 schools with rolls declining by more than $10 \%$, only one lists their population as predominantly of a middle-high socio-economic status

- All 4 schools in the highest socio-economic status group have experienced increases in their roll during the same period. 
mechanism to require governments to comply with international human rights obligations. ${ }^{84}$

Polarisation is also undesirable in terms of its impact on school performance and the consequences of a spiral of decline and instability of school roll for schools facing middle class exodus, bringing a series of additional problems which place these schools under enormous pressure. A third issue is the negative impact of polarisation on the overall performance of the education system as a whole. "The school mix hypothesis...claims that the better mixed a school is, the higher the outcomes for working class students" (Hughes et al. 1996:2).

\section{There is a direct co-relation between student achievement and socio-economic} environment of families and communities. ${ }^{85}$ In a competitive model disparities that already exist are likely to be consolidated rather than reduced. Middleton argues "that factors that lead to the so-called 'failure' of South Auckland schools were built into the reforms and since then...that failure has become explicit and blatant" (Middleton 1998:332). A policy approach that prescribes in generalities at a macro level speaking of a 'homogeneous education system', can not address in any serious way the needs of specific schools in areas such as South Auckland.

Inherent to the concept of the educational marketplace is the notion of winners and losers. This raises moral and practical questions around setting up a system of public education which is designed to create failures as well as successes, among both the institutions and individual students. Many parents use NZQA achievement results as "league tables". Education International (EI) have condemned the practice of "conducting

\footnotetext{
${ }^{84}$ The legal regime establishing the WTO and the disputes settlement mechanism "nowhere explicitly recognises that trade rules are subordinated to, or at very least must take into account, fundamental human rights and the obligations they confer on national governments" (Grieshaber-Otto and Sanger 2002:156). There is however growing appreciation that GATS must not be viewed in isolation. Howse and Mutua, cited in Grieshaber-Otto and Sanger, recently concluded that: "in the event of a conflict between a universally recognised human right and a commitment ensuing from international treaty law such as a trade agreement, the latter must be interpreted to be consistent with the former. When properly interpreted and applied, the trade regime recognises that human rights are fundamental and prior to free trade itself" (Grieshaber-Otto and Sanger 2002:11).

${ }^{85}$ For example the issue of transience has a significant impact on educational deprivation for students, and also poses difficulties for teachers trying to maintain a forward momentum and quality education programmes in classrooms with high student turnover - effectively all students suffer in communities with high mobility. A study by the Child Poverty Action Group in 2002 showed that every Monday morning 400 students change schools in South Auckland (Minto 2003a:1).
} 
assessment in order to produce a ranking of schools... rather than to support student learning [as] an unacceptable use of scarce resources" (Education International 2001:3). Market choice factors are now impacting on the reporting of NCEA results. With school image at stake, some schools are not reporting non-achievement results, a practice which is apparently acceptable to NZQA (Richardson 2004).

Access and quality remain the critical issues for early childhood education. "A rampant private early childhood sector continues to be government funded while public centres struggle to meet the needs of early childhood children and their families" (Cooke 2003:1). The inequities that existed in 1989 continue in 2003, with disparities in access associated with family income and ethnicity. While Te Whariki is described as a "visionary curriculum document" for early childhood education, the reality falls well short of its promise ${ }^{86}$ (Minto 2003a:2). Barriers to participation are significant issues in ECE especially for particular communities and groups of children (especially Pacific Island and Maori children). Cost, lack of suitable or flexible hours or local services were cited as reasons early childhood services were not accessed by those wanting to participate in training or employment in a Department of Labour and National Advisory Committee on the Employment of Women report (Department of Labour and National Advisory Committee on the Employment of Women 1999).

\section{Pedagogical issues and consequences for curricula development:}

Education has several core purposes, including socialisation, and particularly in one sense, education is the way in which society and the state forms citizens, which is in that sense a hegemonic project, the formation of personnel for the labour market, in which the economy dictates certain forms of education and a further purpose is the arousal of intellectual curiosity, critical ability, imagination and creativity (Dale and Robertson 2003).

Through the 1990s the shaping of new constructions of childhood and education were linked to global economic agendas. Economic imperatives have contributed significantly

\footnotetext{
${ }^{86}$ Minto recommends increased government funding for family and community based early childhood education and removal of funding for 'for profit' providers. To be permissible under GATS this would require classifying community centres as fundamentally distinct from private providers, and providing transparent justification to do so (Minto 2003b).
} 
to 'resiting' New Zealand in the 'Asia-Pacific' region, embraced also as a key market for export education. The former Minister of Education, Lockwood Smith, illustrated the extent to which these economic imperatives directed the development of the new curriculum framework, pointing out

that the curriculum will acknowledge New Zealand's relationships with the peoples of Asia and the South Pacific...[and] that the essential skills in the curriculum framework are skills required to compete with the Asian economies..[and] a knowledge of appropriate international languages and appropriate cultural behaviours, when combined with skills such as those of marketing and economics, is likely to contribute to gaining the competitive edge

cited in (Dale and Robertson 1997:220)

The primacy of economics is visible in the New Zealand Curriculum Framework for the compulsory school sector (Ministry of Education 1993). National curricula across the education sector focused on nationally defined 'learning outcomes' and 'essential skills' for participation in the knowledge economy. The school curriculum seeks to develop students who will "participate effectively and productively in New Zealand's democratic society and in a competitive world economy" (Ministry of Education 1993:3).

The business agenda for education has lead to a more outcome oriented and vocationally relevant curriculum ${ }^{87}$ appropriate to a technologically-driven "knowledge economy'. The present government's emphasis on economic transformation through initiatives to create a 'knowledge wave' are reflected in its education priorities with a focus on developing a highly skilled workforce and research capability and innovation that will lift productivity (Ministry of Education 2003c).

The interests of business and the interests of a good society are not, by any means the same...business needs team players who are not resistant or iconoclastic and do not waste precious time with metaphors or ethics. But society needs prophets, poets, trouble-makers, saints and rebels, beautiful dream-makers, glorious eccentrics"

(Kozol 1997:6).

While the economic benefits of a 'knowledge society' are heavily promoted, cultural questions are consigned to the status of afterthought. The coveting and commodification of 'knowledge' has serious implications. What does it mean for knowledge to become a market economy? What is included in the 'body of knowledge'? And with economic

${ }^{87}$ Refer to ERO review of curriculum (Education Review Office 2001). 
restrictions on access to knowledge and its public infrastructure (schools and libraries), who will be able to 'afford' to learn?

Educational practices and programmes, curriculum approaches, and the management of educational institutions, must reflect the needs, identities, perspectives and cultures of this society. "Social contexts are not universal...social codes are shaped by national and local cultures" (Woolf 2002:13). In the thrust towards educational systems being disaggregated into elements that are then delivered through the open market, lies the failure to explicitly recognise that reality is constructed variously through diverse and subjective perspectives and therefore that educational practice, material and systems etc can not be abstracted and applied universally, outside of their socially embedded contexts. What is taught, and how, is crucial.

Paulo Freire's insistence on situating educational activity in the lived experience of participants provided a significant pedagogical basis to educational practice. While acknowledging that education always implies programme, content, method, objectives and so on, his concept of a 'good education' focused first and foremost on engagement with people (Bell, Gaventa, and Peters 1990). The key point is the inherent difficulty in disembedding educational programme, content, techniques and material from their social context.

The introduction of a national curriculum ${ }^{88}$ for early childhood education, Te Whariki (Ministry of Education 1996), recognised the integration of education and care for young children, and provided a holistic and sociocultural model of learning ${ }^{89}$ that is applicable to the embedded nature of the diverse range of early childhood services in New Zealand (Meade 2000). Conceptually the starting point of Te Whariki is 'the child', surrounded by home and community. This child focus is embodied in the concept of mana whenua, belonging, that affirms the child's place in their environment and their links and relationships with family and community. However the external requirements of NPM are

\footnotetext{
${ }^{88}$ The term 'curriculum' is used in Te Whariki "to describe the sum total of the experiences, activities, and events, whether direct or indirect, which occur within an environment designed to foster children's learning and development" (Ministry of Education 1996:10).

${ }^{89}$ sociocultural theory argues that it is important to understand the contexts in which children learn, and the cooperative nature of learning, which is acknowledged in Te Whariki as the rationale for the principle that "children learn through responsive and reciprocal relationships with people, places and things (Ministry of Education 1996:35).
} 
incompatible with many of the less tangible aspirations of Te Whariki that for example, focus on identity, socialisation and relationships the embedded nature intrinsic to quality early childhood education.

Quality early childhood education is central to the well-being of families with young children. Early childhood education services provide children with the opportunity to interact with others beyond the family and enhance children's growth and development through enriching programmes. They assist in passing on the language and culture... [and play] many of the roles and functions of the extended family

(Early Childhood Education Project 1996:7)

The government policy responses and the early childhood sector have acknowledged the obligations of the Treaty of Waitangi. In particular this is reflected in the bicultural basis of Te Whariki. This paradigm of bicultural development requires understandings and commitments in its application that are embedded in the training and development of educators and their own sociocultural experiences (Ritchie 2002). The ideas and practices of early childhood education and curriculum decision-making are largely informed by sociocultural theories of learning and experienced as active interpretative processes. There is an unfathomable discrepancy between these educational discourses and the discourse of education as an internationally tradable commodity.

The redirection of state funding from programme provision to programme regulation carried with it the separation of policy making and from educational delivery, distancing teachers from both policy advising and curriculum development roles in which they were previously involved.

Operating the national curriculum framework within a managerial culture of detailed standards and performance accountabilities, has resulted in a loss of critical thought (Hill 2003). This culture of performativity and managerialism also furthers this economic appropriation of the cultural realm, and favours centralism over pluralism, undermining the capacity for school communities to be learning communities (Macpherson 1998b). Within a framework that embraces the notions of bi-cultural nation building and 'good society', Macpherson promotes a policy approach that finds a balance: only sufficient 'centralism for emancipation and equity's sake' to promote national goal formation and 
models of excellence that value and accommodate pluralism and foster learning communities.

There are significant issues around foreign and transnational companies 'managing' educational services or creating generic teaching resources and interpretation of curriculum requirements. NZEI provides an interesting example of the seemingly benign use of foreign publishers in regard to the printing of curriculum resources:

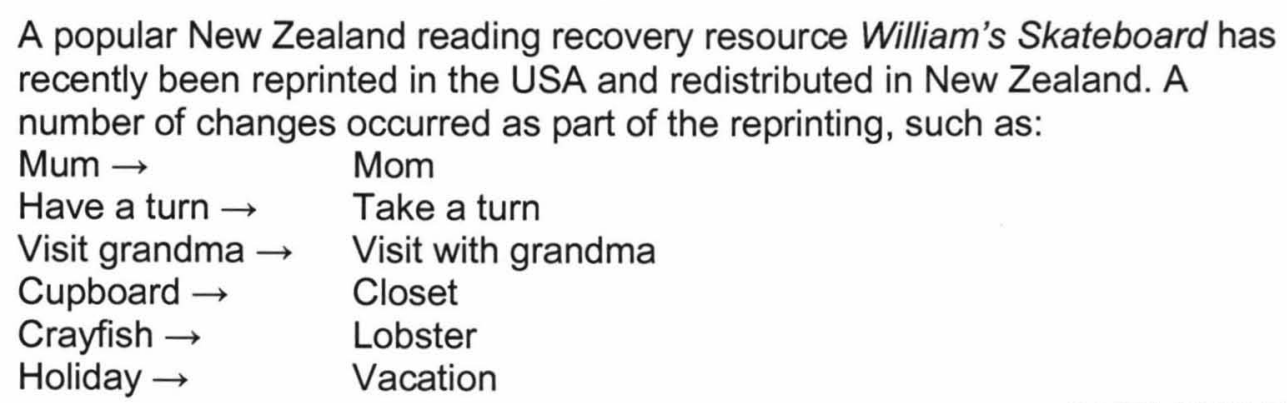

(NZEI 2003:7)

This commercialisation of curriculum resources takes on additional ramifications under GATS, which "would restrict the Ministry of Education's ability to favour New Zealand written and published curriculum resources over foreign produced resources that do not closely reflect New Zealand's cultures and societies" (NZEI 2003:7).

The effective implementation of any curriculum relies on relationships between many factors, but a significant factor is the educators' prior knowledge bases and their beliefs and values and social relations. Within these notions of education, curricula and practice can not be packaged and delivered 'transnationally'. To do so implies a lack of knowledge and sensitivity to the subtle ways in which cultural routines and rules shape decision-making and practices. It also ignores the moral dimension of education, which requires that moral development and caring are not simply universalised principles, but rather the cultivation and practice of moral imagination and caring developed 'in relationship' and in context (Ross 2002).

With these concerns in mind, the risks which need to be debated are on the one hand the extent to which the curriculum, teaching styles, learning environment and pedagogy will need to be tailored to meet the market requirements of export education industry, that is, the extent to which the needs of international customers become 'curriculum 
drivers'. And on the other hand the reach of GATS, in terms of the constraints it could place on domestic regulation for example, "could curriculum guidelines which require locally specific content be challenged as more trade-restrictive than necessary to achieve their educational objective?" (Grieshaber-Otto and Sanger 2002:139-40).

The international education discourse seeks ways to package, commodify, own and trade knowledge and ideas in a competitive environment on the one hand, while endeavouring to evoke notions of transnational connectivity, interculturalism and free flow of ideas as a moral relationship on the other hand (Matthews 2002). Although it is beyond the scope of this paper to discuss in any depth, I refer the reader to several commentaries on educational restructuring in the context of globalisation, and the philosophical and political orientations and assumptions that underpin it (Daun 2002; Matthews 2002; Jones 1998; Woolf 2002; Haigh 2002; Uvalic-Trumbic 2002). There is a movement towards greater homogeneity involving a growing convergence on the AngloSaxton model.

\section{Commercialisation in public education}

Educational institutions have always played an essential part in propagating and disseminating ideas and worldviews that justify and to a certain extent legitimise the dominant views in society. However since the latter part of the $20^{\text {th }}$ century, the education system has been geared to more directly be guided by the needs of capital business, employers, private companies. ${ }^{90}$ The two central processes reflected in these moves are the increased primacy given to the role of the education system to educate the workforce giving more attention to skills and less to knowledge and critical enquiry, and to educate and stimulate consumers and consumption behaviours; and imperatives arising from the pressures of managerial efficiency and market competition (Hirtt et al. 2003).

\footnotetext{
${ }^{90}$ A paper produced for Education Forum discusses the complexities of the relationship between education and economic growth or labour value and productivity (Lattimore 2002a).
} 
To compete in the world market the demand for more and better skilled labour has become more intense (Bowron 2001). I have explored how the reproduction of the conditions and skills necessary to the economy involves changes to curriculum and teaching methods. Mulderrig ${ }^{91}$ argues that it also "involves changing people's behaviour and values in order to create a new self-reliant, risk prepared, enterprise culture"(Mulderrig 2003:3).

As a result there has been a significant shift in the identity-relationship between schools and business, an increasing focus on partnerships between education and industry and an expanding 'merchandisation' of education. There is growing business and industry intervention in schools through business education programmes, personnel (tutors, mentors, resource people, curriculum packages and resource and outreach support services such as careers advice, work experience, site visits.

These developments attract two opposing views: one the one hand the involvement is welcomed by some as a valuable extension to curriculum and on the other it is viewed as "a distorting intervention in the public education system" (Cooke 2003:1). Peter Shirtcliffe, a member of the Business Roundtable, blames New Zealand's static standard of living on weaknesses in our education system:

in particular, there is insufficient emphasis in the state-dominated education on the whole concept of enterprise and entrepreneurship... it is vital to teach students about the role of business, the creation of wealth, and why profits are a fundamental requirement in a modern progressive economy...these manifestations of business and the wealth they collectively generate are the life-blood of the society in which we live

(Shirtcliffe 2003:16)

Enterprise New Zealand Trust (ENZT) funded predominantly by private sector sponsorships (however also funded by the Ministry of Education, for example to deliver teacher training for the delivery of enterprise programmes) has a primary focus to provide programmes that teach the elements of economic and financial literacy in

\footnotetext{
${ }^{91}$ Mulderrig critically assesses the duality of the role of discourse in changing the education system and the role of education policy discourse "in the (re)production and legitimation of capitalism" (Mulderrig 2003:2).
} 
schools and entrepreneurial aptitudes. ${ }^{92}$ While the benefits are promoted as developing positive, cooperative and social skill and behaviours as well as business aptitudes, the values underlying those lessons derive from a specific economic discourse, inculcating a particular world view without critical social comment. For example:

a. Students get paid in the school currency for picking up litter, maintaining school grounds, painting seats in the playground

b. (a teacher) "If the children need help with something, they contract me and I charge them" (NZ Education Gazette/ Tukutuku Korero September 2002 p.10)

(Cooke 2003:6)

"PrEP national director Kathie Willis says by exploring the realities of life in our democratic market system, children discover the economic, social and legal 'rules' that shape society" (NZ Education Gazette/ Tukutuku Korero September 2002 p. 19) cited in (Cooke 2003:7). The critical point here is that democracy is viewed narrowly as a 'market system', the rules and values ${ }^{93}$ of which define society. This actually only acknowledges a certain dimension of society and distorts the established understanding of democracy as "the practice and spirit of social equality... by the people or their elected representatives" (Hanks 1988:297). The national technology curriculum includes a 'Mcdonald's unit'; "this isn't problematised, but rather is presented as technological utopianism" (Cooke 2003:9). There are moves for enterprise education to become a formal strand of learning in the curriculum raising the question, 'what other area of the curriculum will it replace?'

NZEI have raised concerns regarding the increasing commercialisation in schools, citing examples of sponsorships, advertisements in curricular material, commercial

92 Examples of programmes promoted through ENZT include (ENZT 2003):

- Primary Enterprise Programme (PrEP) provides "the operation of a market system for production, exchange, distribution and consumption of goods and services within the [primary] school society" is sponsored by Fletcher Challenge, Contact Energy and Lion Nathan. 150 primary schools participated in 2002

- Enterprise Studies Programme (ESP) focuses on enterprising skills for small businesses for fourth formers, sponsored by BP and endorsed by New Zealand Business Council for Sustainable Development (NZBCSD)

- Financial Literacy Programme (FLP) aims to develop personal financial management in senior school students

- Lion Foundation Young Enterprise Scheme (YES) - formerly sponsored by Fletcher challenge, enables senior secondary school students to "form a company, become directors, develop products and services, which they market and sell".

${ }^{93}$ Building a concept of society as a business entity, values of the market such as the profit motive, definition of human being as economic being, notions of competition, winning and losing (Cooke 2003). 
development of learning packages, technology hardware and software, ${ }^{94}$ vending machines, and the risks of schools becoming targets for corporate promotions (NZEI 2002b). NZEI have initiated their own investigation of advertising and commercialism within New Zealand institutions (ibid). One of the great myths of corporate handouts to schools is that schools are getting something of value for free.

Plentiful examples of sponsorships can be found throughout the education system McDonalds Reading Programme, Ronald McDonald Road Safety programme, Olympic Fun Run, Golden Circle Fun Run, New Zealand Post Better Letters kit, Pizza Hut reading scheme, Telecom Schoolzone to name just a few. Concerns about the implications of the linking of this kind of marketing with education are well expressed in the following letter to the editor of the New Zealand Herald, from a parent:

\begin{abstract}
My 7-year-old and her friend came out of the school gates singing a new song the other day. It goes like this: "McDonald's, McDonald's, Kentucky Fried Chicken and Pizza Hut!"

The new entrants' teacher had taught it to them while they were waiting for the Ronald McDonald Road Safety Show, a simple presentation aimed at junior primary children. Ronald McDonald was there with a nice policewoman.

Does anyone else feel as I do about this - that my child must not be taught to equate road safety and hamburgers? Who on earth thinks it's all right to take new entrants - children just separated from their mothers and swallowing whole the new rules all around them - and instruct them this way?

Everybody knows that a child being hit on the road is one of a parent's worse fears. The children know it, and in their first years at school when they are missing their mums, here comes Ronald McDonald to protect them. Why is this sort of salesmanship fine with the Ministry of Education and Police?
\end{abstract}

(Nannestad 2003)

Apart from the obvious issue of direct marketing to children in a 'captive environment', other ethical concerns need to be debated. Corporate messages are actually taught as a classroom lesson, and often accompanied by product samples or vouchers. Stephen Day, researcher NZEI, mentioned particularly the transmission of the hidden messages and values, the vulnerable position that teachers are placed in terms of ethical and judgement calls regarding these schemes and programmes, and the workload imposed by the administration required. He asks "what do companies expect in return for their investment?" (Day 2003b).

\footnotetext{
${ }^{94}$ Also contracted ICT services - increasing proportions of school education budgets are being devoted to information technology, provided through companies making software and educational products.
} 
Corporate educational development companies internationally are in the business of producing curriculum packages in behalf of corporate sponsors, for example Sponsored Educational Materials (SEMs) (Shaker 1999a). While some blatantly use classroom teaching material to promote product use and familiarity there are other more problematic examples of corporate bias disguised in school lesson packages, such as Dreamkits history classes and Bank of Montreal's Money Investment Kit (Shaker 1999a:8). Web-based curriculum materials are also available on-line, along with the marketing and sales messages. ${ }^{95}$

The National Union of Teachers (NUT) in the UK has begun a campaign of non cooperation over the "unprecedented increase in the use of commercial materials ${ }^{96}$ in schools" (Slater 2003:11). NUT believes such deals undermine teachers' ability to educate children about the dangers of exploitation.

Commercial initiatives are establishing themselves as reputable 'educational' initiatives by providing television channels for schools, for example Channel One in the US and Youth News Network (YNN) in Canada. These daily programmes include frequent commercial advertising, providing advertisers "an absolute guarantee that they are reaching their target audience, because children under the age of 16 years are required to be in school. They cannot leave the room. They cannot turn the channel. They cannot adjust the volume." (Shaker 1999b:2).

A study ${ }^{97}$ of effects of Channel One suggested that regular watching "reinforces materialist attitudes" (Shaker 1999b:2). Apart from the overt commercialism, we need to

\footnotetext{
${ }^{95}$ For example: "the Great Chocolate Experience II begins with telling teachers to purchase enough packages of M\&Ms for their class - students will learn how to graph the results of how many M\&Ms of each colour are in each package" (Shaker 1999a:13).

${ }^{96}$ UK companies now spend an estimated 300 million pounds a year promoting brands in the classroom (Slater 2003:11).

${ }^{97}$ In the study by Greenberg and Brandt students who regularly watched Channel One were also more likely to agree that:

- Money is everything

- A nice car is more important than school

- Designer labels make a difference

- I want what I see advertised

- Wealthy people are happier than the poor

(Shaker 1999b:2).
} 
be concerned about how the messages of both the commercials and the current events broadcast are reinforced in the classroom teaching. The research suggested that the news programme was 'educationally unimportant'. These commercial programmes, targeting underprivileged schools because they are least able to refuse the contracts offered, "do not contribute to an equal, quality system of public education" (ibid). Webbased marketing is also a feature of these packages, along with computer suites and 'educational' software.

The impact of the school environment as the setting for delivery of these advertising messages can not be ignored. The classroom is where we learn and therefore provides an "environment in which children respond more openly and easily to questions and stimuli...and the most effective place to influence behaviour and attitudes" (Shaker 1999b:8). Schools are trusted institutions in society and thus the school environment itself reinforces the legitimacy of the message taught within it. Selling access to students to advertisers undermines both the nature of public education and the integrity of the school.

In the global context the commercialisation of education is evident in the world marketplace. World Education Market (WEM) is unambiguous about its role, promoting itself as

...the premiere international marketplace that brings buyers, government decision-makers and leading institutions together with world-class suppliers of the best and latest in content, technology and expertise...WEM puts you in touch with potential buyers, suppliers, producers, publishers, distributors, or partners for sales, marketing and distribution, for product development, for technical support, localisation and successful market entry into new territories...

WEM web-page (World Education Market 2003)

WEM hosts annual conferences to showcase educational products and services internationally, to provide opportunities for the education industry "to network and develop business partnerships... [and] to shape the future of education" (Nelles 2001:98). The World Bank is also actively promoting market opportunities and resources 
to support transnational companies into education markets, particularly in developing countries. $^{98}$

The tensions around what some perceive as 'the business takeover of schools' is simultaneously a concern about GATS: the greater the business involvement in schools, the more they are opened up to GATS and international markets (Rikowski 2003). The European Round Table of industrialists (ERT) is actively lobbying for progress in liberalisation of trade education services in the current GATS negotiations. Their goal for business to gain greater control of education is very clear; according to the chairman Peter Sutherland "[r]esponsibility for training must be assumed by industry once and for all...education should be considered as a service to the economy" (Kalafatides 2001:3).

\section{The role of education for nation building and identity formation}

In this section I discuss how trade agreements and the market approach may influence and distort our traditional understandings of education services. In particular I focus on the role of education in terms of nation-building, citizenship, identity formation and the influences which shape the culture and values of New Zealand education.

Education provision within the Fraser/Beeby settlement linked conditions of universal access to the rights of citizenship. For the 50 years following, governments

saw economic, cultural and social investment as a principal tool of nation building. To achieve this outcome, the government had to play a primary role in policy, funding and delivery. One result, the modern nation-building university, served the diverse and balanced goals of promoting science and technology, human capital and social democracy

(Kelsey 2000b:1)

Under this settlement, these same principles applied throughout the national system of education which sought to secure "social cohesion through a notion of citizenship as a

\footnotetext{
${ }^{98}$ The WB Edinvest database provides market research in school management, student exchange programmes, student loans, 'indigenous education', assessment tests, educational support services, distance learning; Alliance for Global Learning, a WB initiative co-sponsored by multinationals such as corporate banks JP Morgan and Goldman Sachs, consultancy form Ernst \& Young and IT companies 3Com and Sun Microsystems, "finances IT rooms, trains teachers and works with governments and the private sector to develop intervention programmes" (Kalafatides 2001:4).
} 
form of social contract" (Robertson, Bonal, and Dale 2002:4). The assumption is that education systems are 'services'. The notion of service involves personal and social relationships traditionally embedded in localised communities and societies. They "serve purposes that are intrinsically social, as well as environmental, cultural and economic" (Kelsey 2003b:267).

Citizenship as a medium of democratic governance is promoted in the Millennium Development Goals (UNDP 2003). Education systems play an intrinsic role in the creation of citizens, cohesion of societies and communities, and creation and reproduction of identities (local, national and cultural). Education has, for long periods of history, been a mechanism for social and cultural control over indigenous groups. However education has also been central to the linguistic and cultural renaissance of indigenous people world wide.

Particularly since the 1970's in New Zealand Maori have increasingly asserted processes of revitalisation of language, culture, knowledge and teaching methods. Kohanga reo (early childhood education language nests) and kura kaupapa Maori (schools) not only teach Maori language and knowledge, but also encourage empowerment, cultural identity and Maori development. These institutions are fully embedded in their social, political and cultural context. "Education in this context is not only about acquiring knowledge. It is also about the re-positioning of indigenous language and culture at the centre of education, rather than as an add-on" (Sullivan 1998a:3).

The primary school curriculum locates its centre within New Zealand as a nation. It also acknowledges the Treaty of Waitangi and aims to create a bicultural society. The focus is on children as citizens and the school's role in nation building.

The reshaping of the New Zealand state by the ideology of free market has emphasized a conception of national interest that has been progressively more narrowly interpreted in terms of economic success. One of the implications of recasting education as a tradable commodity is the shift in focus from nation building to economy and market building, which has implications for the nature of education itself. The free market education system, combined with a narrow focus on education for economy building, 
undermines the educational foundation stones of democratic societies. Its aim is to meet the needs of the job market by providing trained individuals for specific sets of jobs. But this is to the detriment of free-thinking, humanistic philosophies based on the notion of a social contract, which regards human beings as being capable of social responsibility rather than merely acting in pursuit of self-interest

(Sullivan 1998a:3)

This shift away from this responsibility for national identity embedded in a national system is reflected in the changes in education governance. At the sub-national level this is manifested in the reforms of the late 1980s that restructured governance, management and accountabilities in education. These reforms relied on economic rationalism, centralism ${ }^{99}$ and public choice, and ignored the complexity and interlinked nature of the social and economic problems and both the collective needs and pluralistic nature of New Zealand society.

The outcomes, according the Macpherson "violate basic principles of 'good government'. The worsening inequities contradict the principle of distributional justice. Disconnecting personal outcomes from national social and economic progress breeds alienation" (Macpherson 1998a:2). The message is that a market focused education system is failing in its nation-building responsibilities. The market detached from its societal context has devalued equity, democracy, social mobility and emancipation. From the perspective of concerned educationalists, the redress must begin with the recall of the notions of citizenship, pluralism, social contract and social cohesion as a nation. As Macpherson states

This means starting where we began, as a nation. The first article of the Maori text of the Treaty of Waitangi exchanges governorship for partnership in nation-building. The second article guarantees the right to define what is significant and valuable, and to hold custodial rights in perpetuity. The third article guarantees civil rights, that is, to full participation in society, while the fourth specifies religious and cultural freedoms

(Macpherson 1998a:2)

At the supranational level this shift in education governance is manifested in the globalised competitive marketplace. Here the conditions are being created for further disembedding of educational activity from its nationally regulated domain and potentially

\footnotetext{
${ }^{99}$ Referring here to the centralist role of the Ministry of Education in policy formation, and systems of accountability.
} 
"[establishing] a new set of global rules...for the governance of education within national territories" (Robertson, Bonal, and Dale 2002:11). Specifically Robertson et al are referring to "the attempt to rearticulate the nature and form of education and its governance through GATS to make education systems and education provision within nation-states more amenable to a global [capital] accumulation strategy" (Robertson, Bonal, and Dale 2002:5) which give advanced states a comparative advantage through their development of 'knowledge economies'. The commitments under GATS and other international trade imperatives pose constraints and limitations on the government's ability to control their own education policy choices (Dale and Robertson 1997).

'Nation-building' implies a shared understanding of social, political, cultural and material aspirations and norms. A 'nation' is a construct, an 'imagined community' (Anderson 1991). This requires us to know what kind of nation we are seeking to build. "Generally, however, there is little recognition in New Zealand, of the concept of a New Zealand nation. If it is mentioned at all, it is disparaged. The cultural-cringe, dependency approach [a relic of colonialism] is still commonly heard" (Jesson 1999:26).

At any particular time the concept of national identity and nation-building goals reflect the interests and values of the hegemony. New Zealand's education system has historically reflected a colonial, mono-cultural and Eurocentric view of the nation (Kelsey 2000a). One of the goals of the reforms was to redress this weakness to provide greater opportunities for pluralism through community involvement and choice in education policy and practice. In fact this claim was specious; the market model reforms offering 'choice' served rather to impose an alternative hegemony, one of "society as a network of interacting markets within a global economy, and the central human value as selfmaximising individualism" (ibid: 13).

Education's 'nation-building' role has become part of the rhetoric of the current labour government. This was reflected in the terms of reference for the Tertiary Advisory Commission "Nation-Building: Lifelong Learning in a Knowledge Society" (Maharey 2000). The current Labour government platform of a knowledge 'society' implies a 
broader understanding of the value, acquisition and application of knowledge by all members of society than the limited focus of the knowledge economy. ${ }^{100}$

This 'nation-building' policy platform however lacks the guidance of explicit principles. It is also hugely difficult to implement given the changes in the shape, culture and spirit of system as a result of structural and managerial changes of the free market approach which lead to a loss of intellectual and institutional capacity. ${ }^{101}$ The language that sets the scene for current education priorities embraces the rhetoric

[e]ducation provides self-esteem and a sense of identity....gives [people] a chance to play an active part in their community... also helps to shape our unique culture and the way we live within our environment...is at the heart of what it means to be a New Zealander... plays a crucial role in supporting te reo and tikanga Maori, and providing opportunities to help access te ao Maori, the Maori world

(Mallard 2003:1) $)^{102}$

But the priorities are still primarily economic focused to be achieved through an explicitly managerial culture focused on outcomes and performance. Furthermore there are now significant players ${ }^{103}$ within the education system with vested interests in ensuring the continuation of the commercial market ideology. And indeed the nation-building rhetoric is not carried consistently across all sectors of the ministry of education or through to related areas of other government departments. For example MFAT is still promoting the expansion of the knowledge economy, as a means to reduce the reliance on agricultural exports (MFAT 2003e).

This continued commitment to commercial and deregulated environments and priority to the expansion of the education export education industry is problematic to a nationbuilding role for education. New Zealand's export education has focused particularly on the opening up of Asian markets. The economic imperative has contributed powerfully to

\footnotetext{
100 The National Government in 1999 sought to create a knowledge economy (Ministry of Commerce 1999) with a focus on technology and e-learning. The concept was commercially driven, "detached from the social, cultural, indigenous and political context in which the economy operates" (Kelsey 2000a:10).

${ }^{101}$ Kelsey refers to the 'colonisation' of the government education agencies by an almost singular focus on the design and implementation of the market regime, and to great losses to the intellectual and physical infrastructure and institutional memory throughout the system (Kelsey 2000a, 2000b).

102 See also (Fancy 2003b)on policy directions for secondary schools.

${ }^{103}$ I refer here to pro education trade lobbies such as Education Forum, Education New Zealand and the Trade Liberalisation network, business and corporate interests in disaggregated parts of school/ education services, export education industry, both the private sector and also major players in the public education institutions with significant FFPS and who have embraced other commercial practices and opportunities.
} 
the pressures to reduce non-official discrimination (e.g. cultural barriers) to trade. It has also driven what Dale and Robertson have conceptualised as 'resiting' the nation whereby the "New Zealand state has sought to redefine its identity in terms of a new pole of political and economic growth and power: the 'Asia-Pacific'104 (Dale and Robertson 1997:213). While national economy building is an important dimension of nation-building, the danger lies in the appropriation of the rhetoric of nation building to further the market oriented agenda. "[N]ation building, within a system driven by the commercial and ideological imperatives of the economy, is ... a contradiction in terms" (Kelsey 2000b:5).

This economic premise "challenges the very notion of education as a nation-building social democratic structure, to which people have 'rights"' (Gordon 1999:248). This issue is taken up by Kelsey who also brings this Gramscian perspective to her discussion of the role of education in establishing and maintaining the hegemony of dominant ideologies (Kelsey 2000a). She views the current political rhetoric of 'nation-building' as masking further adjustments to the market-focused system, and calls on educators and the public, as citizens, "to take the lead in debating not only the future direction of the education system, but the kind of 'nation' to which we want ourselves and our children to belong" (Kelsey 2000a:25).

Gordon promotes a new commitment to a nation-building education system, which she claims would require "a high level of central planning, stronger partnerships between state agencies and schools and Tino Rangatiratanga" ${ }^{105}$ (Gordon 1999). Participation is at the heart of how education and development occur (Daun 2002:2). Macpherson calls for national goals for education to be founded on a policy and process of bi-cultural nation-building, which reflects the plural nature of 'public interest' (Macpherson 1998b, 1998a). Values fundamental to biculturalism include self-determination, empowerment and cultural pluralism (Thomas and Nikora 1992). These values need to be guiding principles of educational policy, yet their implicitly embedded social and culture nature is diametrically contrary to the detached values of commodity markets.

\footnotetext{
${ }^{104}$ An imprecise and connotative identity, excluding significant territories of these regions and defined more by transnational economics than geography (Dale and Robertson 1997:213-214).

105 "Tino Rangatiratanga provides the basis for a future system of self governing Maori Education within a model which mixes autonomy with state responsibility" (Gordon 1999:253).
} 
Early childhood services have a vital function as 'forums in civil society' - providing, both within and for communities, "a space for activities and relationships, enabling the coconstruction of knowledge and identity" (Dahlberg, Moss, and Pence 1999:76). This intrinsic role in terms of the construction of identity and social knowledge is acknowledged in Te Whariki in its founding aspiration for children:

To grow up as competent and confident learners and communicators, healthy in mind, body and spirit, secure in their sense of belonging and in the knowledge that they make a valued contribution to society

(Ministry of Education 1996)

Te Whariki is envisioned as a woven mat with four principles - empowerment, holistic development, family and community and relationships; interwoven with five strands well-being, belonging, contribution, communication and exploration. It requires the education programme to provide opportunities for children to learn about New Zealand's dual cultural heritage and provide resources and activities that reflect the Maori language, culture and values.

Yet again there is the inherent contradiction between these aspirations and neoliberal market model. Hamer emphasizes a need to move away from new public management (NPM) approaches as essential to achieve such a goal, noting "that when early childhood services operate within a competitive market they are less likely, and possibly less able, to place community concerns as their foremost purpose" (Hamer 2002:40), and therefore as Dahlberg et al also note, early childhood services "situated in the economic sphere...cannot also be forums within civil society" (Dahlberg, Moss, and Pence 1999:75).

Jackson sees the 'commodification' requirement of GATS "as an increasing assault on some quite fundamental Maori values... [and] in that sense GATS is a continuation of the same colonising belief system as the idea of preemptive attack... [commodification] assumes that even the most valued treasures of a people can be redefined in terms of a monetary value and then taken over by someone else" (Jackson 2003:46). He highlights the potential risks of specific Maori kaupapa being seen as barriers to foreign companies and therefore challenged under GATS.

Efforts to re-focus the role of education in nation-building, identity formation and transmission of cultural values are severely limited by our existing GATS commitments. 
Rosenburg claims that "despite public assurances that the Treaty of Waitangi would be protected, the government is still relying on the current inadequate commitment which provides protection only to commercial and industrial activities of Maori" (Rosenburg 2003:1). GATS treats education solely

as a commercial, tradable commodity. There is no recognition of its role as a means of nation-building; a local storehouse of knowledge; the vehicle to transmit culture and language; the pre-requisite for a vibrant democracy and a contest of idea; a source of innovation and change

(Kelsey 1999:1)

This chapter has addressed some wide ranging issues arising from the neo-liberal agenda that prioritised economic goals, commodified education and created education markets. The next chapter returns more directly to the rules and processes of GATS, drawing on the issues and trends that emerged in this chapter to anticipate some of the possible consequences of GATS and demonstrate how GATS locks in this narrow neoliberal perspective of education that excludes its non-marketable value and limits the government ability to make policy to incorporate these values, if such policy could be perceived as discriminating against foreign providers or as unnecessary barriers to trade. 


\section{Chapter Six}

\section{DISCUSSION AND CONCLUSIONS}

In this chapter my objective is to revisit the main ideas and issues discussed in earlier chapters and to link them more specifically to anticipating implications of possible consequences of GATS for education in New Zealand. The findings are discussed in relation to their implications for the main 'social actors' in education, students and families, schools, teachers, government, communities and society, and in relation to the position of education in current policy and socio-political context. The fundamental argument weaving through the themes discussed and the recommendations for public debate, policy review and further research focuses on the need to address the following central questions:

- 'where are we going?' and 'is it desirable?'

- 'whose interests count?' and 'how can we expect these interests to be determined?'

- 'What do we value about NZ education and who judges?'

- 'what are the main risks for the future?' and 'what should be done?'

\section{Discussion of research findings}

Proponents of trade liberalisation of education services are pursuing greater commitments to market access for education exports, while opponents see GATS as increasing the power of multinational institutions and commercial objectives at the expense of public education providers, educational objectives and democratic control over educational policies (Ziguras 2003). 
The potential implications of GATS for New Zealand education relate to long term simmering issues of marketisation. The NPM and PCT approaches of economic rationalism opened the door to free markets in education, relying on market forces such as competition and the power of consumer choice (Codd 1999). These neoliberal reforms have already been significantly and powerfully challenged for their effects in deepening social inequities. Furthering this agenda in the international arena through GATS will exacerbate these impacts. The review of the trends and issues emerging out of the reforms in Chapter Five provides some central themes concerned with marketisation that can provide a basis to extrapolate further consequences and impacts that may arise with the imposition of international trade rules and to identify questions 'not yet asked' within the sector.

Ministry of Education reports and policy papers, discussed in Chapter Three, view this marketisation process as 'natural' implicitly assuming that growth in export education is positive and should continue. Their attention is focused on trade questions and challenges which affect the industry's reputation and market development opportunities, such as difficulties regarding the recognition or varied qualifications, quality assurance and accreditation systems, and issues of care for FFP students. Policy recommendations are aimed at overcoming these. The broader implications of trade in education on domestic education for New Zealanders are not given more than a cursory glance in such discussions and policy processes, on the assumption that there are no significant negative impacts.

The priority given to export education imperatives is illustrated by the comments of a Manawatu school representative reflecting on the need for "changes in the pedagogy in our schools ... [and] in goal setting [to meet the new accountability requirements regarding international students] (Evening Standard 2002:2). While we can hope that these changes may enhance learning opportunities and achievement for all students, the issue is that the focus and priority for goal setting, teaching practices and curriculum is increasingly directed to meet the needs of export trade, rather than intrinsic educational and pedagogical objectives, and local cultural needs and dimensions.

Other questions and issues raised in Chapter Three yet to be addressed by the Ministry, include the extent to which the volatility of the export education market affects the 
performance of the New Zealand (public) education system and its delivery to domestic students, and the consequences of New Zealand becoming effectively dependent on FFP student income for the maintenance of an acceptable level of education provision.

\section{How GATS may affect the ability of future governments to shape the education system and its service 'markets'}

The 'locked in' nature of the GATS process is a principal concern of critics who claim it undermines the rights and freedoms of individual democratic societies. This research has highlighted the growing tension between the rights of societies and governments to determine the rules that govern all companies established within their borders and international trade rules promoting the 'rights' of companies. GATS assigns new rights to foreign companies involved in education services which ensure they have access to the market with no 'unnecessary' barriers or conditions imposed by New Zealand's domestic regulations, policies and systems. This test of necessity will force the education system at all levels of governance to demonstrate compliance in all policies and practices and establishes the priority precedence of commercial over social principles.

Although the government has played down the risk of GATS to public education by saying that only private education is covered by GATS the implications are far more wide reaching. Trade in services as defined in GATS is so all-encompassing that many initiatives and activities within the public education system, quite apart from recruitment of FFP students which most institutions understand is a competitive international trade activity, are already within its scope. In many of these, educators, ECE governance bodies and school BOTs and policy makers, are unaware of the trade implications of their decisions. Many services within the education system are not restricted to the 'educational services' classification, but rather fall under other GATS classifications, such as "Business Services", in which New Zealand has made unlimited specific commitments. 
Disaggregating parts of education services has provided opportunities for public school BOTs to outsource services through private contracts (Rikowski 2003; Kelsey 2003a)\}. ${ }^{106}$ NZEI advised that a number of support services and special education services are already provided through private contract and speculates on the possibility of further services such as the National Library Service that could also be restructured and contracted out. All such services are exposed to competitive tenders from foreign providers, without discrimination and are now directly subject to GATS rules and dispute settlement mechanism. ${ }^{107}$

\section{Grieshaber-Otto and Sanger note that:}

Classification issues involving education are likely to become increasingly contentious. In a paper released in May 2002, the Liberalization of Trade in Services Committee of London explicitly distinguishes between 'core' and 'ancillary' education services, arguing for increased liberalization of the latter within the GATS

(Grieshaber-Otto and Sanger 2002:115)

\section{WTO Services Division contracted with a private company, the Global Alliance for}

Transnational Education "to document worldwide policies that discriminate against foreign education providers". Barlow asserts that "the results of this study will be used to pressure countries with public education systems to relinquish them to the global privatised marketplace" (Barlow 2001c:41).

\footnotetext{
${ }^{106}$ Examples of such services include cleaning contracts, property maintenance, facility management and leasing, human resource recruitment and performance management services and packages, management consulting services, contracted services for the development of teaching materials, curriculum, assessment and evaluation packages, audio-visual materials, printing and publishing services, financial management, data processing and administration, software packages and ICT services, secretarial services, advertising and marketing services, event management and conference services, food and catering services, libraries, tutoring services, recreation, cultural and sporting services, transport services, research and development, counselling services, specialist teaching services.

${ }^{107}$ For example existing GATS restrictions could apply to the following examples, adapted from (GrieshaberOtto and Sanger 2002:138-140):
}

- Teachers promoting extra-curricular tutoring through private tutoring agencies, which may be local franchises of foreign owned businesses

- Use of internet-based courses and activities; noting that locally designed programmes compete with international suppliers. Under GATS, privately offered distance education programmes should be recognised as having equivalent credit towards school qualifications

- School BOTs become suppliers of a commercial business service when they sell advertising space in newsletters and on school property. For example, determining that the advertising space will not be granted to soft-drink vendors may be challenged as a 'trade barrier'. Under the transparency rule of GATS, other WTO members must be notified

- Under GATS most favoured nation rule educational institutions must provide the same level of access to all foreign-based providers for any service contracted out to a local company, prohibiting discriminating against a transnational or foreign firm bidding for the development of curriculum or assessment packages, resource development and education support services. 
Educational services primarily concerned with recreational or cultural activities are contained in the Recreational, Cultural and Sporting sector. ${ }^{108}$ The AUS submission on New Zealand's GATS offer asserts that these should be treated in the same way as other education. It should be noted that the New Zealand negotiating proposal previously tabled with WTO in 2001 does request this reclassification (WTO 2001b).

GATS transparency rules apply to all education policy and regulation and are aimed at ensuring quality and consumer protection. This would appear at face value a positive accountability measure. However this becomes a highly contentious matter when put in context of the issues created by NPM systems and debates about what constitutes appropriate mechanisms for transparency and accountability in education, along with consideration of whose interests are to be met by transparency. For example "WTO's view of appropriate transparency focuses strongly on the rights of trans-national enterprises to information they might need to facilitate their business, whereas NZEl's view of transparency would focus more upon the rights of staff, students and parents to information about the education in which they are engaged" (NZEI 2003:6).

Defenders of GATS refer to the preamble in the Agreement which recognises "the right of members to regulate... in order to meet national policy objectives" (WTO 2003b) to refute concerns that aspects of GATS articles represent an encroachment on national sovereignty and governmental authority over publicly-funded services such as education (Sauve and OECD 2002). Making the distinction that "progressive liberalisation, not deregulation, of services is the goal of the GATS", Sauve firstly acknowledges the importance of regulation in services such as education, but then admits that "GATS can affect the regulatory conduct of member countries... [justified as] necessary to reaping the full benefits from international co-operation in a rules-based system" (ibid: 62). This and the voluntary nature of specific commitments are deemed sufficient reason by promoters of GATS to dismiss the concerns of critics.

\footnotetext{
108 "This includes both the academic study and teaching of sport and recreational activities [as formal courses and as extra-curricular activities]....and the instruction of groups or individuals in the practice of a sport, which includes activities in the recreational facilities available" (AUS 2003b:18).
} 
In must be remembered that the right to regulate is subject first to the overriding requirements to abide by the MFN, transparency, market access and national treatment rules and that all regulation is potentially challengeable as creating unnecessary barriers to trade. Identifying barriers is significant in itself, illuminating the tension between those who see the 'barriers' as key elements of a public education system that need to be maintained and those who see them as impediments to trade (Knight 2002c).

The current negotiations to formulate new rules regarding domestic regulation potentially allow global trade rules to supercede national policies and WTO, through its disputes procedures, to oversee domestic processes and standards to ensure they meet those global rules. The draft WTO Ministerial agreement prepared for the Cancun negotiations, September 2003 called for commitment

to intensifying our efforts to conclude the negotiations on rule-making under GATS Articles VI:4, X, XIII and XV in accordance with their respective mandates and deadlines....

We reaffirm that the negotiations shall aim to achieve progressively higher levels of liberalisation with no a priori exclusion of any service sector or mode of supply...

Paragraph 6 quoted in (Cooke 2003)

The pressure for progressive liberalisation in on-going negotiation will continue for two core reasons. Firstly GATS is perceived as a mechanism to assist efforts to internationalise curriculum, harmonise qualifications, policy guidelines and corporate cultures and structures to facilitate international education trade, deregulation and privatisation of segments at least, of education sectors. Secondly education will become part of a general negotiation game where governments may have to open up access to the education market in order to access to other markets.

Speculating on a global educational marketplace governed by global trade rules raises a number of crucial questions which need to be explored:

- How might national and local governments use regulations to protect and promote public interests, interests of special groups, rights of diversity within communities, when for example policies to protect the cultural diversity of communities, minorities and countries could be considered obstacles to trade?

- Could locally specific content in curriculum guidelines be challenged as more trade restrictive than necessary? 
- How might education address its roles of constructing national identity and social cohesion and ensuring cultural rights and expression?

- What are the adverse affects in terms of accessibility and equal opportunity?

\section{Exposing New Zealand's education system to foreign providers: what could it mean?}

In this section I draw on discussions in the literature to explore the risks of opening New Zealand's domestic education system to foreign providers. The market access principle of GATS means the government can not discriminate between domestic and foreign suppliers. Once commitments have been made, it is very difficult to introduce protectionist measures in the future.

The MFN principle covers the licensing and registration of early childhood centres and private schools for purposes of public funding and the registration and certification of teachers, permitting a foreign provider to establish here as a private school or early childhood centre as long as the criteria are met. As already documented, New Zealand has committed its early childhood and schooling education 'markets' to foreign providers on the same basis as domestic private providers, which commits the government to subsidising foreign private providers on the same basis as New Zealand private schools and early childhood centres.

In April 2003 Kidicorp ${ }^{109}$ announced a deal to purchase 22 childcare centres (The New Zealand Herald 2003). This demonstrates the possibilities open to any transnational chain of early childhood centres. There is both a significant absence of research and commentary addressing the potential impacts of foreign providers emerging in the New Zealand education market and absence of mechanisms instituted to subsequently monitor and advise on its consequences.

\footnotetext{
${ }^{109}$ Kidicorp group Ltd is a New Zealand childcare company that recently listed on the New Zealand stock exchange, backed into the shell of Feverpitch International, a gambling software venture. Kidicorp has a combined licence capacity to care for over 2,000 children and is New Zealand's largest operator of private early childhood centres.
} 
The disparities of the competitive model discussed in Chapter Five are likely to increase with greater exposure to international markets. Foreign providers are not likely to adequately address equity and access issues. Studies in ECE have shown a significant difference between private provision and community-based provision. Trans-corporate private companies entering the market are likely to exasperate polarisation, inequalities and other social consequences a 'winners and losers' environment. The impacts of market forces could also to create greater instability in the education system as a whole.

Integrated Schools are privately owned, but operating under the requirements of the Private Schools Conditional Integration ACT. As private education institutions these schools are fully committed in New Zealand's schedule. Given the ease to which schools can become integrated, for example the 'Unlimited' school that recently integrated in Christchurch, it also allows foreign providers the possibility of foreign access to the full operational and salary funding available to integrated schools. For example, Edison schools, from the US, and SERCO, from UK, could arguably demonstrate that they are of a similar nature to Unlimited, and thus to deliberately discriminate against them would be in breach of GATS (Day and Norman 2003:1). NZEl is concerned that

[t]he Minister of Education's ability to either use his or her discretion to refuse to integrate some foreign owned private schools or to change the integration legislation so that he or she can protect the present situation is constrained by free trade agreements that prevent discrimination against foreign providers of education

(NZEI 2003:8).

The number of private tertiary institutions registered with NZQA has not changed significantly since 1994 , and there are as yet no foreign private universities operating in New Zealand (Ziguras 2003). Foreign institutions must register with NZQA to receive government funded subsidies and to for their programmes to be accredited (quality assurance system).

Ziguras concludes that the size of the registered private sector, in New Zealand tertiary education at least, "has been primarily influenced by the extent of public funding they receive, and this is not bound ${ }^{110}$ by the GATS" (ibid). I suspect that the size of the New

\footnotetext{
${ }^{110}$ Under Article XIII - GATS national treatment and market access principles do not apply to government procurement; i.e. the government is not obliged to fund the private sector to the extent of the public sector, however subsidies offered to the local private sector must be available to foreign providers on the same terms and conditions.
} 
Zealand market, along with the reputation and competition from public institutions that a foreign provider would be up against, have also been deterrents.

However "[a]t present, there is no requirement for transnational providers to meet New Zealand quality standards unless they are seeking public tuition subsidies or seeking to have their programs recognised under the National Qualifications Framework" (Ziguras 2003:95). Current legislation allowed anyone to set up training schools without NZQA registration, provided their courses are less than three months duration. Kelsey notes that New Zealand "is becoming a significant education importer with the presence of foreign education companies and the franchising of overseas courses to New Zealand firms and institutions" (Kelsey 2003c:46).

A Christchurch developer plans to build an educational campus and shopping centre in the centre of Queenstown, and at the time of the news report was in discussions with Australian and US universities (NZPA 2003a).While there are some positive examples Kelsey also quotes less scrupulous and desirable examples both in terms of business practice and ethics and pedagogical value (Kelsey 2003c). Many private English language institutions in New Zealand are foreign owned. The failure of the Modern Age Institute in 2003 revealed unscrupulous financial practices, unpaid debts and missing Trust $^{111}$ funds (Bolland 2003b).

There is also controversy over how GATS will affect the balance of mix between public and private provision in each of the education sectors (Bolland 2003b). There is ongoing pressure from the private school sector to gain a greater share of the market, through increased subsidies. ${ }^{112}$ The context of GATS exacerbates public sector concerns over the public funding of private education. Under our current commitments, the government can not restrict foreign private providers from establishing primary schools in New Zealand without offering the National curriculum and still be eligible for private school subsidies. The drain on public funds has the potential to weaken the public schools system, fueling the speculation "that privatisation for schools in wealthy communities

\footnotetext{
${ }^{111}$ NZQA requires training organisations to hold independent Trust funds to cover student fees and homestay costs.

${ }^{112}$ In reference to the National Party education policy paper September 2003, QPEC comments that "National claims to want to make private schools more accessible to low and middle income earners and yet the policy direction proposed will simply put more money in the coffer of wealthy private schools" (Cooke 2003).
} 
appears a relief' (Minto 2002:2). PPTA has expressed concern regarding foreign owned private schools, with resources of large corporations behind them, competing for students and staff with New Zealand public and private schools, while receiving public funded subsidies (Keen 2003).

Putting an opposing view the Education Forum asserts that "foreign providers competing with New Zealand education providers is not necessarily a bad thing... if they bring topclass, world-leading education, our children are the ones who will benefit and surely that is something we should all welcome" (LaRocque 2003a:1)

Teacher education in New Zealand is $33 \%$ privately funded. Of the 30 ECE teacher education providers 6 are privately owned and of 22 primary teacher education providers 2 are privately owned. Government policies and subsidies that favour domestic providers over foreign providers are potentially in breach of GATS. If the Teacher Registration Board or Teacher Council recognises New Zealand colleges of education qualifications but not those of foreign owned providers this would be perceived to be a trade barrier. The current government wants to limit the number of providers and reduce competition, however this may not be permissible under GATS. They also can not distinguish between existing domestic providers and new foreign owned teacher training providers (Clarkin-Phillips 2003).

Attempts by the present government to remove some of the elements of competition from the early childhood and tertiary sectors are restricted by GATS. Regulations must meet the 'least restrictive necessary' test, making some measures to introduce regulatory mechanisms to guarantee quality and consistency impossible (NZEI 2002a).

Because GATS is a relatively new, untested and complex trade agreement, there is considerable controversy around its potential to threaten public funding and national quality regimes, but no empirical evidence to date. However there is 'worst case scenario' concern that for example public funding directed to public institutions could be interpreted as an unfair subsidy by private/ foreign providers and that therefore these subsidies would have to be made available to private providers or that public funding would be decreased (Knight 2002a). 
Although not yet tested, it could also be argued that the New Zealand public education system is already tied into GATS because the principal -agency approach of government funding has established a commercial or semi-commercial system of contracts.

The distinction between private and public institutions has become blurred in recent years. Wylie identifies five significant ways this is occurring:

1. The ease with which private schools can integrate ${ }^{113}$ if they choose

2. The marked increase in government funding for private schools, and the form it has taken

3. The individual voucher scheme (Targeted Individual Entitlement Scheme) $)^{114}$

4. The way some state schools have started to behave as private schools and

5. The way some state schools have acted in their own self-interest rather than as part of a national system ${ }^{115}$

(Wylie 1999a:102-3)

To this list we can add the changing sources of funding for state schools. A 2000 report reveals the relative decline over time, in the share of government funding as a percentage of total revenue in state schools and the increasing contribution from local and non-government sources (ESRA 2000). ${ }^{116}$ By 1998, non-government funding (from fundraising, trading activities, leasing out school facilities for non-school activities, activity fees and investment income) was providing just over $12 \%$ of the total revenue for the school sector as a whole. For primary schools this represents an increase of $115 \%$ over the period 1992 - 1998. Without this additional non-government income (above the

\footnotetext{
${ }^{113}$ Since 1988 the integrated schools sector has had the fastest growth (Wylie 1999a). Integrated schools receive full government funding for teacher salaries and operational costs, but meet their own capital costs; this allows schools to charge parents for contributions to capital costs, activity payments, contributions to providing for the 'special nature' of the school, enrolment bonds etc, making the fees at some newly integrated schools higher than some private school fees. For example, Rathkeale College, Wairarapa, an integrated school, has day pupil fees of $\$ 3420$ p.a. and Lindisfarne College, Hawkes Bay, charges day pupils $\$ 4200$ (Quirke 2003b).

${ }^{114}$ Since 1996, this scheme offers children from low income families positions in private schools.

${ }^{115}$ There is growing anecdotal material indicates that some state schools have become more self-serving for example through enrolment schemes, school funded-buses, competitive marketing, increased voluntary donations ('schools fees') (Walsh 2003; Sheeran 2003; Wylie 1999a).

${ }^{116}$ In 1992 total primary school revenue was comprised $93.2 \%$ government grants and $6.8 \%$ nongovernment funds; by 1998 this had changed to government grants being $90.39 \%$ and non-government funds $9.61 \%$ of total revenue. For secondary schools were in 1992 government grants made up $90.91 \%$, non-government funds $9.09 \%$ and in 1998 the percentages were $84.75 \%$ and $15.25 \%$ respectively (ESRA 2000:appendices 2 \& 3).
} 
1992 level) "primary schools would now collectively be in deficit to the tune of $\$ 60$ million" (ESRA 2000:3). ${ }^{117}$

The new phenomenon of education management organisations has risen rapidly overseas. Examples from Canada, US and UK ${ }^{118}$ highlight the issues and how some impacts of commercialisation and GATS are inextricably linked and mutually reinforcing (Grieshaber-Otto and Sanger 2002). NZEI has expressed concern that commitments under GATS open the door to foreign franchise education companies that

may come here to 'milk the cow' of FFP students and the government will be required to resource them equally to schools. This provides a significant threat to the ability of the New Zealand government to continue to fully fund New Zealand's education system. It would undermine the government's professional standards, curriculum content and culturally specific resource allocation

(NZEI 2002c:4-5)

The question New Zealanders must ask is 'are we willing to accept the levels of 'homogenisation' of pedagogical approaches and the undermining of local institutional and educational cultures that could result?'

At the Quality Public Education Conference, 2003, Kelsey outlined how the notion of trade in services is interfacing with the next phase of restructuring of public education. In particular she discussed the public-private partnerships (PPPs) and private sector finance initiatives (PFIs) developing overseas ${ }^{119}$ which "will undoubtedly be here before long" (Kelsey 2003a:transcript notes). ${ }^{120}$ These initiatives are contractual agreements between government and private sector to finance, design, build and often also to operate facilities. The latter function may vary from property maintenance, security and

\footnotetext{
117 There is however another perspective on the increasing pressure to raise additional fund in schools. Day raises the possibility that schools have developed an assumption that they have to raise funds to survive which is not necessarily true. A combination of the imposition of a competitive entrepreneurial culture into the management of schools and the 'luxury' standards of technological equipment and 'suites' set by high decile schools have created expectations which do not necessarily improve the 'quality' of education (Day 2003b).

${ }^{118}$ Examples are discussed in Perilous Lessons (Grieshaber-Otto and Sanger 2002); background information is also available through NZEI, demonstrating how the situation could easily arise in New Zealand refer www. docushare.nzei.org.nz/dscgi/ds.py/get/file-9120/2002 and www.docushare.nzei.org.nz/dscgi/ds.py/get/file-10916/2003

${ }^{119}$ Public-private partnerships are on the increase as governments look for new ways to fund expensive infrastructure. The private sector interest is based on the low risk and guaranteed income associated with a public asset, while suiting government budget and financial accounting processes. (Sexton 2003).

${ }^{120}$ Transcript from recording of the presentation delivered at QPEC 2003 conference, Massey.
} 
facility management functions, through ICT services, financial management and other support services to the entire management of schools.

Kelsey cautioned educators and citizens to "anticipate what in five years time we might be confronting and how we might develop some pre-emptive strike in relation to those developments" (ibid). Overseas reports ${ }^{121}$ suggest PPPs "may not deliver the expected long-term benefits to the public. Supposed cost savings are disputed and there is also concern that such moves signal the beginning of more widespread privatisation of educational services, such a teaching" (Sexton 2003:12). ${ }^{122}$

In February 2003 the UK government announced plans to introduce competition for all new schools, i.e. requiring all local authorities (responsible for education in UK) to seek bids from private businesses, charities and parents' groups to run new schools. The move is intended "to break the dominance of local authorities... [and] the Secretary of State will decide whether the school should by run by the local authority or a private body" (Halpin 2003:1). The announcement has outraged teacher's unions who have responded "[that] education should be run for the benefit of children and not for the benefit of shareholders and company proprietors. There is no evidence that private companies provide a better service" (ibid: 1 ).

The benign and even flattering language of 'partnership' in public-private partnerships disguises the nature of power in these relationships. There is not authentic partnership in a commercial contractual relationship between a private interest and a public responsibility. Yet schools and their communities are co-opted by specious rhetoric such as this example from the Ethical Guidelines for Business-Education Partnerships,

Conference Board of Canada:

Business-education partnerships are mutually beneficial relationships between employers and educators that are designed to enhance the learning for students and other learners...most business-education partnerships are co-operative relationships in which partners share values, objectives, human, material or financial resources, roles and responsibilities in order to achieve desired learning outcomes

(Shaker 1999a:18)

\footnotetext{
${ }^{121}$ Refer to British Audit Commission Report, January 2003, cited in (Sexton 2003).

122 "At a 2001 workshop discussing NSW government's [Australia] green paper on public/ private partnerships, a representative of services multinational Serco said that private businesses should not be limited to 'non-core services'...teaching was given as an example" (Sexton 2003:12).
} 
When business involvement is acquired as a means to supplement public funding it creates "a dependent mode of supplication" (Kozol 1997:4). Because PPPs are contractual arrangements, the details are concealed by 'commercial- in-confidence' requirements. There are also concerns that PPPs will hinder educational aims and distrust that private companies will not always act in the interests of the school community. PPPs pose an unacceptable risk of market failure to core public services as experienced in the US with the financial collapse of Edison schools. ${ }^{123}$ The risks of market failure implicit in the free market and GATS paradigm are politically and ethically unacceptable for education services.

The culture of public education institutions has significantly changed as they "[adapt] to the role of entrepreneurs in a competitive education marketplace" (Kelsey 2000a:11). This impact of marketisation on the professional 'culture' of education referred to in Chapter Five, can not be ignored in considering the further consequences of expansion into international markets. NPM culture of perfomativity and managerialism, favouring universality of centralism over pluralism, will be cemented in as apparently the only way to ensure some control over standards of delivery by foreign providers. Efforts educationalists to introduce alternative, socially and culturally appropriate approaches to accountability and quality assurance based on around professional communities of learning will be more difficult to achieve. Such approaches would be hard to implement in the 'market environment' and could also be perceived as barriers to trade.

Concerns anticipating how trade liberalisation agreements threaten to erode public education have been most widely documented in literature from Canada. The first and most significant of these by Calvert (Calvert, Kuehn, and et al 1993) written following the North American Free Trade Agreement negotiations (NFTA) in 1993, emphasizes the potential threat of 'American imperialism'. Whilst the fears of the threats may appear overstated at this stage, it could equally be argued that they remain possible but have yet to be realised.

\footnotetext{
${ }^{123}$ Edison operates 150 schools in 23 states, however its shares crashed from a high of $\$ 21.68$ to less than a dollar on the stock exchange in 2002,resulting in bizarre measures being taken in schools (Day 2003a). The company survived by trimming back both the level of services and its growth strategy, and de-listing from the stock-exchange (Henriques 2003).
} 


\section{Implications for democracy}

This section briefly discusses the implications of GATs in regard to 'democracy' from two perspectives. The first considers the role of education in creating and maintaining a 'democratic society' and the second considers the nature of the processes of GATS and WTO. I start by acknowledging that the word 'democracy' has a series of contested meanings. Drawing on Nietzsche's view of a living, rhetorical language, the meanings given to the word democracy are firstly and foremost an assertion of power, and therefore provide an insight into whose interests are served in the expression of democracy (Bingham 1998).

In John Ralston Saul's definition democracy is a signifier of active citizen participation:

[lt is] an existential system in which words are more important than actions. Not a judgemental system. Democracy is not intended to be efficient, linear, logical, cheap, the source of absolute truth, manned by angels, saints or virgins, profitable, the justification for any particular economic system, a simple matter of majority rule or for that matter a simple matter of majorities. Nor is it an administrative procedure, patriotic, a reflection of tribalism, a passive servant of either law or regulation, elegant or particularly charming. Democracy is the only system capable of reflecting the humanist premise of equilibrium or balance. The key to its secret is the involvement of the citizen.

(Saul 1994:94)

Dahl argues that democratic participation develops out of the 'logic of equality', that all members are considered politically equal (Dahl 1998). Dahl promotes five essential criteria for democratic process: effective participation, voting equality, enlightened understanding, control of agenda and inclusion (full citizen rights). To have a democratic political culture, citizens and leaders must strongly support democratic ideas, values and practices. These are established and maintained through the institutions of socialisation, but particularly the education system through curriculum content, teaching methodologies and classroom cultures and equality of opportunities and outcomes.

Apple argues that "neoliberalism transforms our very idea of democracy, ${ }^{124}$ making it only an economic concept, not a political one" (Apple 2001:18). The idea of consumer as portrayed by

\footnotetext{
${ }^{124}$ Apple goes on to cite McChesney "to be effective, democracy requires that people feel a connection to their fellow citizens, and that this connection manifests itself through a variety of non-market organisations and institutions. A vibrant political culture needs community groups, libraries, public meeting places,
} 
the notion of 'consumer choice' is central to Apple's argument. Under neoliberalism, "consumer choice' is the guarantor of democracy... [and] thus, democracy is turned into consumption practices...the ideal of the citizen is that of the purchaser" (ibid: 39 ). In other words, the political concept of democracy is transformed into an economic concept. Democracy in this context is a signifier of capitalism. The ideologies revolving around economic determinism have also installed an strong sense of inevitability, so that whatever is defined as 'true' we feel obliged to accept as inevitable, which in turn has infected the citizenry with passivity.

The possibilities for democracy and participation of citizens in democratic processes are a direct ramification of the nature of the education system. Disaggregated and packaged educational 'products' transacted in the marketplace are less likely to produce an engaged democratic society. Freire said "the more people participate in the process of their own education...the better the democracy" (Bell, Gaventa, and Peters 1990:145).

\section{Determination of access to and ownership of education services and determination of} pedagogical and ideological directions are issues regarding the expression of democracy, and the interface between citizens and the state (Bennett 2003).

The imposition of international binding rules through GATS is a major issue for democratic changes in government. These rules do not allow for changing national policy as a result of changes in government, or indeed other democratic processes that could result in a change in policy.

The 1994 commitments under GATS were negotiated by the government in secret, and without consultation. The secrecy of trade negotiations has become controversial and viewed as undermining democracy within member countries. Although member countries can determine their own process of consultation with their own constituents, there is in reality a general lack of transparency and public scrutiny in the negotiation process. In New Zealand for example, Cabinet, not Parliament, has sole management and oversight of negotiations and power to sign off and ratify international treaties. Since 1998, international treaties must be tabled in 
Parliament before ratification, however the power to ratify remains with Cabinet (Kelsey 2003c). Kelsey believes these agreements should be treated similarly to national legislation with full public consultation, informed public debate, independent cost-benefit analysis and full parliamentary scrutiny.

GATS "comes across as an impenetrable treaty remote from the concerns of parents...and the daily challenges of teachers" (Grieshaber-Otto and Sanger 2002:137). GATS establishes, particularly through its disputes settlement process an administration and decision-making mechanism distant and removed and only very indirectly accountable to citizens within member countries, which "conflicts with the basic principles underlying public education systems" (Grieshaber-Otto and Sanger 2002:77). The result is a loss of democracy and democratic accountability (Hill 2003).

\section{Recommendations}

The Chinese character for 'development' comprises the two characters crisis and opportunity. The approach taken in this section is to encourage policy makers to view growing awareness of potential consequences of trade liberalisation in education services as an opportunity to shift from abstract theoretical approaches to policy making and reassess the ideological underpinnings and drivers that have dominated policy making over the last two decades.

"Globalisation is not a simple, vast, unstoppable thing. As always there are choices to be made. Governments, corporations, communities and individuals have chosen to make certain decisions that have led us down particular paths" New Zealand has the (bounded) freedom to make its own social and national and transnational histories. The aim here is to provide an accessible, informative, provocative starting point for debate. 


\section{Recommendations for New Zealand policy making:}

Policy making needs to both reflect New Zealand society in its outcomes and be inclusive in its process. Policy making is about people and should be informed by people-centered views of questions and matters that form the subject of policy. This requires policy making to be a process embedded in the communities that comprise New Zealand society, "developed through participation of all parties with a major interest in the outcome" (Kelsey 2002:128). This is a tall order for government policy makers, but a necessary and more democratic one. It requires a paradigm shift in understandings of 'consultation' and 'partnership', an engagement with histories and ways to create dialogue and build relationships that involve relevant sectors in the development of policy.

Trade Policy: As identified, New Zealand's approach to trade policy has been informed by 'liberalisation', on the basis that lowering trade barriers through an open world trade system of 'fair' rules would provide New Zealand the best economic opportunities to overcome our disadvantages of size and location. However with the reality of power imbalances, naked economic self-interest, inherent institutional barriers and complications, it is obvious that world trade is in no sense 'free' or governed by 'fair' rules, and "a continued fixation with liberalisation as an ideal can only be judged as at best naïve and at worst negligent" (Oehlers 2003:A17). Oehlers suggests a change in thinking, towards a more strategic and "nuanced approach to the management of trade issues" informed by 'institutionalism'125 (ibid). Alternative approaches, which recognise contingent and contextual conditions, are needed to infuse public debate and policy discussions.

Nobel prize winning economist Joseph Stiglitz has likewise voiced a change in thinking, rejecting his previous "over zealous, even naïve faith in the market" and outlining what he calls a "New Democratic Idealism" as an alternative, based on social justice and a balance role for government and the market" (da Costa 2003). To which I would add, the social-cultural sector.

\footnotetext{
${ }^{125}$ According to Oehlers institutionalism emphasises the evolutionary character of world markets, providing insights into the rigidities, power structures and inherent barriers in institutions governing trade, as well as the opportunities (Oehlers 2003).
} 
Trade ministers and MFAT officials need to be accountable for societal impacts of trade decisions and commitments. There is a need to ensure trade policy analysis 'makes good' its responsibility regarding the concern for democracy. This will require government policy units to transform their methodological approaches and practices of policy making more generally "to include an assessment of the political interests and needs of the larger political community" (Fischer 1998:134). ${ }^{126}$ Especially important in this view, is the need to reframe the relationships between the roles of citizens, analysts and decision makers. It requires a participatory or collaborative relationship of mutual exploration, to facilitate the kind of open discussion necessary for meaningful dialogue and critical engagement.

The secrecy surrounding WTO negotiations needs to be lifted to allow full open public discussion about GATS. These need to be informed by comprehensive independent research on the impact of GATS on education (see below). The debates must also address the issues arising from the power relations and political economy that underlies GATS. Any commitments under international trade agreements must follow rather than precede informed public debate and resolution of issues and concerns.

By creating participatory democracy in policy making and analysis a shift in trade policy is feasible. New Zealand's processes towards making trade agreements need to be more open and democratic, involving full public engagement, select committee processes and debate and ratification by parliament. It is critically important that wide ranging debate about the significance of GATS for education takes place across all stakeholder communities, including a wide process of public participation.

New Zealand also has a role to play in the international arena, promoting a greater degree of democracy in WTO processes, advocating for agreements that advance common good, accessibility and equity (Schugurensky and Davidson-Harden 2003).

Concern over the ambiguities and interpretations of GATS rules has been raised previously. There needs to be in-depth analysis of the rules as they apply to education, and within the

\footnotetext{
${ }^{126}$ According to Deborah Stone, "the political community is inhabited by citizens who live in a web of interdependence, loyalties, and associations [in which] they envision and fight for the public interest as well as their own individual interests" quoted in (Fischer 1998:133).
} 
context that they will be applied. As discussed in Chapter Four New Zealand's 1994 GATS commitments with regard to education were made without examining domestic policy implications and lacked recognition by government of the possibility of potential issues for domestic education policy arising from free trade commitments or from the impacts of the growth in export education. This examination needs to happen with some urgency.

There is an immediate need to assess potential problems that could arise from restrictions on a government's ability to regulate (only where 'necessary'). Processes and commitment to ongoing dialogue between trade officials and education officials and professionals should be established, other wise education policy will be increasingly decided by trade ministers in the context of trade policy instead of education ministers.

To protect the education system for the adverse effects of GATS NZEI suggests there are two primary options: "remove privatisation from the education sector or fundamentally alter the nature of the GATS" (NZEI 2002a:7). The latter could include a number of possibilities from changing GATS rules so that education, and possibly all core social and cultural services are excluded, to building into GATS more recognition and protection for social responsibilities of governments and allowing governments to retract and change their commitments and agreements in these areas depending upon their changing political and social circumstances.

As a starting point and without conceding the fundamental argument that education should not be covered by GATS or any other multilateral trade agreement, NZEI proposed several immediate measures to simply bring GATS and New Zealand's schedule into line with the government's interpretation (NZEI 2002b). CTU has called on government to make explicit reservations in New Zealand's schedule to protect all publicly funded services from GATS ${ }^{127}$ coverage (CTU 2001). As a fundamental bottom line the NZPPTA asserts "governments must retain a right to legislate in their own national interest" (Alison and Velde 2002).

Educational policy: Much of what is written regarding the neoliberal reforms focuses on the effects of managerialism and market choice within an unequal society, (Baker 2000;

\footnotetext{
127 The current schedule currently commits private institutions, which also commits considerable publicly funded services.
} 
Wylie 1999b; Fiske and Ladd 2000). However attention has also been drawn to the implications of an underlying premise of Ministry of Education policy and methodology: that economic analysis is an appropriate domain for evaluating education, because of the taxpayer investment in public education.

\section{The Education Policy Response Group, formed to provide critique and encourage} debate about national education policy, showed that Ministry of Education policy initiatives covering the period $1997-98$ continue

the paradoxical and incompatible mix of neo-liberal, or hands off, and neoconservative, or hands-on, approaches... based on the narrow and idealised definition of education as a 'private good' or 'commodity' to be purchased by individuals in an increasingly self-financing and aggressively competitive provider marketplace ${ }^{128}$

(O'Neill and Snook 1999:iix). It becomes much more difficult to consider and address the consequences of GATS for education in such a policy environment. The Ministry of Education needs to heed the considerable guidance in the literature on alternative policy approaches and alternative constructions of leadership and management more appropriate to the sociocultural contexts of education. Many build on the imperatives of institutional responsiveness and educational leadership. Ethics must be integral to educational policy, management and pedagogy.

For example, Scrivens draws on the ideas of "the ethic of care" as a means of reconceptualising leadership in early childhood (Scrivens 2002). Ethics are not easy, and at times dangerous, but they are "at certain times, the only thing we have if we intend to speak with truth to power and defend the interests of the very young and very poor who have no power at all" (Kozol 1997:6).

Educational policy bases need to acknowledge the importance of an approach embedded in community, both in terms of the relationship of policy-makers themselves

\footnotetext{
${ }^{128}$ For example the teacher education review (Quality Teachers for Quality Learning, 1997 green paper) presents provider competition as the preferred model for both pre- and in-service teacher education, tempered by a 'competency-led' model of provision, which demonstrates "the tension between an ideological commitment to the free marketplace and an unarticulated admission that these educational markets lead in practice to poorer, not better quality of provision" (O'Neill and Snook 1999:ix). However the attempt to address this by more managerialism (specification and measurement of competencies) misunderstands the professionalism of teaching. That is its diverse, multidimensional, relationship and situational and embedded nature that requires the development of flexible "self-management and complex-knowledge-in-action ....and situation-specific judgements" (ibid).
} 
and their own multiple roles in the community and their professional capacities, and also in terms of embedding the policy content to contextual frameworks. For example the report of the Early childhood Development Project provides a good lead for developing these policies, linking government funding subsidies to requirements suggesting a requirement that "services in receipt of government funding include parents/ whanau as democratically elected representatives on management and policy-making bodies" to ensure "parents and whanau are involved as decision-makers in their early childhood service" (Early Childhood Education Project 1996:49).

There is an opportunity to build awareness within the education sector ${ }^{129}$ and public concerning the purposes of education in a complex modern democracy, with special reference to nation building and the Treaty of Waitangi. Such forums could re-build awareness of "what a state education system is and why it is important" (Clarkin-Phillips 2003) and publicly debate the questions about education and society such as:

- What do we value about New Zealand education?

- What are public versus private interests in education?

- What kind of education do we want?

- What kind of society do we want?

\footnotetext{
${ }^{129}$ It is worth returning to a set of questions for consideration about the transformation of a "matrix of cultures in the New Zealand education system" back in 1998 (Grace 1998:2), which remain poignant for the policy debate recommended in this paper:

- The culture of education itself - in particular its definition and living out as a public good within the spirit of the Fraser/ Beeby declaration; or its existence in the marketplace as a commodity like any other, as proposed in the 1987 Treasury briefing to the incoming government. Had any new settlement been achieved?

- The culture of lived democracy and citizenship. Had it been strengthened by the reform process?

- The culture of educational improvement. Is the system performing at a higher level?

- The culture of equal opportunities. Have differences reduced or widened over time?

- The culture and the language of tangata whenua. Have these been strengthened or diminished over time?

- The culture of efficiency. Has value for money improved over time?

- The culture of the self-managing school, a concept powerful across the Anglo cultures. What have been the gains and losses as the concept has been realised?

- The culture of internationalism. Has performance been affected by the international economy?

- The culture of parental participation. Has involvement increased, and across all schools?

- The culture of young people. How are young people experiencing the reforms and have they been asked?
} 
There is need for critical discernment in business-school relationships. This needs to be an issue for policy debate to review the extent to which business interests and commercial forces determine the content and culture of education.

Education policy can not continue its disaggregated approach whereby policy concerning export education is isolated from and uninformed by policy and pedagogical perspectives of early childhood and primary services. It is time to develop a policy of educational guiding principles for internationalisation. Other models can be considered for managing and regulating global education provision outside of international trade agreements, which could contribute to ensuring quality and flexibility without undermining the social and cultural nature of education (Robertson and Dale Draft 2003).

Dimmock and Walker highlight the importance of societal culture ${ }^{130}$ in developing theory, policy and practice within an increasingly globalised educational context, identifying the dangers both of applying business management to diverse educational contexts and of transporting theory, policy and practice globally as traded commodities of a market system (Dimmock and Walker 2000). They promote an alternative scenario in which societal culture is incorporated into international exchange of educational policy, research and practice and "each society demonstrates capability of transforming globalised policies and practices in culturally sensitive ways that respect the integrity of its indigenous culture while allowing room for change and development" (ibid: 8).

If a truly inclusive participatory approach is taken providing genuine voice for diverse cultures, the answers to these questions will necessarily be multidimensional. Education has a vital role to play to "reinvigorate intellectual and cultural life of the nation and stimulate a contest of ideas that empowers ordinary people to play an informed role in shaping their future" (Kelsey 2002:135).

\section{Directions for further research}

There are gaps, indeed a complete absence, in the literature documenting examples of impacts that may already be occurring within the primary and early childhood sectors. It

\footnotetext{
${ }^{130}$ By 'Societal culture' they mean "those enduring sets of values, beliefs and practices that distinguish one group of people from another (Dimmock and Walker 2000).
} 
was beyond the scope of this research to collect the empirical information and qualitative evidence required to support the issues under discussion.

The much needed debates in both the public and educational arenas must be informed by further in-depth, comprehensive research on potential consequences of GATS. A series of studies inside the primary school and early childhood contexts would be useful. These could include a scoping the current situation collating qualitative, anecdotal and empirical data as well as 'interpretive' impact assessments, which by necessity would be partially speculative, but informed by the views of educators, parents, administrators and communities of 'what happens' in these environments and of the outcomes of marketisation, and thereby develop scenarios regarding what might or could happen through the application of GATS imperatives and disciplines.

Research is needed to understand the perceived rationale and benefits of reducing barriers to trade in regard to consequences to the core values and qualities of the public education system. Research into community perspectives and public expectations of the education system and its social goals would also be useful.

The question of commercialisation in schools also needs to be researched. This could build on the informal research being undertaken by NZEI on the extent of exposure, influence and impact commercial sponsorships and advertising are having in schools and early childhood centres. This research needs to address issues as wide ranging as pedagogical impacts and use of school time. It would be useful to establish studies and monitoring mechanisms to explore the potential impacts of foreign providers emerging in the New Zealand education market.

Comprehensive research scoping the range of issues regarding the impacts of export education, exploring its educational value to New Zealand children is required, as raised in Chapter Three. This should include specific research to assess educational, social and cultural impacts of FFP students within communities, attitudes of host communities and within educational institutions.

In the wider international context research could also look at the implications of New Zealand's expanding export education industry and GATS drive for progressive trade 
liberalisation for developing countries. The scope of this study did not permit discussion on this topic. The voices of developing countries need to be heard. The risks and benefits of increased educational trade need to be clear and must not undermine efforts in these countries to develop and enhance their own education systems.

\section{Conclusions}

This research has presented the substantive argument that the principles of GATS are in conflict with the principles of public education as a socially embedded service. Education as a tradable commodity in a deregulated international free-trade market is incompatible with the principle of quality public education that is free and universally available, accessible and equitable.

The question whether education should be a social embedded service versus detached commodity is an ideological debate - a debate that needs to be held in the public arena.

when education, through the GATS process, is transformed into a commercial activity regulated by global trading agreements, are national governments able to ensure the 'public good' and 'public service' status of education and if not, does it matter, why and to whom?

(Robertson and Dale Draft 2003:6, emphasis in original)

It is only in forums such as ARENA, QPEC and the professional teachers associations that questions such as whether education, a public service, can be treated as tradable and whether sectors of education will be subordinated to profit regimes, and where the consequences of commodification of education and the formation of global education market are beginning to be explored. Stephen Day expressed the frustration felt by educationalists who recognise that the values of WTO and its trade agreements are very different from the values embodied in national curriculum documents, particularly $\mathrm{Te}$ Whariki, and yet trade officials can impose these trade rules without the involvement of educationalists (Day 2003b).

Education is one of society's primary sites for the formation of social practice and preferences. The overall neoliberal project to re-form society however, can not assure the 'social capital' required by a market society nor the sustainability of the cultural 
(educational) institutions on which the market itself depends. One of the problems with markets is that consumer demand can not be seen as equivalent to social needs. The market is a very poor guide to social need. Markets fail to be centrally concerned with equality in the distribution of resources or opportunity and fail to protect democratic rights. Indeed the neo-liberal advocacy of unregulated markets contradicts some established principles of democracy.

The coveting and commodification of 'knowledge' has serious implications that need to be debated. What does it mean for knowledge to become a market economy? What is included in the 'body of knowledge'? Who will be able to 'afford' to learn? What does the shift in focus from building a society to building an economy mean for the nature of education, and for the nature of society itself?

The discussion in Chapter Five on education's nation-building role highlighted a critical issue regarding the underlying conflicts between New Zealand's international trade policies and citizen priorities. Ideas of nation and national identities must always be open to contest. Vigorous, open and inclusive debate about the kind of nation we wish to build, who we are and where we are going is needed; debate that "actively engages with issues of social justice, decolonisation and reconceptualisation of New Zealand as a 'nation'" (Kelsey 2000a:16). Social and cultural principles remain fundamental to individual and group identities and therefore must inform policy and practice throughout education systems and institutions.

Underlying the discussions throughout this paper are fundamental issues of power. The educational reforms Tomorrows Schools and Before Five proposed a radical social change in the intention to share power with communities through the devolved governance to community BOTs. But cast in the neoliberal ideology of NPM, 'market choice' and the new roles of the state agencies, it is not the communities that have been empowered. Rather, it is the imperatives of capital (market forces) that now share the power of the state.

The apparent inevitability of the commercial/ corporate presence in all facets of daily life is largely unquestioned. It is concerning that many people seem to feel that commercialisation in schools is appropriate, or at least a 'necessary evil'. 
Commercialisation is changing the power structures of education, ensuring the private sector a greater role in managing and directing education. "When the private sector is allowed to dictate the terms and goals of education, it is the private sector that will ultimately control it" (Shaker 1999b:10). Commercialisation creates an ethical dilemma concerning priorities for BOTs and school management. When schools become a 'profit making forum' activities that do not generate a profit are at risk.

Who is advantaged and who is disadvantaged? Under market regimes, rich schools and private businesses grow richer and poor schools grow poorer. The children of the most privileged circumstances are the most advantaged.

GATS is an unfinished framework designed for continuous expansion through progressive negotiations. It is not possible to know the outcome of current or future negotiations. There will be mounting pressure over the next few years for countries to open up their education sector to global markets, and New Zealand is perceived by other countries as a leading proponent of ever-increasing market access for commercial education.

There is a growing international groundswell of opposition to the coverage of education and other public services in GATS. There will also be increasing contestation and collective oppositional action within member states and regions. In particular domestic coalitions may develop in around sectors such as education, which previously assumed an embedded social contract. Lobby groups may also emerge, ironically from elements of the domestic private sector which perceive competition from foreign companies as a potential threat (Mundy and Iga 2003). These pressures could encourage the government to greater caution in GATS negotiations.

Concerns about trade considerations eroding the public good agenda in education do not negate the need for education to participate effectively in an increasingly globalising environment and the need for genuine international collaboration. Expansion of export education, if appropriate, can and should be facilitated and managed outside of multilateral trade agreements. "It is naïve for government to believe it can do some sort of balancing act between exporting educational services to other countries and protecting the integrity of public education at home" (Minto 2002:3). 
There has been very little assessment of the implications of GATS undertaken by governments and there is a great deal of uncertainty about what GATS will mean in the long term. The risks presented by GATS need to be managed. The public interest must be put before the corporate interest. Both the education sector particularly and also the wider public, need to be fully informed, proactive and working closely with the trade negotiators to ensure they are aware of consequences of GATS related decisions. The ambiguity, uncertainty and the fact that future consequences have yet to be realised, make some of the debate speculative and hard to demonstrate. However if it is ignored by citizens and educators the future effects of GATS, including consolidating and reinforcing commercial trends and circumscribing governments regulatory ability in the education field, could prove to be both profound and unprecedented. 


\section{References}

Ainsworth, V., T. Anderson, C. Clements, S. Heggie, R. Rogers, and D. Martin. 1996. Tomorrow's Schools and Freedom of Choice - A Recipe for Disaster. A study of the effects of roll changes on Christchurch state schools. Christchurch: Education Policy Unit, University of Canterbury.

Alison, J., and M. Velde. 2002. GATS Position Paper and Strategy. Wellington, December 2002.

Allen, S. 2003. Chinese warn: NZ a school for crime. The Dominion Post, 13-8-03. 2004a. Drug dealers 'target foreign students'. The Dominion Post, 28-1-04. 2004b. Education boosts economy. The Dominion Post, 28-1-04. 2004c. Six more language schools close down. The Dominion Post, 19-1-04.

Allen, S., and M. Quirke. 2003. Chinese want education guarantees. The Dominion Post, 16-9-03.

Allen, S., and M. Torbit. 2003. 600-student language institute goes under. The Dominion Post, 6-9-03.

Anderson, B. 1991. Imagined Communities: Reflections on the Originand Spread of Nationalism. London: Verso.

Apple, M. 2001. Education the "Right" Way: Markets, Standards, God and Inequity. New York: RoutledgeFalmer. ed. 2003. The State and the Politics of Knowledge. New York: Routledge Falmer.

Asia 2000 Foundation. 2003. The Export Education Industry: Challenges for New Zealand. Asia 2000 Foundation of New Zealand, An Occasional Paper www.asia2000.org.nz [cited 10-6-03].

Association of Universities and Colleges of Canada et al. 2001. Joint Declaration on Higher Education and the General Agreement on Trade in Services. Ottawa, Washington DC and Brussels: Association of Universities and Colleges of Canada, American Council on Education, European University Association and Council for Higher Education Accreditation.

AUS. 2003a. Degree online for Global University. Association of University Staff www.aus.ac.nz [cited 14-8-03].

2003b. Submission to the Ministry of Foreign Affairs and Trade on New Zealand's Approach to the General Agreement on Trade in Services (GATS) Initial offer. In Association of University Staff of New Zealand. Wellington. 
Australian Government, and AEI-International Education Network. 2002. Strategies for Negotiating Trade in Education Services: Options for Australia. Canberra: Commonwealth of Australia.

Baker, R. 2000. Regional Seminar on Educational Research for Policy and Practice: with particular reference to secondary reform. Wellington: New Zealand Council for Educational Research.

Barblan, A. O. 2002. The International Provision of Higher Education: Do Universities Need GATS? Higher Education Management and Policy 14 (3): 77-92.

Barlow, M. 2001a. The Fourth Ministerial Meeting of the World Trade Organisation: An Analysis. Council of Canadians, www.canadians.org [cited 10-3-03]. 2001b. A GATS Primer. Council of Canadians, www.canadians.org [cited 10-303].

2001c. The Last Frontier. The Ecologist 31 (1): 38-42.

Bell, B., J. Gaventa, and J. Peters, eds. 1990. We make the Road by Walking: Conversations on Education and Social Change: Myles Horton and Paulo Freire. Philadelphia: Highlander Research and Education Center.

Bello, W. 2003. Implications of Cancun www.zmag.org. zmag [cited 23-09-03].

Bennett, G. 2003. Facing the Challenge of Public Services. Fabian Global Forum www.fabianglobalforum.net [cited 12-3-03].

Benton, R. 1987. How Fair is New Zealand's Education?: Report to Royal Commission on Social Policy, Part 1. Wellington: NZCER.

Bingham, C. 1998. The goals of language, the language of goals: Nietzsche's concern with rhetoric and its educational implications. Educational Theory 48 (2): 229241.

Blundell, K. 2004. Language school faces hard times. The Dominion Post, 10-1-04.

Bolland, M. J. 2003a. Chinese warned after student kidnap. The Dominion Post, 25-403.

2003b. Failed school's funds disappeared. The Dominion Post, 29-9-03.

Bowron, T. 2001. The Corporate Agenda in Education. Paper read at Dunedin Branch of the International Socialists, July 2001, at Dunedin.

Boyd, R. 1998. A case Study of Change in National Education Administration, PostPicot. Paper read at NZEAS Biennial Conference - Ten Years On: Reforming New Zealand Education, 11-14 January 1998, at Wellington.

Bronner, S. E., and D. M. Kellner. 1989. Critcial Theory and Society. London: Routledge.

Burchill, S. 1996. Liberal Internationalism. In Theories of International Relations, edited by Linklater, S. B. a. A. New York: St Martin's Press.

Butcher, A. 2002. A Report on the Demographic, Social and Economic Impact of the International Students on North Shore City. Auckland: Massey University.

Butterworth, G. a. S. 1998a. Letting the Genie out of the Bottle: An Inside View of the Genesis of the Education Reforms. Paper read at NZEAS Biennial Conference - 
Ten Years On: Reforming New Zealand Education, 11-14 January 1998, at Wellington.

1998b. Reforming Education: The New Zealand Experience, 1984-1996. 2 vols.

Palmerston North: Dunmore Press.

Byers, S. 2003. I was wrong, Free market trade policies hurt the poor. The Guardian, 195-03.

Calvert, J., L. Kuehn, and et al. 1993. Pandora's Box: Corporate Power, Free Trade and Canadian Education, Our Schools/ Ourselves. Toronto: Education Foundation.

Carter, N. 2003. Foreign students a booming industry. Daily News, 14-1-03.

CID. 2003. Public Consultation on New Zealand's approach to the next stage of WTO services negotiations. NZ: Submission by the Council for International Development, NZ.

Clare, J. 2003. Writing Critical Research. In Writing research: Transforming Data into Text, edited by Clare, J. and H. Hamilton. London: Elsevier Science.

Clark, J. 1998. Education as a Public Good or in the Public Good? Implications for Social Justice. Paper read at NZEAS Biennial Conference - Ten Years On: Reforming New Zealand Education, 11-14 January 1998, at Wellington.

Clarkin-Phillips, J. 2003. The Education Shopping Trolley: Commercialisation and Globalisation in Early Years Education. Paper read at QPEC Conference 2003, 12-7-03, at Palmerston North.

Coates, B. 2003. Challenging GATS. Fabian Global Forum www.fabianglobalforum.net [cited 12-3-03].

Codd, J. 1990. Managerialism: The problem with today's schools. Delta 44: 17-25. . 1999. Educational Reform, Accountability and the Culture of Distrust. New Zealand Journal of Educational Studies Special Issue - A Decade of Reform in New Zealand: Where to Now? 34 (1): 45-53.

Cooke, D. 2003. Business Involvement in Education: Benign or Malign? Paper read at QPEC Conference 2003, 12-7-03, at Palmerston North.

Cowen, M., and R. Shenton. 1995. The Invention of Development. In Power of Development, edited by Crush, J. London: Routledge.

CTU. 2001. CTU Analysis of MFAT's responses to our questions on GATS and Education. Wellington: Council of Trade Unions.

da Costa, P. N. 2003. Professor's faith misplaced. Weekend Herald.

Dahl, R. 1998. On Democracy. Yale: Yale University Press.

Dahlberg, G., P. Moss, and A. Pence. 1999. Beyond quality in early childhood education and care: Postmodern perspectives. London: Falmer Press.

Dale, R., and S. Robertson. 1997. 'Resiting' the Nation, 'Reshaping' the State: Globalisation Effects on Education Policy in New Zealand. In Education Policy in New Zealand: the 1990s and beyond, edited by Olssen, M. and K. Morris Matthews. Palmerston North: The Dunmore Press. 
2003. Interview with Robert W. Cox. Globalisation, Societies and Education 1

(3): 13-23.

Daun, H., ed. 2002. Educational Restructuring in the Context of Globalisation and national Policy. New York \& London: Routledge Falmer.

Day, S. 2003a. Memo: Public Private Partnerships and Private Finance Initiatives (PPP/PFIs) - communications with National Executive, Te Reo Areare. Wellington, 28-2-03.

2003b. Verbal communications. Wellington, 21-8-03.

Day, S., and R. Norman. 2003. Oral questions in parliament (personal communications). Wellington, 12 \&13-3-03.

Department of Education. 1988a. Administering for Excellence: Effective Administration in Education. (Picot Report). Wellington: Government Printer.

1988b. Report of the Early Childhood Care and Education Working Group.

(Meade Report). Wellington: Government Printer.

1988c. Tomorrow's Schools: The reform of educational administration in New Zealand. Wellington: Government Printer.

1989. Before Five: The Government's policy for early childhood care and education. Wellington: Government Printer.

Department of Labour, and National Advisory Committee on the Employment of Women. 1999. Childcare, families and work: the New Zealand Childcare Survey 1998. Wellington: Labour Market Policy Group, Department of Labour.

Dimmock, C., and A. Walker. 2000. Globalisation and Societal Culture: Redefining Schooling and School Leadership in the Twenty-first Century. Compare 30 (3): 303-312.

Dodd, M. 2002. Nation Building and Maori Development. Paper read at 2002 Devnet Conference - Contesting Development: Pathways to Better Practice 5-7 December, at Palmerston North.

Early Childhood Education Project. 1996. Future Directions: Early Childhood Education in New Zealand, revised edition 2000. Wellington: The New Zealand Education Institute.

Education Forum. 2003. School Choice and Competition. Education Forum www.educationforum.org.nz [cited 10-6-03].

Education International. 2001. Global Campaign to Defend and Enhance Public Education. Education International www.ei-ie.org [cited 15-1-04].

Education Review Office. 2001. The New Zealand Curriculum: An ERO Perspective. Wellington: Education Review Office www.ero.govt.nz.

ENZT. 2003. Programme profiles. Enterprise New Zealand Trust www.enzt.co.nz [cited 10-4-03].

ESRA. 2000. Sources of School Revenue. Wellington: Economic and Social Research Associates Ltd. 
Evans, S. 2003. Downturn expected in international market. NZ Education Review, 5-303.

Evening Standard. 2002. Schools now accountable for student gains. Evening Standard, 6-12-02.

Fancy, H. 2003a. Forging the Future: Quality Education Essential to Export Education Success. Paper read at Education New Zealand Conference, 13-8-03, at Wellington.

2003b. SPANZ Article - Four Challenges. Ministry of Education www.minedu.govt.nz [cited 24-3-03].

Fischer, F. 1998. Beyond Empiricism: Policy Inquiry in Postpostitivist Perspective. Policy Studies Journal 26 (1): 129-146.

Fiske, E., and H. Ladd. 2000. When Schools Compete: A Cautionary Tale. Washington DC: The Brookings Institution.

Fitzsimons, P., M. Peters, and P. Roberts. 1999. Economics and the Educational Policy Process in New Zealand. New Zealand Journal of Educational Studies Special Issue - A Decade of Reform in New Zealand: Where to Now? 34 (1): 45-53.

Flyvbjerg, B. 2001. Making Social Science Matter: Why social inquiry fails and how it can succeed again. Cambridge: Cambridge University.

Foucault, M. 1980. Truth and Power. In Michael Foucault: Power/ Knowledge, edited by Gordon, C. Sussex: Harvester Press.

Fraser, P. 1939. Report of the Minister of Education. Wellington: AJHR.

Freire, P. 1970. Pedagogy of the Oppressed. New York: Seabury Press.

Gale, T. 1999. Critical Policy Methodology: Making connections between the stories we tell about policy and the data we use to tell them. Paper read at Joint Conference of the Australian Association for Research in Education (AARE) and the New Zealand Association for Research in Education (NZARE), 29 November - 2 December, at Melbourne.

Gilpin, R. 1987. The Political Economy of International Relations. New Jersey: Princeton University Press.

Gordon, C. 1991. Governmental Rationality: An Introduction. In The Foucault effect: Studies in governmentality -with two lectures by and an interview with Michael Foucault, edited by Burchell, G., C. Gordon and P. Miller. Wheatsheaf: Hemel Hempstead.

Gordon, L. 1997. Tomorrow's Schools' Today: School Choice and the Education QuasiMarket. In Education Policy in New Zealand: the 1990s and beyond, edited by Olssen, M. and K. Morris Matthews. Palmerston North: The Dunmore Press.

1999. From Nation-building to Profit-Making: The Past, Present and Future of Schooling in New Zealand. New Zealand Journal of Educational Studies Special Issue - A Decade of Reform in New Zealand: Where to Now? 34 (1): 247-254.

Goulter, P. S. C. 2002. GATS and Education/ Public Services. Wellington, 11-7-02. 
Grace, G. 1998. Section One: Appraising Cultural Change - The Broad Agenda, A Policy Scholarship Perspective; Section Two: A Focussed Appraisal Agenda - Historical Settlements, Reform Principles and the Potentialities of Educational Change; Section Three: What is the Balance Sheet of Outcomes? The evidence from the research. Paper read at NZEAS Biennial Conference - Ten Years On: Reforming New Zealand Education, 11-14 January 1998, at Wellington.

Grieshaber-Otto, J., and M. Sanger. 2002. Perilous Lessons: The Impact of the WTO Services Agreement (GATS) on Canada's Public Education System. Ottawa: Canadian Centre for Policy Alternatives.

Grunwell, R. 2003. Sick, troubled students allowed to study here. Sunday Star Times, 17-8-03.

Haigh, M. 2002. Internationalisation of the Curriculum: Designing inclusive Education for a Small World. Journal of Geography in Higher Education 26 (1): 49-66.

Haines, L., and S. Allen. 2003. Age bar set for foreign students. The Dominion Post, 9-903.

Halpin, T. 2003. Private sector to bid for all new schools. Times online, 11 February 2003.

Hamer, J. 2002. The Impact of New Public Management on Early Childhood in New Zealand: Where to form here? Delta 54 (1 \& 2): 29-42.

Hanks, P., ed. 1988. The Collins Concise Dictionary of the English Language. London: Guild Publishing.

Harvey, L. 1990. Critical Social Research. London: Allen and Unwin.

Henriques, D. 2003. Edison stays afloat by altering course. New YorkTimes, 3-7-03.

Hill, D. 2003. Global Neoliberalism, the Deformation of Education and Resistance. Journal for Critical Education Policy Studies www.jceps.com 1 (1).

Hirtt, N., U. Fredriksson, S. Robertson, M. Lawn, and I. Lohman. 2003. Trading in Education Services - Examining GATS. Paper read at European Conference of Educational Research 17-20 September 2003, at Hamburg.

Hoare, Q., and G. N. Smith, eds. 1971. Selections From The Prison Notebooks of Antonio Gramsci. London: Lawrence and Wishart.

Hobden, S., and R. W. Jones. 1997. World System Theory. In The globalisation of World Politics: An Introduction to International Relations, edited by Baylis, J. and S. Smith. Oxford: Oxford University Press.

Hoekman, B., A. Matto, and P. E. English. 2002. Development, Trade and the WTO: A Handbook. Washington DC: The World Bank www. cid.harvard.edu/cidtrade.

Holloway, J. 2003. A Professional Development Programme for Tertiary Providers of International Education in New Zealand 2003-2005. Wellington: Education New Zealand, for the NZ Ministry of Education.

Howarth, D., and Y. Stravrakakis. 2000. Discourse theory and political analyis: Identities, Hegemonies, and social change. Manchester: Manchester University. 
Hughes, D., H. Lauder, S. Watson, J. Hamlin, and I. Simiyu. 1996. Markets in Education: Testing the Polarisation Thesis. The Smithfield Project Phase Two, Fourth Report. Wellington: Ministry of Education.

Jackson, M. 2003. The Pre-emptive Attack. Mana April-May 2003 (51): 46.

Jesson, B. 1999. To Build a Nation. New Zealand Political Review 8 (2): 24-33.

Johnston, R. J., D. Gregory, G. Pratt, and M. Watts, eds. 2000. The Dictionary of Human Geography. Oxford: Blackwell Publishers Ltd.

Jones, J., and S. Borbasi. 2003. Interpretive Research: weaving a phenomenological text. In Writing research: Transforming Data into Text, edited by Clare, J. and $\mathrm{H}$. Hamilton. London: Elsevier Science.

Jones, P. 1998. Globalisation and Internationalism: Democratic Prospects for World Education. Comparative Education 34 (2): 143-155.

Kalafatides, L. 2001. Education: On the Ropes. The Ecologist 31 (9): 26-31.

Keen, R. 2003. Threat to the Education System, PPTA warns. The Press, 5-3-03.

Kelsey, J. 1999. 10 Reasons Why the General Agreement in Trade in Services (GATS) is Bad for Public Education. Association of University Staff [cited 12-8-03].

2000a. The Nation-Building Role of Education. Delta 52 (1): 5-26.

2000b. The University Environment: Contradictions in the Market and NationBuilding Agendas. Public Service Association www.library.psa.org.nz [cited 20-104].

2002. At The Crossroads: Three Essays. Wellington: Bridget Williams Books.

2003a. GATS and other new threats to public education. Paper read at QPEC Conference 2003, 12-7-03, at Palmerston North.

2003b. Legal Fetishism and the Contradictions of the GATS. Globalisation, Societies and Education 1 (3): 267-280.

2003c. Serving Whose Interests? A guide to NZ's Commitments under the WTO General Agreement on Trade in Services. Christchurch: Arena.

Knight, J. 2002a. GATS and Higher Education - On-line Discussion, 4 April 2002. The

Observatory on Borderless Higher Education [cited 3-9-03]. Available from www.obhe.ac.uk.

2002b. Trade in Higher Education Services: The Implications of GATS. London: The Observatory on Borderless Higher Education.

2002c. Trade Talk: An Analysis of the Impact of Trade Liberalisation and the General Agreement on Trade in Services on Higher Education. Journal of Studies in International Education 6 (3): 209-229.

2003. GATS, Trade and Higher Education: Perspective 2003 - Where are we? London: The Observatory on Borderless Higher Education.

Knight, J., B. Lingard, and P. Porter. 1993. Restructuring Schooling towards the 1990s. In Schooling Reform in Hard Times, edited by B Lingard, J. K. a. P. P. London: Falmer Press. 
Korten, D. 1995. When Corporations Rule the World. US: Berrett-Koehler.

Kozol, J. 1997. Students' Needs or Corporate Greed? The Education Digest 63 (September): 4-6.

Krajewski, M. 2001. Public Services and the Scope of the General Agreement on Trade in Services. Centre for International Environmental Law www.ciel.org/Publications/PublicServicesScope.pdf [cited 16-4-03].

LaRocque, N. 2003a. GATS will help maximise education industry growth. Media release: Education Forum www.educationforum.org.nz, 31-3-03.

2003b. Pirates on the High Seas of Education: GATS and the Globalisation of New Zealand Education. Palmerston North, 15 April 2003.

Larsen, K., J. Martin, and R. Morris. 2002. Trade in Educational Services: Trends and Emerging Issues. The World Economy 25 (6): 849-868.

Larsen, K., and S. Vincent-Lancrin. 2002. International Trade in Educational Services: Good or Bad? Higher Education Management and Policy 14 (3): 9-45.

Lattimore, R. 2002a. Education and Growth: the seed and the flower of economic development: Education Forum Briefing Papers No.1 August 02 www.educationforum.org.nz.

2002b. Trade in Education: "Schools for children, not markets!" Education Forum Briefing Papers No.2 August 02 www.educationforum.org.nz.

Lauder, H., D. Hughes, and S. Watson. 1999. The Introduction of Educational Markets in New Zealand: Questions and Consequences. New Zealand Journal of Educational Studies Special Issue - A Decade of Reform in New Zealand: Where to Now? 34 (1): 86-98.

Lauder, H., D. Hughes, S. Watson, I. Simiyu, R. Strathdee, and S. Waslander. 1995. Trading In Futures: The Nature of Market Choice in Educational Markets in New Zealand. The Smithfield Project Phase One, Third Report. Wellington: Ministry of Education.

Loveridge, J. 2002. Working with Young Children and their Families in Early Education. Delta 54 (1 \& 2): 171-191.

Macpherson, R. 1998a. Nation-building through Education. NZEAS media release www.list.waikato.ac.nz [cited 20-1-04].

1998b. Towards the Daughter of Picot - He Kaupapa Tangatarua mo Aotearoa: Bicultural Nation-Building for New Zealand. Paper read at NZEAS Biennial Conference - Ten Years On: Reforming New Zealand Education, 11-14 January 1998 , at Wellington.

Maharey, S. 2000. Nation-Building: Lifelong Learning in a Knowledge Society. Tertiary Education Advisory Commission - Terms of Reference www.minedu.govt.nz [cited 12-12-03].

Mallard, T. 2003. Education Priorities for New Zealand. Ministry of Education www.minedu.govt.nz [cited 20-5-03]. 
Martin, S. 1998. Choosing a Secondary School: is it the same as buying a new washing machine? Paper read at NZEAS Biennial Conference - Ten Years On: Reforming New Zealand Education, 11-14 January 1998, at Wellington.

Matthews, J. 2002. International Education and Internationalisation Are Not the Same as Globalisation: Emerging Issues for Secondary Schools. Journal of Studies in International Education 6 (4): 369-390.

May, H. 1999. The Price of Partnership: The Before Five decade. New Zealand Journal of Educational Studies Special Issue - A Decade of Reform in New Zealand: Where to Now? 34 (1): 18-27.

2002. "Blue skies" Talk in the "Playground". Delta 54 (1 \& 2): 9-28.

McCathy, P. 2002. Schools cannot rely on foreign fees- principal. Oamaru Mail, 26-1102.

McKenzie, D. 1999. The Clouded Trail: Ten years of Public Education Post-Picot. New Zealand Journal of Educational Studies Special Issue - A Decade of Reform in New Zealand: Where to Now? 34 (1): 8-17.

McKinlay, A. 2002. New Zealand's Education Exports. Education Forum Briefing Papers No.4 September 2002 www.educationforum.org.nz [cited 10-6-03].

Meade, A. 1993. Market Ideology and Accountability: Case Studies in the Early Childhood and Special Education sectors in New Zealand. International Studies in Sociology of Education 3 (2): 255-270.

2000. The early childhood landscape in New Zealand. In Landscapes in Early Childhood Education, edited by Hayden, J. New York: Peter Land.

Meehan, J., ed. 1995. Feminists Read Habermas: Gendering the Subject of Discourse: Routledge.

MFAT. 2000. New Zealand Exports of Education Services [cited 10-6-03].

2003a. Foreign Trade Policy: Trade in Services. Ministry of Foreign Affairs and Trade www. mfat.govt.nz [cited 10-3-03].

2003b. NZ and the WTO - About the WTO. Ministry of Foreign Affairs and Trade www.mfat.govt.nz [cited 10-3-03].

2003c. Questions for a Trading Nation. Ministry of Foreign Affairs and Trade www.mfat.govt.nz [cited 10-3-03].

2003d. Services: The GATS Negotiations: Public Consultation on New Zealand's approach to the next stage of the WTO Services Negotiations. Ministry of Foreign Affairs and Trade www.mfat.govt.nz [cited 10-3-03].

2003e. Why "Trade Matters?" Trade you can't carry - WTO Services

Negotiations (August 2003). Ministry of Foreign Affairs and Trade www.mfat.govt.nz [cited 10-11-03].

2003f. The WTO Services Negotiations - Initial Conditional Offer from New Zealand. Ministry of Foreign Affairs and Trade www.mfat.govt.nz [cited 10-4-03]. 
Middleton, S. 1998. Planting Cabbages and expecting Cauliflowers: The Reforms and Multicultural Schools. Paper read at NZEAS Biennial Conference - Ten Years On: Reforming New Zealand Education, 11-14 January 1998, at Wellington.

Ministry of Commerce. 1999. Bright Future: making ideas work for New Zealand: Five steps ahead: an overview. Wellington: Ministry of Commerce.

Ministry of Education. 1993. New Zealand Curriculum Framework. New Zealand Ministry of Education www. minedu.govt.nz [cited 10-6-03].

1996. Te Whariki: He Whariki Matauranga mo nga Mo Aotearoa/ Early Childhood Curriculum. Wellington: Learning Media.

2001a. Early Childhood Equity Funding - The Payment of Equity Funding to eligible community based childhood services from March 2002. Circular 2001/4. Ministry of Education [cited 12-12-03].

2001b. Export Education in New Zealand: A Strategic Approach to Developing the Sector, August 2001: New Zealand Ministry of Education www.minedu.govt.nz.

2002a. Developing Export Education - The Export Education Industry

Development Fund and Levy: Discussion Document, October 2002. New

Zealand Ministry of Education www.minedu.govt.nz [cited 10-6-03].

2002b. Foreign Fee Paying Students in New Zealand: Trends, June 2002. New Zealand Ministry of Education www.minedu.govt.nz [cited 11-6-03].

2002c. Foreign Fee Paying Students: Statistics to 2001, August 2002. New

Zealand Ministry of Education www.minedu.govt.nz [cited 11-6-03].

2002d. New Zealand's Off-shore Public tertiary Education Programmes - Initial Stocktake, April 2002: New Zealand Ministry of Education www.minedu.govt.nz.

2002e. Revised Statement of Desirable Objectives and Practices (DOPs) for Chartered Early Childhood Centre. Ministry of Education www.minedu.govt.nz [cited 10-10-03].

2003a. Code of Practice for the Pastoral Care of International Students: New Zealand Ministry of Education www.minedu.govt.nz.

2003b. Education Beyond Our Shores - Defining the Way Forward: Workshop Report, May 2003. New Zealand Ministry of Education www.minedu.govt.nz [cited 10-6-03].

2003c. Education Priorities for New Zealand, May 2003. New Zealand Ministry of Education www. minedu.govt.nz [cited 10-6-03].

2003d. New Zealand Early Childhood Education Statistics. Ministry of Education [cited 12-12-03].

2003e. Resources for Primary and Secondary Schools: Code of Practice, June 2003. New Zealand Ministry of Education www.minedu.govt.nz [cited 10-6-03].

Minto, J. 2002. Bid for our schools silent and sinister. The New Zealand Herald, 30-1002. 
2003a. Measuring Current Education Policy and Outcomes Against the Beeby/Fraser Quote of 1938. Paper read at QPEC, 12-7-03, at Palmerston North.

2003b. Public Education and the 2004 Budget. Media Release by QPEC, 12-903.

Mitchell, L. 2001. Bulk Funding of New Zealand's Early Childhood Services - An Analysis of the Impact. Wellington: New Zealand Council for Educational Research.

2002. Differences Between Community Owned and Privately Owned Early Childhood Centres: A Review of the Evidence. NZCER Occasional Paper 2002/2 (www.nzcer.org.nz/pdfs/11743.pdf).

Mitchell, L., and R. Noonan. 1995. Early Childhood Education. Paper read at Rights and Responsibilities. The Year of the Family Symposium on the Rights and Responsibilities of the Family, at Wellington.

Monbiot, G. 2001. GATS Gaffes - The WTO, Which Meets in Geneva Today, Wields Enormous Power Yet is Unaccountable. The Guardian, 22-3-01.

Moore, M. 2003. A World Without Walls: Freedom, Development, Free Trade and Global Governance. Cambridge: Cambridge University press.

Morgenthau, H. 1966. The Balance of Power, Chapter 11. In Politics Among Nations: The Struggle for Power and Peace. New York: A.A. Knopf.

Mulderrig, J. 2003. Consuming education: a critical discourse analysis of social actors in New Labour's education policy. Journal for Critical Education Policy Studies www.jceps.com 1 (1).

Mundy, K., and M. Iga. 2003. Hegemonic Exceptionalism and Legitimating Bet-Hedging: paradoxes and lessons from the US and Japanese approaches to education services under the GATS. Globalisation, Societies and Education 1 (3): 281-319.

Murray, W., and J. Overton. 2003. Designing development research. In Development Fieldwork, edited by Scheyens, R. and D. Storey. London: Sage.

Nannestad, E. 2003. Hamburger campaign - Letter to the Editor. The New Zealand Herald, 30-8-03.

Neal, T. 2002. Push for schools overseas. Nelson Mail, 3-10-02.

Nelles, W. 2001. The world education market comes to Canada: competition in a two trillion dollar global "industry". Our Schools/ Our Selves 10,2 (62): 93-100.

New Zealand Educational Administration Society. 1998. Conference Proceedings. Paper read at NZEAS Biennial Conference - Ten Years On: Reforming New Zealand Education, 11-14 January 1998, at Wellington.

NZEI. 1998. Profit in Childcare. Rourou 9 (12): 2.

2002a. Cattle and Classrooms, the Kiwi Commodities: The Global Free Trade of Education. New Zealand Educational Institute Occasional Papers.

2002b. GATS and Private Investment in Education. In New Zealand Educational Institute. Wellington. 
2002c. Submission on Developing Export Education: The Export Education Development Fund and Levy. In New Zealand Educational Institute. Wellington.

2003. Submission on New Zealand's Approach to the Next Stage of the WTO Services Negotiations. In New Zealand Educational Institute. Wellington.

NZER. 2002. International education needs to benefit the regions. NZ Education Review, 11-9-02.

NZPA. 2003a. High-level education plan. BOP Times, 22-3-03, 9.

_. 2003b. Mallard seeks inquiry into fee-paying firm. BOP Times, 22-3-03, 7.

2003c. Parents demand Lessons for their toddlers. The Dominion Post, 18-8-03.

NZPPTA. 1997. Foreign Fee-Paying Students. Paper read at NZPPTA Annual Conference 1997.

2002. Submission on Discussion Document 'Developing Export Education - The Export Education Industry Development Fund and Levy". In New Zealand Post Primary Teachers Association. Wellington.

2003. Submission in GATS Consultation Document. In New Zealand Post Primary Teachers Association. Wellington.

NZPPTA Auckland Region. 1995. Foreign Fee-Paying Students. Paper read at NZPPTA Annual Conference 1995.

Oehlers, A. 2003. Facts are changed, so we'd better, too. The New Zealand Herald, 910-03.

Olssen, M. 1999. Restructuring New Zealand Education: Insights from the Work of Ruth Jonathon. New Zealand Journal of Educational Studies Special Issue - A Decade of Reform in New Zealand: Where to Now? 34 (1): 54-65.

2002. The Neo-liberal Appropriation of Tertiary Education Policy in New Zealand: Accountability, Research and Academic Freedom: NZARE.

Olssen, M., and K. Morris Matthews, eds. 1997. Education Policy in New Zealand: the 1990s and beyond. Palmerston North: The Dunmore Press.

O'Neill, J. 1998. Primary School Principals' Experiences of the Tomorrows Schools Reforms. Paper read at NZEAS Biennial Conference - Ten Years On: Reforming New Zealand Education, 11-14 January 1998, at Wellington.

O'Neill, J., and I. Snook, eds. 1999. Against the Tide: A Critique of the Coalition Government's Education Policy Proposals 1997-98. Palmerston North: Education Policy Response Group, Massey University.

Perris, L. 1998. Implementing Education Reforms in New Zealand: 1987-97 A Case Study. Vol. 1 (1): The Education Reform and Management Series Human Development Network The World Bank.

Peters, M. 2002. Environmental Education, Neo-liberalism and Globalisation: The New Zealand Experiment. Education Philosophy and Theory 33 (2): 203-216.

Peters, M., and J. Marshall. 1988. The Politics of "Choice" and "Community". Access 7: 84-109. 
1996. The politics of Curriculum. Delta 48: 33-46.

Pettman, R. 2000. Commonsense Constructivism - or the making of world affairs, International Relations in a Constructed World. Armonk: M E Sharpe.

Quirke, M. 2003a. ERO backs treatment of foreign students. The Dominion Post, 11-703, A5.

. 2003b. Fee-charging schools 'milking law'. The Dominion Post, 6-9-03.

- 2003c. NZ firm starts school in China. The Dominion Post, 25-9-03, A5.

2003d. Student swap scheme ends. The Dominion Post, 1-7-03, A12.

Richardson, A. 2004. Anger as schools told not to record students who fail. Sunday Star Times, 18-1-04.

Rikowski, G. 2003. Schools and the GATS Enigma. Journal for Critical Education Policy Studies www.jceps.com 1 (1).

Ritchie, J. 2002. Applying a Commitment to Bicultural Development within Early Childhood Teacher Education: A Discussion. Delta 54 (1 \& 2): 71-90.

Robertson, S. 2003. WTO/GATS and the Global Education Services Industry. Globalisation, Societies and Education 1 (3): 259 -266.

Robertson, S., X. Bonal, and R. Dale. 2002. GATS and the Education Service Industry: The Politics of Scale and Global Reterritorialisation. Comparative Education Review 46 (4): 472-496.

Robertson, S., and R. Dale. Draft 2003. This is What the Fuss is About! The Implications of GATS for Education Systems in the North and the South. GENIE - the Globalisation and Europeanisation Network in Education www.genie-tn.net [cited 20-12-03].

Rosenburg, B. 2003. GATS concerns remain for tertiary education. AUS Tertiary Update, 3-4-03.

Ross, H. 2002. The Space between Us: The Relevance of Relational Theories to Comparative Education. Comparative Education Review 46 (4): 407-432.

Ross, T. 2003. Anomalies in foreign pupil enrolments. The Press.

Saul, J. R. 1994. The Doubters Companion: A Dictionary of Aggressive Common Sense. Toronto: Penguin Books.

2001. On Equilibrium. Toronto: Penguin Books.

Sauve, P., and OECD. 2002. Trade Education and the GATS: What's In, What's Out, What's All the Fuss About? Higher Education Management and Policy 14 (3): 4769 .

Schugurensky, D., and A. Davidson-Harden. 2003. From Cordoba to Washington: WTO/GATS and Latin American Education. Globalisation, Societies and Education 1 (3): 321-357.

Scrivens, C. 2002. Redefining Leadership. Delta 54 (1 \& 2): 43-56.

Sexton, F. 2003. Dangerous Liaisons. Australian Educator 37 (Autumn): 12-13. 
Shackleford, L. 2003. Worry over student shortfall. Howick \& Pakuranga Times, 19-5-03.

Shaker, E. 1999a. Corporate Content inside and Outside the Classroom. Education Limited 1 (2): 1-35.

1999b. Youth News Network and the Commercial Carpet-Bombing of the Classroom. Education Limited 5 (October 1999): 1-18.

Sheeran, G. 2003. The expensive business of teaching our children. Sunday Star Times, 16-11-03.

Shirtcliffe, P. 2003. Education and Enterprise. New Zealand Management September 2003: 16.

Slater, J. 2003. Sweet sponsors leave sour taste (May 2003) [web-journal]. www.tes.co.uk [cited 20-5-03].

Smith, S. 1997. New Approaches to International Theory. In The globalisation of World Politics: An Introduction to International Relations, edited by Baylis, J. and S. Smith. Oxford: Oxford University Press.

Sullivan, K. 1998a. Education in the Pacific Rim, Beyond Economic Expectations. Asian Studies Institute Victoria University $\mathrm{H} \backslash$ :Asian Studies Institute - Asian Quarterly.htm [cited 20-1-04].

ed. 1998b. Education and Change in the Pacific Rim: Meeting the Challenges.

Vol. 7 (1). Oxfordshire: Oxford Studies in Comparative Education.

Sutton, M. 2002. Think beyond students as 'cash cows', schools told. Waikato Times, 21-11-02.

The Dominion Post. 2002. A hub for education. The Dominion Post, 26-11-02. 2003. US Complains of quarantine bar. The Dominion Post, 3-4-03.

The New Zealand Herald. 2002. Govt to probe complaints by foreign pupils. NZ Herald, 18-11-02, C3.

2003. Child's Play. Weekend Herald, 12-4-03, C3.

The Treasury. 1987. Government Management. Brief to the incoming government (Vol. 2). Wellington: The Treasury.

Thomas, D. R., and L. W. Nikora. 1992. From Assimilation to Biculturalism: Changing Patterns in Maori-Pakeha Relationships. In Community Psychology and Social Change: Australian and New Zealand Perspectives, edited by Thomas, D. R. and A. Veno. Palmerston North: Dunmore.

Thrupp, M., ed. 1999. A Decade of Reform in New Zealand Education: Where to Now? NZ Journal of Education Studies. Vol. 34 (1). Hamilton: University of Waikato.

Twyford, P. 2003. Does Trade Liberalisation Exacerbate or Reduce Poverty? Trade and Globalisation in the lead up to the Cancun Ministerial. Paper read at CID Forum 20-2-03, at Wellington.

UNDP. 2003. Human Development Report - Millennium Goals. United Nations www.un.org [cited 20-8-03]. 
United Nations. 1948. Universal declaration of Human Rights. United Nations www.un.org [cited 10-3-03].

1966. International Covenant on Economic, Social and Cultural Rights. United Nations Office of the High Commissioner for Human Rights www.unhchr.ch [cited 10-3-03].

Uvalic-Trumbic, S. E. 2002. Globalisation and the Market in Higher Education: Quality, Accreditation and Qualifications. Paris: UNESCO Division of Higher Education.

Van Morrison. I forgot that love existed. Poetic Champions Compose. London: Caledonia Productions. CD.

Walsh, F. 2003. Positioning Polly. Metro June 2003.

Ward, C. 2001. The Impact of International Students on Domestic Students and Host Institutions: A Literature Review. Wellington: Export Education Policy Project, Strategic Information and Resourcing Division, New Zealand Ministry of Education.

Weir, J. 2003. Pye sees goldmine in chinese schools. The Dominion Post, 9-10-03, C1.

Williams, R. 1983 revised edition. Keywords. London: Fontana Paperbacks.

Wiseman, J. 1998. Global Nation? Australia and the politics of globalisation. Cambridge: Cambridge University.

Woolf, M. 2002. Harmony and Dissonance in International Education: The limits of Globalisation. Journal of Studies in International Education 6 (1): 5-15.

World Development Movement. 2003. WTO Campaign. World Development Movement www.wdm.org [cited 20-3-03].

World Education Market. 2003. About WEM. World Education Market www.wemex.com/aboutwem/ [cited 12-12-03].

WTO. 1998. Communication from the United States - Education Services. Geneva: Council for Trade in Services, World Trade Organisation.

2001a. Communication from Australia - Negotiating Proposal for Education Services. Geneva: Council for Trade in Services, World Trade Organisation.

2001b. Communication from New Zealand - Negotiating Proposal for Education Services. Geneva: Council for Trade in Services, World Trade Organisation.

2001c. WTO Policy Issues for Parliamentarians. WTO www.wto.org [cited 13-3ง3].

2003a. GATS Fact and Fiction. WTO www.wto.org [cited 13-3-03].

2003b. Legal Texts: The WTO Agreements. WTO www.wto.org [cited 13-3-03].

2003c. Trading into the Future. WTO www.wto.org [cited 13-3-03].

Wylie, C. 1995. Contrary Currents: The application of the public sector reform framework in education. New Zealand Journal of Educational Studies 30 (2): 149-164.

1998. Can vouchers deliver better education? A review of the literature with special reference to New Zealand. Wellington: New Zealand Council for Education Research. 
1999a. Is the Land of the Flightless Bird the Home of the Voucherless Voucher? New Zealand Journal of Educational Studies Special Issue - A Decade of Reform in New Zealand: Where to Now? 34 (1): 99-109.

1999b. Ten Years On: How Schools View Education Reform. Wellington: New Zealand Council for Education Research.

Ziguras, C. 2003. The Impact of the GATS on Transnational Tertiary Education:

Comparing Experiences of New Zealand, Australia, Singapore and Malaysia. The Australian Educational Researcher 30 (3): 89-109.

Ziguras, C., G. McBurnie, and L. Reinke. 2003. Implications of the GATS: are foreign universities entitled to Australian funding? Paper read at 17th IDP Australian International Education Conference, at Melbourne.

Zmag. 2003. Can The WTO Serve the Interests of the Developing Countries. zmag www.zmag.org [cited 21-10-03]. 